\title{
Playing, Gaming, Working and Labouring: Framing the Con- cepts and Relations
}

\author{
Arwid Lund
}

Department of ALM, Uppsala University, Uppsala, Sweden, arwid.lund@abm.uu.se

\begin{abstract}
The aim of this article is to define the concepts of playing, working, gaming, and labouring, through a literature study, and to construct a typology. This typology will be used to create a field model that is structured by the horizontal parameters of qualitative-quantitative (characteristics) and the vertical parameters of activity-result (in focus). It is shown how this model can be used to visualise different theoretical positions in empirical material, which connects to the concepts and their relations. Working and labouring are distinguished into a trans-historical and a historical, capitalist, category, and likewise playing and gaming, where the former is the trans-historical category and the latter the historical one. The main focus of the article, since working and labouring is well covered within the critical Marxist tradition, is on playing and its relation to working, with the aim of understanding and criticising the concept of playbour.
\end{abstract}

Keywords: Playing, Working, Gaming, Labouring, Play, Work, Game, Games, Labour, Labor, Cognitive Capitalism, General intellect, Peer Production, Crowdsourcing, Playbour, Playbor, Immaterial labour, Marxism, Marx, Autonomist Marxism, Ideology

Acknowledgement: The labour on this article has partly been made possible by a scholarship from the EU COST Action, "Dynamics of Virtual Work" (see http://dynamicsofvirtualwork.com/), and special thanks go to Christian Fuchs, University of Westminster, and Ursula Huws, University of Hertfordshire Business School

Many thinkers during the capitalist era have touched upon the relation between play and labour. The concepts have been thought of as each other's opposites by some and as sharing certain constructive or creative attributes by others. For some conservatives the political aim has been to keep the two realms apart, and some radicals have wanted to infuse their contemporary society, characterized by labour, with playing modes of life, while yet others have wanted to see a shrinking of the necessary hard labour and an increasing realm of freedom built on a synthesis of play and work into a higher unity characterized by attractive or pleasurable productivity.

The main aim of this article is to contribute to the dismantling of the ideological concept of "playbour". The notion of playbour pretends to point at a higher unity of play and labour within the capitalist mode of production and as such it is a highly ideological concept, which I aim to show with a study of related categories and concepts. In order to succeed with this I will develop my study in two steps: First I will develop and propose a typology of the central concepts, thereby introducing a verb form of the concept 'game', gaming ("spela" in Swedish), that traditionally does not exist in English. The typology will consist of four concepts: playing, working, gaming and labouring. All of them in some way relate to the human condition that Hannah Arendt described in her work Vita Activa (Arendt 1998). The typology will be grounded in a literature study with a special focus on identifying shared dimensions by which to compare the different categories. The result will be visualised in a field model that in a later step can be used to map the position of different statements and opinions. This typology and its model will help me to analyse and criticise the contemporary use of the term playbour, as well as give future empirical research a means by which to visualise and place opinions in empirical materials in the created field structure. In a second part I will focus, also through a literature study, on the character of the relations between the concepts of the typology with the two-fold aim of providing further examples of positions (that can be placed in the field 
model) and identifying statements of synergies and conflicts in the relations to counter the rather static picture of the field model. This last study can hopefully, when more fully developed, lay the foundation for yet another, future model to come, on the direction and forces as well as synergies and conflicts within the processes which build up the relation in the interface between the categories of activities. Such a model, and future studies using it, also holds the promise of helping us to deepen our understanding of the concept of playbour.

The first hypothesis of the investigation is that the concepts of playing and working have a qualitative character. Playing is engaged in for the pleasure of the activity in itself and work for the satisfaction of a qualitative need by the production of a certain use value. Gaming and labouring, on the other hand, are understood as quantitative in that they contain measurement of a person's activities in relation to him- or herself or others in gaming, or in relation to the exchange of values on the market within labouring.

Secondly, both playing and gaming are engaged in by actors mainly for their own sake. The activity in itself is the important thing, even if the result does have some role within gaming. In contrast to this, working and labouring are engaged in for the results of the activity. Working is focused on use values and is performed within society for social needs. Labour is focused on the exchange that it makes possible for the labourer, but on the exploitation needed for the accumulation of profit when it comes to the representatives of the capitalist class.

Behavioural categories like these are often defined in terms of structural or physical descriptions, functions, causations and motivations. It is important to keep these dimensions distinct (Pellegrini 2009, 7). The literary study has convinced me to use structural, functional and motivational dimensions in developing the typology. The structural dimension will be divided in two sub-dimensions that was identified in the study: Degree of voluntariness (distribution of power) surrounding the activity (in both subjective and objective terms), and Form of practice. Function will be understood in the light of the meta-question: is the activity mainly specific to a certain society and time or is it mainly trans-historical?

Anthony D. Pellegrini addresses the problematic of conflating structural aspects with functional aspects when it comes to play, because of the elusiveness of the functions in this field (Pellegrini 2009, 7). The problem complex is even wider. It always involves the risk of circular logic when you trace a function from a structure, or entails that the analyses remains on the surface of phenomena, but sometimes the existing structure is the best thing we have to build our understanding on.

The dimension of causation will not be treated as a dimension in itself. To determine the causation of a certain structure or behavioural pattern is even more difficult. A structure could have functions that can be theorised with the help of empirical observations or more abstract theorisation. The causations behind a certain structure (with several functions), on the other hand, could be any number of unknown factors, which as a rule are not related to the structure as existing structure with certain functions.

Even so I will include causation in the dimensions of function and motivation in this investigation, simply to point to the fact that sometimes the function is the only factor (as in the case with structure above) that can help us theorize about the causation of a structure within a biological or psychological perspective (here I depend heavily on biological and psychological research outside of my field of expertise). But the main focus in the article will be cultural and social in character. If we analyse a structure from a cultural or social perspective, we also have to take into account the motivations of the individuals and groups involved in the processes of the structure. Motives can be empirically accessed through different techniques, and can also be used to theorise about the causation, undoubtedly with other scientific risks involved. The dimension of motivations will be divided into the sub-dimension Organising purpose, and Associated feeling (even if it is hard to see the feelings associated with forced wage labour as a motivating force; here the economic incitement or greed together with the necessity of making a living can be used as alternative descriptions). 
The physical dimension, finally, permeates all of the categories in the sense that humans are physical beings in a physical world, and will not be investigated further here. In total this gives us five dimensions: Organising purpose, Form of practice, Mainly trans-historical or mainly historical, Degree of voluntariness and Associated feeling. In the work on the typology I will use the dimensions identified to highlight the differences and similarities between the categories. The five dimensions will together be necessary and sufficient for defining an activity as belonging to a specific category. The categories of playing, working, gaming and labouring will be visualised in a model in accordance with their relation to quality/quantity and activity/result, resulting in a quadrant (see section 2)

The relations between the categories can for now, to get an overview, be visualised like this:

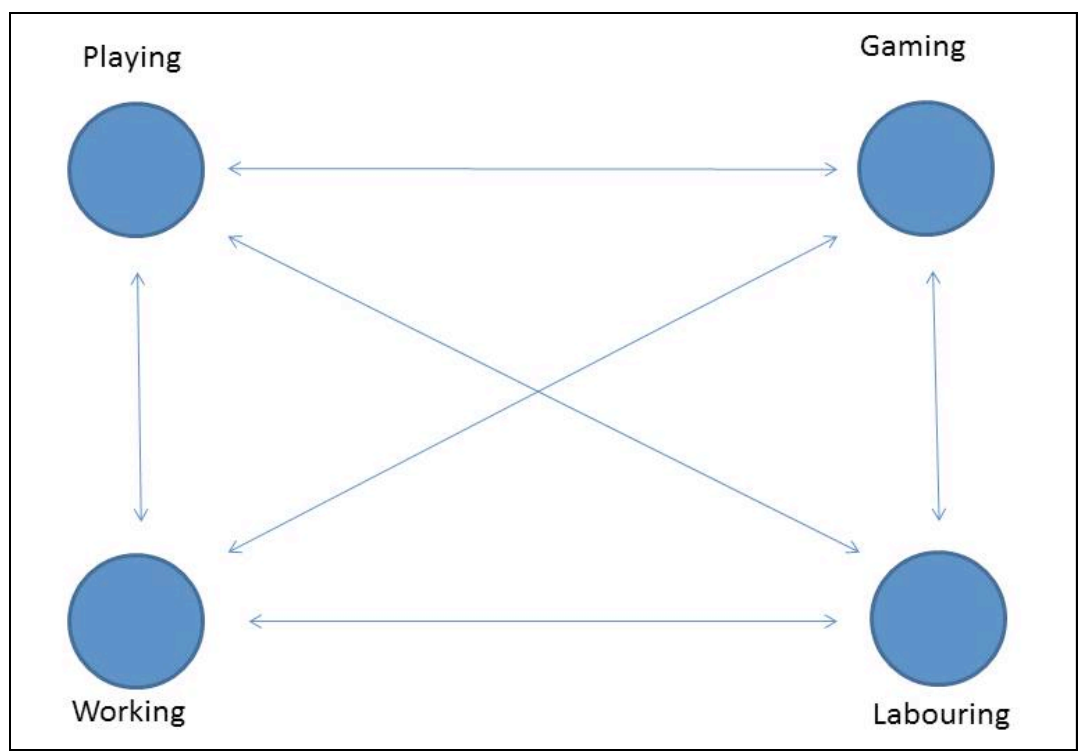

Figure 1: Relations between the four concepts (Arwid Lund 2014)

From the typology, the axes of quality/quantity and activity/result, and the scheme of the relations between the concepts, it is possible to develop a field model for mapping empirical results and the position of various opinions within the field. But this model does not say anything about the character of the relations between the categories. This theme will be touched upon in the last section of the article, together with the ambition of providing examples of empirical positions within the field. ${ }^{1}$ A more in-depth study will have to wait.

Before ending the introductory part of the article it is necessary to comment on the heavy focus on play in what is to come. In the contemporary critical discussion on digital labour, and especially of so-called playbour, there are a lot of influences of Marxism, and work and labour therefore has a theoretical grounding, which play and gaming do not have. When it comes to the relation between play/game and work/labour, central to the understanding of the ideological concept of playbour, the theoretical grounding is lacking to an even higher degree.

\section{The Typology: Playing, Gaming, Working and Labouring}

The conservative Dutch cultural historian Johan Huizinga defined play in an influential way in Homo Ludens: Proeve Ener Bepaling Van Het Spelelement Der Cultuur (1938). He did not distinguish between free-form play and rule-based games, probably because play and game in Dutch, as in German "Spiel", was covered by the one concept "spel". Huizinga was not un-

\footnotetext{
${ }^{1}$ This twofold aim creates some tension in the text. The force and direction characterising a relation, according to some thinker or text, cannot be presented adequately in the field model, which is developed to display static ideological positions. The third and last section should hence be read as a preliminary and tentative attempt to approach rather difficult theoretical questions.
} 
aware of the differences between different languages regarding the word for play, and he concluded that there were as many cultures that distinguished between play and contest as ones which did not (Hägglund 1989, 48). The same word for the two connotations is for example used in Dutch, German, French and Spanish. This fact is commented upon in the Swedish translation due to the fact that in Swedish the two forms have their own terms: leka (playing) and spela ("gaming"), and both in contrast to the English language, are verbs. You play a game in English, you do not game it.

Game is a concept that focuses more on rules, which make it possible to compare and measure performances, and therefore results in more competitive features of the play (and changes the character of playing). I will use the concept gaming in this article and distinguish it from playing.

Jesper Juul comments on the broad definition of play that Huizinga uses and criticises him for his sketchy descriptions of the actual games. Johan Asplund, a social psychologist, instead criticises Huizinga for focusing on rule-based games and not the more informal and improvised forms of play that he counts as an elementary social form (Asplund 1987, 64-65). Given their different scientific missions, both of them are correct.

Juul explicitly focus on games in his study where he provides a definition that he calls the classical game model. He builds on, but also criticises, the former surrealist and scholar, Roger Caillois's categorization of different games into four categories: Agôn (competition), Alea (chance), Mimicry (simulation) and Illinx (vertigo). The categorisation implied according to Juul that you had to make a choice between different sorts of games, but in reality Caillois clearly stressed that the categorisation of a game depended on the category that is dominant in it, hence, that every actual game could contain several categories within it (Juul 2005,10; Caillois 2001).

Caillois in turn criticised Huizingas definition for being both too narrow and too broad (writing in French he did not distinguishing play and game from each other), and contended it was wrong in its connection of play to the secret and mysterious. Play and fiction would be a detriment to the mysterious, not taking it seriously. Play was seen, in contrast to the mysterious, as unserious in the old surrealist's interpretation. He also contended that Huizinga was wrong in denuding play of all material interest. Games of chance contained playing with money even if it was not productive (Caillois 2001).

Johan Asplund makes a sharp distinction between play and game (Asplund 1987). Gaming is organised play, meaning that it is not play anymore. Games are clear-cut in their social responsiveness; one action leads to another action. Play is capricious in its behaviour and does not follow rules in an explicit and uniform way; play involves a lot of negotiations and improvisation; it can even break with some rules. Play is social responsiveness pure and simple according to him (Asplund 1987, 64-67).

Regarding the concepts of work and labour Hannah Arendt claimed that it was necessary to make a distinction between the two. Such a distinction could be traced back to John Locke, who made a distinction between: "The Labour of his Body, and the Work of his Hands" (Locke 1988, 287-288), or even back to Antiquity and the Greek language where cheirotechnes stood for working handicraft men in contrast to the slaves and house animals that were labouring with their bodies (later in Latin called animal laborans in contrast to homo faber) (Arendt 1998,120-126).

Her main argument, though, is that the distinction has been made and maintained in all European languages, with the exception of two nouns in German and French that include both connotations: Arbeit and Travail (Arendt 1998). This has led to some confusion in the interpretation of the works of Karl Marx. Fuchs and Sevignani have shown that insufficient sensibility to this fact has led to grave errors in the English translations of work and labour in Marx oeuvre. This is of some importance because it takes place at the epicentre of Marxian thought. Marx himself claimed that his distinction between concrete and abstract labour in Capital was crucial for the understanding of the rest of that work (Marx and Engels 1972, 73; Marx 1867, 49). Fuchs and Sevignani claim that the dual character of labour reflects the fact 
that Marx was writing both a critique and an economic theory at the same time and that therefore two series of categories were developed on two different levels:

[O]n the one hand that which is specific for capitalism and on the other hand that which forms the essence of all economies and therefore also exists in capitalism and interacts dialectically with capitalism's historic reality. (Fuchs and Sevignani 2013, 247-248)

The trans-historical categories, according to them, are work, use value, concrete labour, labour process (living labour) and necessary labour. The historical categories under capitalism are labour, exchange value, abstract labour, valorisation process and surplus labour (Fuchs and Sevignani 2013,248 ). In the following I will use work for the activity that is mainly focused on the kind of concrete labour which always has to exist, albeit in different historical forms, and labour for the historical form of abstract labour in capitalism which is mainly focused on production of exchange values, surplus value and accumulation according to its own abstract logic. This manoeuver does not in itself answer the question whether some historical mode of production transforms the trans-historical form of work into something qualitatively different. Bands of hunters and gatherers, feudal societies and emergent forms of peer production are historical variations, in the same formal way as capitalism, in relation to transhistorical work.

In line with a critical Marxist perspective I contend that abstract labour introduces a social mechanism that dominates work, the societal production of use values, in a negative way that is uncontrolled by the producers themselves and not in their interest. This not mainly as a result of existing social inequalities in class society, but as a result of a domination of the mode of producing ${ }^{2}$ under abstract standards and an abstract logic of permanent growth and accumulation for the few. This dynamic and expanding character makes capitalism qualitatively different than other historic forms of deviations from the trans-historical work, which also have been built on forced and alienated forms of work. ${ }^{3}$ In order to point to the progressive potential that exist today (as well as yesterday) I reserve the trans-historically inclined concept of work for historical modes of production and distributions of use values that are not characterised by, to borrow a concept from Moishe Postone, run-away growth for un-social private or partial economic interests (Postone 1993,17, 312, 314) but for societal needs that has been decided upon in at least freer forms of associations between (wo)men.

This is a political choice of mine that is also historically evidenced to some degree. On the one hand I tend to agree with Max Horkheimer when he states in 1937 that particular judgements about what is human or not can only acquire their correct meaning in a historical context. The problem is that in an unjust society criminals are not inferior according to Horkheimer, whereas they will be viewed as un-human in a fully just society. In today's society this justifies a political critique against a naturalised run-away growth. In this it helps to remember that the association of free men is not an abstract utopia: "the possibility in question can be shown to be real even at the present stage of productive forces" (Horkheimer 1972, 242). On the other hand, I do believe Postone has a point when he concludes that capitalism is a mode of production that is qualitatively different from all other modes of production in human history. Circulation of commodities and money existed before capitalism, and it was only in capitalism that the commodity became universal, when labour power became a commodity and introduced wage labour. Prices thus preceded value. "Value as a totalizing category is constituted only in capitalist society" (Postone 1993, 270-271).

To complicate the discussion further it has to be stressed that capitalism, in being qualitatively different in all of its quantitative logic, also creates the possibilities of its own abolishment when the quest for relative surplus value results in "a growing disparity" between the

\footnotetext{
${ }^{2}$ The connotation of the term is the form of practice of abstract labour and should not be confused with the concept of mode of production. The term Mode of producing was coined by Moishe Postone (1993, 67-68).

${ }^{3}$ Feudalism and slavery are arguably also modes of productions which deviate from the trans-historical version of work in a qualitatively and radical way. However the notion of labour will be reserved for abstract labour within capitalism in this article.
} 
conditions for the "production of wealth" from "those for the generation of value" (Postone 1993, 298):

In the course of capitalist development a form of production based upon the knowledge, skills, and labor of the immediate producers gives rise to another form, based upon the accumulated knowledge and experience of humanity [...] the social necessity for the expenditure of direct human labor in production gradually is diminished. Production based upon the present, upon the expenditure of abstract labour time, thus generates its own negation-the objectification of historical time. (Postone 1993, 298)

In the contemporary field of digital labour peer production forms an emergent and historic mode of production that is growing in the emancipatory potential that has its material ground in the developments described here. Peer production has a pronounced focus on the concrete labour and the production of use values in free associations of (wo)men, and can thus be associated with the trans-historic aspect of human work. Hence, the instrumental reason of Horkheimer, that is the "constitution in alienated form of social general modes of knowledge and experience" which have a negative effect on much immediate labour, gives rise to the possible emancipation of people "from the sway of their own labour" and their "reappropriation of the socially general knowledge and power first constituted historically in alienated form" (Postone 1993, 328).

This leaves us with four concepts to understand and define in the typology: Playing, Working, Gaming and Labouring.

\subsection{Playing}

In Grundrisse Marx concludes that not-labour under capitalism appears as freedom and happiness, but when labour has created the subjective and objective conditions for itself it would instead transform itself into attractive work in the realm of freedom. He does not say anything about play in this context, apart from criticising Charles Fourier for believing that labour could become play. Self-realisation through attractive work was not to be understood as "mere fun, mere amusement" (Marx 1973, 611-612). Play was thus mere fun and amusement and unproductive to him.

Against this stands the idealistic tradition, which goes back to the ancient Greece. Johan Huizinga especially liked Plato when it came to the long tradition of viewing (wo)man and society sub specie ludi. Plato stated that:

A man ought to be in serious earnest about serious things, and not about trifles; and that the object really worth of all serious and blessed effort is God, while man is created [...] to be the plaything of God, and the best part of him is surely just that; and thus I say that every man and woman ought to pass through life in accordance with this character, playing at the noblest of pastimes, being otherwise minded than they now are (Plato, Laws, Cf. Anchor 1978, 63)

Friedrich Schiller added that man was truly a man when playing. Robert Anchor contends that not just Hegel, Nietzsche and Heidegger, and several other modern philosophers, had similar thoughts, but also, though wrongly it seems, Marx (Anchor 1978, 63). Marx's view of play as something non-important and unproductive will partly be challenged in this article. His perspective does not contribute to a full understanding of the importance of the category. This will demand that we scrutinize playing as a proper category with its social importance in relation to working, but also how it affects and becomes affected by gaming and labouring under capitalism.

Johan Huizinga explicitly pointed to the relation between play and culture/civilisation. He thought that civilization "arises and unfolds in and as play", it was not about placing play within culture but ascertaining "how far culture itself bears the character of play". He was fiercely anti-Marxist and claimed that the $19^{\text {th }}$ century had left little room for play with its utilitarianism and industrialism thus resulting in a luxation of the intellects that helped the misconceptions 
of Marxism, that "economic forces and material interest determine the course of the world", to be put about and believed (Huizinga 1955, 191-92). He also stated that "where there is no visible action there can be no play" (Huizinga [1938] 1955,166).

In contrast with this idealistic perspective I assume that play has to be understood historically and socially, even if this article mainly focuses on this when it comes to the historical period of capitalism, as well as pointing to play's both constructive and destructive powers.

Sigmund Freud first viewed play from the biological and psychological perspective and first only indirectly connected play to culture as an intermediary sphere of compensation either for a deficiency of energy or compensation (as a release of surplus energy) for the instinctual renunciation that the reality principle inflicted upon the pleasure principle. This sublimation of the libido became in later phases of his theories more explicitly connected-as the instinct Eros-to the construction of culture (Reich 2012; Fromm 1988) This biological and psychological perspective has inspired me to theorise play's trans-historical character as being part of our constitution. The perspective of Freud almost equates play with work. This demands some discussion. Play is not mere fun as Marx thought, but neither is it the same thing as work. Asplund's distinction between playing and gaming is important. Play is not well planned but capricious, spontaneous, social responsive and not uniformly produced. I would therefore say that play can be productive, very similar to work in its effects, but it is also something else and more immediate. Humans indeed have a need to play, but the reason for playing is not primarily and consciously to produce a use value that satisfies a consciously felt need; play is not thought of in an instrumental way. You can play just for the fun of it, as well as a child un-consciously can work his/her way through a problematic experience by play. And is it not true that play also, for various reasons, can be destructive in relation to use values? Breaking the rules can be fun.

At any rate play has been of major interest to a whole spectrum of disciplines-from biologists and psychologist to philosophers, anthropologist and cultural historians-during the last hundred years.

\subsubsection{Play as the Meeting Point of Biological Energies and Psychological Needs}

Let us start the discussion of play as part of the human constitution with a comparison between Friedrich Schiller and the Greek philosophes of Antiquity. Friedrich Schiller saw human play as an intermediary expression between the purely sensuous and the rational. As a synthesis of the sensuous and formal impulses, play cancelled the authority of both and liberated man physically and morally. In the play experience (wo)man's dual nature was harmonized and humanized (Hein 1968, 67). Play was then freedom, and freedom humanized the human.

Johan Asplund stresses that it is hard to speak of a theory of play in the case of Schiller. The key concept Spieltrieb (play drive) had the power to reconcile the two essential drives (matter and form) that in turn were the foundation of many dichotomies like affects and reason, life and representation, transformation and identity, passivity and activity and so on. The matter drive was life and total presence in the senses; the form drive was connected to reason. In play humans were truly humans and as soon as mankind could spare some energy in the quest for survival they started to mould, perform and play. Asplund stresses that play had an abundant, exuberant and redundant character for Schiller. In play humans and animals went outside of themselves and created an object for him/herself (Asplund 1987, 5658).

For Schiller the nearby aesthetic activity was "the contemplative one rather than the creative experience", the highest form of which was the "free exercise of the imaginative and intellectual faculties rather than the physical" (Hein 1968, 67) According to Hein this largely imaginative play contributed to the "moral enhancement of the individual and society" (Hein $1968,67)$. This effect was unintended on the part of the individual because the player was perceived as voluntarily engaged in the activity "for its own sake" (Hein 1968, 67). "In this respect play is properly contrasted with work, which is stimulated by deprivation and is en- 
gaged in as a means to a practical end" (Hein 1968, 67). Play was a non-utilitarian activity, (Hein 1968, 67) even if it was essential for the creation of works of art. Artistic activity resulted in an end but did not produce use values, and for the artist the activity was important in itself. Art was understood as derived from play, but not as synonymous to it.

Schiller did not articulate the relation between play and art in a clear way. Hein assumes that both play and art were manifestations of the play impulse for Schiller. She interprets Schiller's view of art as "gratuitous exercise of higher level, i.e. intellectual, faculties" that was a "more mature or complex form of play" (Hein 1968, 67). This is also the primary deficiency in Schiller's theory on play according to her:

[T] he alleged value of play lies in a feature which is not merely nonessential but is in fact in direct conflict with the essential nature of play. If play by definition is spontaneous activity engaged in exclusively for its own sake, then to value it for its possible consequences is a denial of its essence. (Hein 1968, 67-68)

The productivity or non-productivity of play was a recurrent theme even in ancient Greece. Plato and Aristotle regarded play as "sensuous in character and as a natural expression of animal restlessness" (Hein 1968, 68) Play was not necessary to rationality, but neither necessarily antagonistic to it. It "could be used to both good and evil ends, but was in itself nonserious and of little consequence."(Hein 1968, 68) Play was thus not an intermediary synthesis, but was sensuous, even though not antagonistic to reason in the referred view. More parallel to Schiller's view was the opinion that play itself was of little consequence, but could be manipulated for productive or non-productive ends. But playfulness had an ethical dimension for the Greeks. Aristotle's Eudaimonia, happiness, was an end in itself but only philosophers - a leisurely attitude was needed to engage in theories - were "properly predisposed to play" with the right "seriousness and disdain for decadence" (Nagel 1996, 2-3). The same contradiction as Hein point at in the thought of Schiller thus existed in Antiquity, even if Schiller's and Kant's concepts of play as creativity, freedom and autonomy were alien to the world view of Aristotle according to Nagel (Nagel 1996, 2).

But the ancient Greeks also made a distinction between Apollonian, logocentric, and Dionysian, tragic and bacchanalian, forces when they discussed play. Play was both matter and form in the words of Schiller. Aristotle clearly favoured Apollonian play, and it was with him that the abjection of play as the Other to reason originated - the Other being mere play and nothing serious. The tragic Dionysian play became eclipsed by Aristotle rather than Plato (Nagel 1996, 4-5). For Plato play and seriousness could instead, in the right moment (kairos), be contiguous. This was not so for Aristotle, even if he stressed "the instrumental value of paidia for children's and young men's education" (Nagel 1996, 1, 4, 6-7).

These two examples, Schiller and the ancient philosophers, show a certain ambiguity with the concept of play. The major stress is put on it being engaged in for its own sake and not for any other serious reason. Play is thus the opposite of reason or an intermediary synthesis between the senses and the reason. At the same time it could have unintended good effects, even being the foundation of the arts, according to the former, but it could also have bad effects according to the ancient philosophers. Play could be manipulated as an instrument in the hands of external parties, even if the result was unintended by the player.

Neither Schiller nor the major Greek thinkers gave any importance to the ludic Dionysos. It was Hegel who first gave equal importance to the Apollonian and Dionysian play impulses, when he compared truth with a Bacchanalian whirl "which is the interplay of drunken frenzy and calm repose". This trope was a central category in Hegel's play theory (Nagel 1996, vii, 2,7 ). Hegel thus pre-empted Friedrich Nietzsche's ludic perspective (Nagel 1996, 3), even if it becomes clear that Nietzsche view on Apollonian and Dionysian play has a lot to do with gaming rather than playing.

Friedrich Nietzsche stressed play as part of the instincts of life and the drive to enhance life, and he affirmed the frenzied and irrational aspect of Dionysian play which he thought of as intertwined dialectically with Apollonian play in a unity of opposites (Nagel 1996, 3). If play 
was part of a truth-seeking in the thoughts of Hegel, Nietzsche stressed that play in its Dionysian forms was something in it itself, being life. Life was inherently affirmative according to Nietzsche, very much in the same way as play has been understood, but he also advocated values and actions which enhanced life (Mitcheson 2013) in a rather specific way as competition with other wills to conquer power. This latter focus is better conceived of as gaming than playing. Nietzsche dismissed scientific reason in the name of life and affirmed art in a playful manner, much like Schiller. An artist brought something forth that did not exist until then (Heidegger 1991, 69). The creativeness of art and play was practised outside of the rules, in a world that was not ruled by the existent.

Evolutionary biologists in the $19^{\text {th }}$ century like Karl Groos and Konrad Lange, and social Darwinist Herbert Spencer, broke with the picture of play as a joyous expenditure of surplus energy and instead explained play as having evolutionary functions, rather than involving pleasure. Play was for them a conscious self-deception as a compensation for disappointments in life and as preparation for serious activities. Play thus got a teleological orientation as a preparation for life or as a conscious self-deception that compensated for disappointments in life. Play could function as a safety valve for these biologists, "enabling the organism to discharge the emotions which experience generates but for which it provides no adequate outlet". Play according to Herbert Spencer had "survival value" and yielded "rewards beyond itself" (Hein 1968, 68).

It was at this time that the classical play theories were developed according to the drama pedagogue Kent Hägglund: 1) The Energy Surplus theory of Herbert Spencer (who was inspired by Schiller) that claimed that the play of children could be categorized as sense-motor (body movements), artistic-aesthetic play, rules-based play, and imitation play. 2) The Recreational Theory developed by Moritz Lazarus and Heymann Steinthal that stressed that play was relaxing. 3) The Exercise Theory developed by Karl Groos that stated that play was an instinct that directed the child to play out things and abilities that they were going to need as adults. An animal high up in the developmental chain needed a longer period of adolescence. 4) The Recapitulate Theory of Granville Stanley Hall (see above) who was influenced by Ernst Haeckel's theory of Recapitulation and the thesis that ontogeny recapitulates phylogeny (Hägglund 1989, 12-13, 5-61; Wikipedia contributors n.d.; Schwartzman 1978, $21-$ 22, 4-42).

Helen B. Schwartzman, the social anthropologist, has criticised many of the abovementioned notions of the defining characteristics of play. Her point of departure is that the systematic study of play was born at the same time as the discipline of social anthropology in the late $19^{\text {th }}$ century. Many scholars were influenced by Charles Darwin and Social Darwinism under this period of time and identified parallels between the development of the species and societal development. All highly developed animals had developed from single-celled organisms, and contemporary civilisation had developed from hunter-and-gatherer societies. Social anthropologists took this view with them when they went out to study primitive societies. They thought they were studying the origins of their own society. Taking on this perspective it was easy to see other societies and cultures as less mature, less valuable and childish, which fitted the interests of imperialist powers of the day. This perspective also made it easy to see children as more primitive, and their development proceeded in the same manner as civilisations were thought to make progress in stages (Hägglund 1989, 12 13, 5-61; Schwartzman 1978, 2-22, 4-42).

Schwartzman especially criticises early anthropologists like Granville Stanley Hall that thought that they could find remnants of old cultures in the play of children, but also Sigmund Freud and Jean Piaget, whose theories about children's mental development in stages (see below) had remnants of this thought pattern (Hägglund 1989, 13, 5-61; Schwartzman 1978, 21-22). Sigmund Freud continued within this biological paradigm but also transcended it by stressing the psychological dimensions of play (Hein 1968, 68). In his first phase Freud argued that play had the same function for the child as dreams and phantasies. (S)he could create his/her own world with objects from the real world in play and repeat pleasurable 
events at will. In play it was also possible to change events so that they met the expectations of the child. These first theories did not answer the question why children in role plays repeat unpleasant experiences (Hägglund 1989, 14-15).

Play's relation to these unpleasant experiences was at the centre of Freud's concerns in his second theoretical phase. Play was now one of the first normal methods applied by the child's mental apparatus and in Beyond the Pleasure Principle he told the story of a year-and a-half-old boy that threw away things that he a moment later, to his great joy, found again. Freud interpreted the story as a great cultural achievement of the child and saw it as a compensation for an instinctual renunciation that the boy had made earlier when he had allowed his mother to go away without protesting. The boy thus staged the disappearance and return of his mother (Freud 1974, 8-9). Hein stresses that play according to Freud could only superficially be described as a "joyous and spontaneous expression of vital freedom" or simple analysis of play "in terms of imitation or aimless pleasure-seeking or instinctive satisfaction of biological needs"; instead, play is regarded as an assimilative activity where the agent "gains active mastery of a situation" and Freud understand play as a form of conquest which also is the reason for the experienced pleasure: "As such it is as serious as any of man's activities and as purposive in its nature as his work" (Hein 1968, 69). Play is thus a psychological technique or mechanism to handle the pleasure principle in its contact with reality.

But at the same time children's play is still seen in Beyond the Pleasure Principle as part of the pleasure principle. Small children cannot get enough of repeating pleasurable experiences, a behaviour that later in life was changed when only new jokes were funny (Freud 1974, 1-11, 29). Freud thus stressed that play at least had two functions for the child: First, helping it to master situations in which (s)he had been passively subordinated, and second, to amuse the child in a joyous manner. Play was then both a drive- "At the dawn of the development of the human soul, free and unhampered play is enjoyed by notions, feelings, desires that at later stages of development would horrify the conscious" (Vološinov 2012, 52) and a function to deal with clashes between it and the reality.

The pleasure principle connected (wo)man with sex, enjoyment and play. In play between adults, jokes and wit could function as a relief for the repressed impulses of Eros: "Jokes and witticism have the tendency to bypass reality, to provide relief from the seriousness of life, and to secure an outlet for repressed infantile impulses, whether sexual or aggressive" (Vološinov 2012, 91-92).

In his final theoretical phase Freud focused on the relation of the instincts and the psyche to the cultural and societal sphere, and stressed the socially constructive roles of humans according to Fromm who emphasises that Freud made a clear connection between Eros and Civilisation, at the same time as the destructive forces were internalised and transferred to Thanatos rather than existing between people in society-which was the point of criticism of the social psychologist Wilhelm Reich (see below) (Fromm 1988; Reich 2012). In contrast to Fromm, Hägglund claims that the relation between Eros and Thanatos was a dialectical one where the former was the drive for sexuality, lust and life in general, and Thanatos the drive for death, destruction and aggression. Hägglund maintains that play here did not belong to Eros but to Thanatos, and its will for repose and balance. Especially repetitive play was part of death drive (Hägglund 1989, 16).

Herbert Marcuse, on the other hand, claimed that the mental forces "opposed" to the reality principle were relegated to the unconscious and therefore could "provide no standards for the construction of the non-repressive mentality, nor for the truth value of such a construction". Instead Freud according to him singled out fantasy as a mental activity that "retains a high-degree of freedom from the reality principle even in the sphere of the developed consciousness". Fantasy links "the deepest layers of the unconscious with the highest products of consciousness (art), the dream with reality; it preserves the archetypes of the genus, the perpetual but repressed ideas of the collective and individual memory, the tabooed images of freedom" (Marcuse 1955, 140-141). 
This theory of the human instincts thus went through several changes. From the beginning when he made a distinction between the pleasure principle (containing play) and the drive for self-preservation or the reality principle, to the middle period when he included the latter within the former, making the pleasure principle all-encompassing (including play as both drive and sublimation), before finally ending up with the final version (Marcuse 1955; Fuchs 2013; Vološinov 2012, 50-54; Reich 2012).

Freud's view on play was further developed in the field of psychology by Lili E. Peller, Erik Homburger Erikson, Daniel Woods Winnicott, and Jean Piaget. Lev Vygotsky and George Herbert Mead were more interested in the relation between the individual and the social world and will therefore be presented in the next sub-section.

Peller was active within the movement of Montessori pedagogy, and systematized Freud's views on play. She maintained that play was about dreams coming true, enjoyment, relief and well-being, but it did not have to do with pleasure all the time; it could also be about compensation. She introduces stages in the use of play of the child. In the last period between seven and twelve years of age the rules becomes more strict and rule-based plays substitute freer forms of play, but even in this period it is more important to follow the rules than to win the game (Hägglund 1989, 18-19). Erik Homburger Erikson assumed that the psychological development of humans did not end in the juvenile period but continued through life. Play was a universe of experiments. (Hägglund 1989, 21-22). Donald Woods Winnicott made the point that psychoanalysts had failed to focus on the function of play in itself and favoured play as an instrument in therapy and research. He speaks of play as the third room, a special mental space between the subject and the external world. This third room still exists for adults, and it is there that play and fantasy that we use for creating art, music and theatre, continue to develop (Hägglund 1989, 26-28).

Jean Piaget started off as a zoologist and later became interested in philosophy and psychology. His main focus was to analyse and systematise how human intelligence developed. $\mathrm{He}$ based his investigation on close and intensive studies of relatively few children, including his own. He was primarily interested in play's central role in the development of the mental processes, rather than play in itself. He worked out the concepts of assimilation, accommodation and adaption. Assimilation meant that the child regulated the world in accordance with his/her needs, accommodation meant the opposite like in plays of imitation. Finally adaption formed a synthesis constructed on the interaction between the former two in a kind of Hegelian dialectic. For the child, whose developmental stages were divided into sense-motor stage, the stage of concrete operations of thought, and the stage of formal operations of thought, the assimilation process was the most important. The stages followed each other in a strict sequence. Piaget identified the exercise form of play in the first stage and symbolic play and role playing in the second one, and finally, the more mature the child, the more organised the play became, leading up to rule-based play and sports (Hägglund 1989, 30-34).

Instead of stressing the difference between autotelism (play meaningful in itself) and heterotelism (the goal of the activity takes the form of a result) Piaget saw play in the contradiction between assimilation and accommodation: "When assimilation and accommodation is not differentiated, as at the beginning of the first year, there seems to be autotelism without there being play in the strict sense, but as assimilation gains on accommodation play is divorced from the corresponding non-ludic activities.". He also stressed that play is not simply spontaneous and it was possible to identify two poles between which play existed: "the one truly spontaneous, since it is uncontrolled, the other controlled by society or by reality" (Piaget 1962, 148). This fits the distinction that I am stressing even though Piaget himself did not distinguish between play and games. In contrast to Piaget the Swedish child psychologist Birgitta Knutsdotter Olofsson contends that play forms do not develop in stages, but coincide or are played out side by side. All forms of play are learnt under the first year of the child according to her (Hägglund 1989, 69-71). 
During the second half of the $20^{\text {th }}$ century biological and psychological research has continued to develop as academic disciplines like sociobiology, evolutionary psychology, behavioural ecology and epigenetic, all of which offer different views on play.

Anthony Pellegrini stresses in The Role of Play in Human Development (2009) that most theorists posit that play is observed only in situations "that are safe and where the organisms are well fed". According to him, Gordon Burghardt has advanced the Surplus Resource Theory of Play, not to be confused with Schillers notion: "While the concept of 'surplus energy' no longer is viewed as scientifically valid, the idea that play is supported only after organisms' basic needs are met is still current" (Pellegrini 2009, 9-16). Pellergrini, himself invested in the field, stresses that evolutionary devlopmental psychology has reached the conclusion that play differs between individuals and contexts in its alternative, and not pre-programmed, responses to the environment. (Pellegrini 2009, 20)

Stephen Miller argued in 1973 that even if it seems difficult to define play there seem to be, funnily enough, a great deal of consistency between untrained observers at the zoo, about, for example, when the animals are playing and not. He concludes that there exists a lot of intuitive knowledge about play that is hard to articulate. He then proceeded in his argumentation with the claim that very much the same patterns or motifs appear in almost all form of play, justifying the use of the one word play for such a "motley bunch of activities". Play, animal and human alike, involves according to him activities that in one situation can be play and in others not. A child's use of a pen can be strictly utilitarian, but also play. Miller cites Piaget, who stressed that a "schema" was never ludic or non-ludic and that it all depended on the context and the actual functioning. Miller suggested that if organized behaviour is viewed as involving some co-ordination of means and ends, then play could be distinguished by the way these are handled by it (Miller 1973, 92):

Play involves a relative autonomy of means. Ends are not obliterated, but they don't, as in some other modes of organization, determine the means. Furthermore this state of affairs implies a degree of autonomy for the actor who manipulates the processes at his disposal, which makes for freedom to assume roles otherwise unreal. Finally, means are elaborated by a psychological process that we thus far referred to as "galumphing"-in general, the voluntary placing of obstacles in one's path. (Miller 1973, 93)

Galumphing is defined as a shorthand term for patterned, voluntary elaborations or complications of processes where the pattern is not under the dominant control of goals (Miller 1973, 92).

Practice play, the word of Piaget for the exercise of activities just for the pleasure of the exercise (confined to individuals in his view and characteristic of the sensory-motor period in a child's development), applies equally well to the patterns in primate play (Miller 1973, 91). Studying the play of baboons, he concludes that it is easy to compile a list of characteristics that delimit play from non-play. The activities involve both animate and inanimate portions of the environment, and the motor-patterns involved resemble patterns from other contexts involving aggression, sex, feeding and so on. The motor-patterns in play can be performed in new and different sequences that are not possible in the other contexts, repetition is normal, and the motor activity is often exaggerated and uneconomical in comparison with the nonplay contexts (Miller 1973, 89). Practice play does involve rules but they are freely chosen and flexibly adapted. "Play is not means without the end; it is a crooked line to the end" (Miller 1973, 93).

Play between baboons also involved the reversal of roles where the mock fights often were initiated by the smaller of two animals. Miller concluded that "[s]uch ahierarchical activity seems to be a general feature of play" (Miller 1973, 89-90).

\subsubsection{Play as the Foundation for Socio-Cultural, Communicative and Political Practice}

Lev Vygotsky, professor in psychology in the Soviet Union was critical towards bourgeois psychology, and in his view on play he focused on it as social process, but like Piaget he 
stressed that each stage in the development of a child has its own drives and motives regarding play - even if the child does not start to play until its third year. The things which are interesting to a one-year-old child are uninteresting to a three-year-old that does not simply exists in a continuous now. Play for Vygotsky was the child's method of coping with the conflict between what you want and what is feasible (Hägglund 1989, 36-38).

In preschool years play encompassed almost all of the activities of the child, but in school "play and work or play and school tasks" become separate and form "two basic streams along which the activity of the schoolchild flows and finally, in the transitional age [...] work moves to first place, putting play in a subordinate and secondary position" (Vygotskij 1987, 27). This is the strongest connection between play and work I have found in my study of the literature on play, and it affirms my claims that play and work are trans-historical categories, implying that we should not treat the two categories dualistically but dialectically focusing both on similarities and differences in the interaction between them.

Vygotsky discusses both the research of Karl Groos and the theory of serious play that a scholar named Stern had proposed. Vygotsky admitted that the latter was not totally wrong. According to him Stern stressed that adolescence occupied a "middle ground between the play of the child and serious activity of adults".(Vygotskij 1987, 27) The theory pointed out two basic areas: the erotic and social relations. For the adolescent play was completely serious and satisfaction came from the functioning of the process and not the result of it. But for Vygotsky the theory had several severe flaws. The first and most important it shared with the theories of Groos. They were "purely naturalistic" teachings that could not establish the "principal difference between the play of an animal and the play of a human child." Play formed a complex developmental process in the child that mixed the natural, biological and organic evolution with the "social-cultural formation" in a complex "synthesis that makes up the real process". Therefore it was too simplistic to claim that the play of the child and the serious activities of the adults could be used to derive "an arithmetical average of both components in the form of serious play." It is in this context that he proposed the definition of play as selfeducation. (Vygotskij 1987, 27-28)

Vygotsky did not base play in the pleasure instinct, with the argument that all play was not pleasurable, for example the one that involved contests (Hägglund 1989, 37-39). The consequence of this observation, and the fact-I would like to add-that he did not distinguish between play and games, is that it is impossible to base play in pleasure.

All the basic activities of the child were not play, even if it looked that way for the adults when the child did things like opening and closing doors, playing with hobby-horses, without thinking of getting anything out of it. He favoured the idea of Groos that experimental play differed so much from other forms of play that it was not play at all. He wanted to break up the concept of play: "Play must be considered as a completely original activity and not as a mixed concept that unites all types of children's activities, particularly those that Groos called experimental play". Early childhood saw games as drinking from an empty cup, but Vygotsky did not want to compare that play with the creation of "imaginary situations". The former was more like the serious play of adolescents, where the play is not totally separated from real situations. It was in this context that he proclaimed that play had a unique relation to reality that for example involved the transference of properties of some objects to others within these imaginary situations. (Vygotskij 1987, 266-267) The claim that play is a kind of selfeducation could be seen as contradictory to the dismissal of experimental play as not-being play.

Hägglund claim that all forms of play contained rules according to Vygotsky. Imaginary situations in play demanded rules and rule-based play always created imaginary situations: role play was rule play and the other way around. And on a very abstract and general level play always performed or represented situations in life within the imaginary situations that lacked the conditional constraints of real situations. In play the cognitive process was separated, within limits, from the objects of the real world, and it was the will of the child that governed 
the rules of the play and not the situation. Rules even made the play more fun (Hägglund 1989, 37-39).

Working in the same tradition as Vygotsky, Aleksei Nikolaevich Leontiev developed a theory that saw human activity as socially situated and complex. He maintained that the active lives of human beings were characterised by play, memorisation and work. These activities dominated different periods in life. Play was most important for children and it functioned as a reflection of the objective real world. The content of play was directed by the children's will to copy the actions of the adults. Play's most important function was then socialization and accommodation (using Piaget's concept) to reality (Hägglund 1989; Wikipedia contributors n.d.). Also, George Herbert Mead, who had his major impact on sociology and social psychology with his theory on symbolic interaction, stressed the role playing for the development of our identities. When the child played being someone else it could see him/herself from the outside. This also led to internalisations of social roles. In contrast to Vygotsky he distinguished games from play. For him play was the spontaneous activity of the little child and games were the co-ordinated activity between several children (Hägglund 1989, 42-43).

Johan Huizinga ridiculed the naïve optimism of enlightenment and its worship of reason, homo sapiens, but also the preference of homo faber in his own time. He concluded that there existed a third function, applicable to both humans and animals, namely playing. "It seems to me that next to Homo Faber, and perhaps on the same level as Homo Sapiens, Homo Ludens, Man the Player, deserves a place in our nomenclature"(Huizinga 1955, Foreword). He conceived of play more as a cultural phenomenon than a biological one; play transcended the physiological and pure biological, and he approached it historically, with a focus on adults, and not in the spirit of the natural sciences (Huizinga 1955). Play was not understood as a utility and was passionate, but play was certainly also rooted in a biological instinct-play had a "primordial quality" in its intensity, tension, absorption, mirth, power of maddening and its fun, that was given by nature (Huizinga 1955, 2-3).

Huizinga focused on play as a function of culture and in this he drew attention to the relation between language and play.

\begin{abstract}
The great archetypal activities of human society are all permeated with play from the start. Take language, for instance- - that first and supreme instrument which man shapes in order to communicate, to teach, to command. Language allows him to distinguish, to establish, to state things; in short to name them and by naming them to raise them into the domain of the spirit. In the making of speech and language the spirit is continually "sparking" between matter and mind, as it were, playing with this wondrous nominative faculty. Behind every abstract expression there lie the boldest of metaphors, and every metaphor is a play upon words (Huizinga 1955, 4).
\end{abstract}

Johan Huizinga defined play as a free and voluntary activity; play that was ordered was not play (at best it was a "forcible imitation"), which had its aim in itself and was consciously performed outside of ordinary life as non-serious, but at the same time it absorbed the player intensely and was accompanied by feelings of tension and joy; play was an activity without material interest and proceeded within its own "boundaries of time and space according to fixed rules and in an orderly manner" that he called play's magical circle, which made play resemble a ritual. The rules were "freely accepted but absolutely binding". Play also demanded "visible action". In all of this it promoted the "formation of social groupings which often surrounded themselves with secrecy and disguises (Huizinga 1955, 7, 10, 13, 28, 166).

Johan Asplund criticises Huizingas definition in a work that aims at grounding his discipline in (wo)man's characteristic sociality and responsiveness (Asplund 1987, 29). Asplund exemplifies with (wo)man's predisposition to "answer" when a question is posed to him/her. In his eyes Huizinga stressed the rules and organisation of play too much. Even if Huizinga did not distinguish between play and game, his focus was on rule-based activities within a certain time and place that assumes a fixed character, according to Asplund. These activities can be repeated and guarded in the same form and become a tradition, and as such they exclude all forms of play that have the character of a one-time event. Improvisation, Asplund 
contends, appears as play only when it is formalised and thus is ended as improvisation. He opposes this and the view that some forms of creativity are not seen by Huizinga as necessary components of play (and to a lesser degree for games). He points to everyday language and contends that we are prone to conceive of capricious behaviours with no perceivable rules as play. Play could even be to break the rules. Asplund even assert that if we could conclude from a stimulus what the response would be, then it is not play, but maybe a game (see gaming). Play, to Asplund, in line with Gadamer (see below), is sheer responsiveness, but he agrees with Huizinga that play is voluntarily engaged in and that you do not do it for useful purposes or any other external goal or purpose. This means that play is exuberant or abundant. You play for the fun of playing, and play is its own reward. The opposite of play is not seriousness but utility, according to Asplund. Play and games are non-productive activities according to him, but they are social activities that can take place in many different places and situations (Asplund 1987, 29, 55, 63-66).

$\mathrm{He}$ admits that Huizinga is correct when he says that play in this improvised sense cannot found or construct a culture, but for Asplund it is play that contributes the matter for the cultural work of sorting and organising. The play precedes the game, the irregular the regular. Culture is created and completed as soon as play has disappeared and everything has become a game, one big treaty. A living culture according to Asplund needs redundancy, useless and exuberant action. The only thing that is left to do when all of such useless and exuberant actions have been persecuted and done away with by legislation is to "flip out" according to him. If Huizingas definition is too narrow in not taking into account non-regulated play (and in that process reifying a complex notion with solid and static concepts), it is too broad in its non- distinction of play from gaming. Asplund contends that a game is not a game unless it, in principle, allows cheating. Play does not allow cheating; it is a kind of cheating (Asplund 1987, 63-66). Asplund's understanding of play correlates well with my use of the concepts playing and gaming in this article.

Michail Bakhtin investigates the relation between play and culture in another way than Huizinga. He maintains in Rabelais and his World (1965) that the serious and the comic aspects of the world and of the deity, in early societies of a "preclass and prepolitical social order", were equally official, but that such equality was impossible in societies where the state and class structure had consolidated itself (Bachtin 2007, 6). "All the comic forms were transferred, some earlier and others later, to a nonofficial level. There they acquired a new meaning, were deepened and rendered more complex, until they became the expression of folk consciousness, of folk culture" (Bachtin 2007, 6-7). The relation of laughter, minstrels, festivities and carnivals to play is central according to Bakhtin. The basis of the laughter in the medieval carnival is free from religion and dogmatism, mysticism and piety, and they "do not command nor do they ask for anything". Some carnival forms parody the cults of the church in such a way that it is clear that the laughter belongs to an "entirely different sphere":

Because of their obvious sensuous character and their strong element of play, carnival images closely resemble certain artistic forms, namely the spectacle. [...] But the basic carnival nucleus of this culture is by no means a purely artistic form nor a spectacle and does not, generally speaking, belong to the sphere of art. It belongs to the borderline between art and life. In reality, it is life itself, but shaped according to a certain pattern of play.

In fact, carnival does not know footlights, in the sense that it does not acknowledge any distinction between actors and spectators. Footlights would destroy a carnival, as the absence of footlights would destroy a theatrical performance (Bachtin 2007, 7).

Bakhtin describes the carnival as play, rather than a game, in a class society. In the turning upside down of the highly hierarchical medieval society, this was not done in a spirit of competition. The festive laughter of people was also directed at those who laughed. "The people do not exclude themselves from the wholeness of the world." They, too, were incomplete (Bachtin 2007, 12). 
Bakhtin stressed that every feast was an important primary form of human culture that could not be explained "merely by the practical conditions of the community's work" and neither, more superficially, by pointing at the psychological demand for "periodic rest". Rather it was connected with the ideological dimension or the "world of ideals" (Bakthin, Rabelais, 8) The Swedish translation mentions here that the feast is no "workplay"' (Bachtin 2007, 9, 20).

If we compare the views of Huizinga, Asplund and Bakhtin with the view of the psychologists and Vygotsky on child play, as well as the perspective of game scholars like Jesper Juul, it seems that the concept of play, like the concept of culture, has two basic definitions: one broad and one narrow, the first focusing on life and social interaction in itself and the other focusing on specific activities (even if they are grounded in psychological development and needs). It is important to remember this difference, and especially the focus on the narrow definition, when we now look at Hans-Georg Gadamer's view on play and later on compare it with the views of language and communication of Hannah Arendt, Jürgen Habermas and Ludwig Wittgenstein.

Play could not exist without action according to Huizinga. Hannah Arendt mainly associated action with communication in a way that resembled Huizinga's view of play (it was meaningful in itself). Remembering the latter's argument about our nominative faculty and its play with words behind every metaphor, we can ask ourselves if play can be necessary for communicative action. Communication and speech acts in their turn have also been described by Jürgen Habermas in a way that has similarities to Huizinga's definition of play and Ludwig Wittgenstein has analysed speech-acts and primitive language in terms of language games. On a cultural level Michail Bachtin has written on the playful character of language and communication in terms of the dialogical word.

But before we examine in depth how communicative action relates to play, we will study Hans-Georg Gadamer's critique of the subjective notion of the concept of play, which saw play as something that happened in the mind or in the impulses of the subject (Vilhauer 2010, 32). In Warheit und Methode (Truth and Method) from 1960 Gadamer makes a distinction between the attitude of the player and play. For the player play is not serious in an ordinary way, like the serious purposes which dominate the world, and this is in fact why he plays. More important than the recreational side of play is play's own sacred form of seriousness. "Play fulfils its purpose only if the player loses himself in his play." Gadamer contends: "only seriousness in playing makes the play wholly play" (Gadamer 1975, 91-92). This mode of being of play does not "allow the player to behave towards play as if it were an object" (Gadamer 1975, 92). But even if (s)he knows what play is, and that (s)he 'only plays a game', the player does not know what exactly (s)he 'knew' in knowing that (Gadamer 1975, 92).

This convinces Gadamer that it is impossible to find an answer regarding play in the "subjective reflection of the player". Instead we should look at the play's very mode of being. He maintains that play has its own essence that is independent of the players. He points to the use of metaphors like play of light, play of the waves, play on words, play of forces to stress that play exists even "when the thematic horizon is not limited by any being-for-itself of subjectivity, and where there are no subjects who are behaving 'playfully'." Play reaches presentation through the players in a movement that has "no goal which brings it to an end" but rather "renews itself in constant repetition". He talks of this as a "to-and-fro movement" that "accords with the original meaning of the world spiel as 'dance"' (Gadamer 1975, 9-93).

The movement backwards and forwards is obviously so central for the definition of a game that it is not important who of what performs this movement. The movement of play as such has, as it were, no substrate. It is the game that is played-it is irrelevant whether or not there is a subject who plays. The play is the performance of the movement as such (Gadamer 1975, 93).

The most original sense of the word play is a "medial one", as in "something is "playing"'. If language is concerned, the subject of play is the play itself. The savage does not according 
to Gadamer know of any "conceptual distinction between being and play" (Gadamer 1975, 9-94). Gadamer holds that even the experiences of play that anthropologists and psychologists have get illuminated by acknowledging the primacy of play over the player's consciousness and by treating play in the medial sense of the word 'spielen':

\begin{abstract}
Play obviously represents an order in which the to-and-fro motion of play follows of itself. It is part of play that the movement is not only without goal or purpose but also without effort. It happens, as it were, by itself. The ease of play, which naturally does not mean that there is any real absence of effort, but phenomenologically refers only to the absence of strain, is experienced subjectively as relaxation. The structure of play absorbs the player into itself, and thus takes from him the burden of the initiative, which constitutes the actual strain of existence (Gadamer 1975, 94).
\end{abstract}

Different games have different spirits as a result of different organisations of the to-and-fro movement. Gadamer stresses the importance of rules and claims it is characteristic of human play that we chooses to play something, a structure of movements, with a definite quality that the individual submits her/himself (Gadamer 1975, 96). Vilhauer interpret this as the pattern of movements in play surpassing the players. All the players belong to the play and "the game tends to master the players" (Vilhauer 2010, 32; Gadamer 1975, 95). The movement of the game is not a free area in which the player plays him/herself out (Gadamer 1975, 96) But at the same time play's character is variable in Vilhauer's interpretation of Gadamer. It cannot be "fully determined or mechanical" and involves "the possibility of spontaneity and variety" that demands that the players' moves "are not identical to each other or totally predictable in advance" (Vilhauer 2010, 33).

The player's submission to play involves at the same time a unique pattern, a subject matter in which the player presents him/herself by playing something that (s)he wants to play. Within this "readiness to play" the player also chooses what (s)he is to play. Human play involves intention or the "choice to constrain one's own freedom to the rules of a game", and is not simply instinctive or caused by external forces according to Vilhauer's interpretation (Gadamer 1975, 96; Vilhauer 2010, 34). Gadamer speaks of the self-discipline and the order we impose on ourselves with effort, ambition and commitment in play and calls this selfpresentation (Hans-Georg Gadamer, "The Relevance of the Beautiful", 1977 cf. Vilhauer 2010, 34).

The form of play is near the mobile form of nature according to Gadamer. Rather than saying that the animals plays too and metaphorically that the lights play, we should instead say that man too plays-a natural process. Play for man, as a part of nature, is "pure selfpresentation" (Gadamer 1975, 94). In an essay from 1973 he contends that play as a phenomenon is blurring the distinction between man and animal. Play is presented as an elementary phenomenon that pervades the animal world and is determinant of man as a natural being. Monica Vilhauer claims that play is essential to all living things in the thinking of Gadamer (Vilhauer 2010, 33).

Gadamer here succeeds in managing both the narrow and broad definition of play at the same time. His focus on the importance of the rules stresses the close connection between play and game and he does not distinguish between them, but I would argue that he implicitly also shows the differences between the two-as in this argumentation:

Every game presents the man who plays it with a task. [...] Thus the child gives itself a task in playing with the ball, and such tasks are playful ones, because the purpose of the game is not really the solution of the task, but the ordering and shaping of the movement of the game itself (Gadamer 1975, 97).

This is clearly about playing. Playing is a natural and creative self-presentation that is not aimed for anyone other than the players, but play could also be play or representation for others. I contend that this latter category of playing is better understood as gaming. 
Gadamer's theoretical understanding of play has some similarities with Lewis Hyde's understanding of the gift. Hyde holds that the creation of a work of art is a gift, not a commodity; work of arts can survive without the market, but if there is no gift involved then there is no art. What does this mean? Hyde claims that gifts are bestowed upon us and point to the fact that we speak of 'talent', intuition and inspiration as gifts; a gift "is a thing we do not get by our own efforts" (Hyde 2012, xxii):

\begin{abstract}
Usually, in fact, the artist does not find himself engaged or exhilarated by the work, nor does it seem authentic, until this gratuitous element has appeared, so that along with any true creation comes the uncanny sense that ' $l$ ', the artist, did not make the work (Hyde 2012, xxii).
\end{abstract}

Play and gifts seems central to the arts, but the art is often performed in front of an audience. If Hyde's remarks above point to the "inner life of art" there is also an "external life" after the work of art has left its maker. Hyde maintains that the gift is central also in this external life. "The art that matters to us-which moves the heart, or revives the soul, or delights our senses, or offers courage for living, however we choose to describe the experience - that work is received by us as a gift is received" (Hyde 2012, xxii). Hyde proceeds by claiming that this feeling is not changed by an entrance fee at the museum, but the way we treat a thing or work of art can change its nature. It is possible to destroy a work of art by converting it into a pure commodity. "The gift portion of the work places a constraint upon our merchandising" according to him (Hyde 2012, xxiii). This roughly correlates with my analysis that play can contain indeed contests and performances, but that external actors have the power to change or destroy its character as play. This possibility is also admitted by Gadamer (Gadamer 1975, 98).

From these inner and external processes we also can conclude that there exists a movement within the world of art, a kind of communication, or inter-play of gifts. Building on anthropological research and aesthetic theory, Hyde asserts that the cardinal property of the gift is that it should always be in motion. What we have been given is supposed to be given away again, not kept: it is even better if the gift is not returned, but instead given to some new "third party". If someone instead commercialises the gift relationships, the whole social fabric of a group is "invariably destroyed" (Hyde 2012, 4-5).

As with Gadamer's play, the gift of Hyde's moves on in a dynamic process. Like a free conversation (exchange of meanings back and forth between humans) rather than a static or reified thing. Asplund's contention of play as an elementary social form, Hyde's proclamation of the gift as a source of social life, and Jürgen Habermas' focus on the importance of a public sphere created by free communication all share a focus on a similar dialectical movement. The sociality and the ease of the performance of the activities stem from them being part of the human constitution.

To this family of theories we can also include Michail Bakhtin who stressed the continuous dialogue going on in the world literature around the most essential questions concerning human existence. The poet, novelist, prophet, leader or scientist all have to justify their words, they have to represent something for someone (Bachtin 1988).

Bakhtin stressed that the reader or listener contributes something proper and new to the work of art. The reader of the work does not exist in the same time and work as the author; there is a distinction. The other is alien to the author, but they are connected through a dialectic relation. Bakhtin did not conceive of any first word or last word, or any boundaries for the context of dialogue in the past or in the future. Not even the dialogues of the past can be seen in fixed forms according to him, they will always keep on changing in the coming dialogues of the future. In every moment of the development of the dialogue there exist huge unlimited masses of forgotten significations that someday will be activated and come to life again in a new context (Bachtin 1988, 269-270).

After this presentation of Gadamer's concept of play as a movement back and forth, as a kind of dialogue, it hopefully seems less strange to connect the thoughts of Huizinga, 
Asplund, Bachtin and Gadamer to the thoughts of Hannah Arendt and Jürgen Habermas on (communicative) action. The main purpose of this section of the article is to examine the connection between communication and play. I will first show how, in the thinking of Hannah Arendt, speech and action are connected in an idealised way to Huizinga's and Gadamer's definition of play, and then I will make some critical remarks of the importance of bringing in history into the equation. After this I will compare and identify the links between Arendt's concepts of speech and action (praxis) with Jürgen Habermas' concept of communicative action.

The idealistic focus of Huizinga on thoughts and mentalities as the driving force of history corresponds to Hannah Arendt's highlighting and appreciation of action and speech in an idealised and truly political sphere, at the cost of work (as in creating lasting works and use values) and labour (as in ceaseless and repetitive toil for survival) that she contends have been endorsed by modern political economy. Arendt was inspired by ancient Greek thought and the focus on political dialogue within the polis.

Arendt stresses, very much as how Gadamer describes the conditions for play, that the plurality of humans is the condition for action, as well as for speech. Plurality is displayed as similarity and difference; without the former, people would not be able to make themselves understood in social interaction or between generations (or to make plans for the future); without the latter, language and action would not be needed. (Arendt 1998, 237-238) Hence, for Arendt, speech is an especially important form of action and through it action acquires meaning. Action is the human activity that requires words to the highest degree; in work and labour they have a subordinated role (Arendt 1998, 242).

Play needed action according to Huizinga; communication is action in itself, but also forms part of other action to a high degree according to Arendt. Communication then goes together well with play, especially if playing with words is an integral part of it, and communication gives play its meaning. Hypothetically I propose that communication can be performed within play in an instrumental way, but then it forms part of a larger play form that is funny in itself, just as it can be playful in itself on other occasions. The proper playfulness of communication can be used, or attempted to be used, within work and labour in instrumental ways: to make the work more attractive, concealing tedious labour or exploitive mechanisms' and alienation. Playing with words in work and in labour will be treated in the section regarding these relations further on in the text. For now I just would like to point to the similarity between play and communication. Playing with words can be playful in connection to the reality and in relation to language's own rules, very much in the same way as Asplund speaks of play as including the joyful breaking of the rules in a pure social responsiveness.

An action puts something in motion according to Arendt; it acts, and it commences and regulates. The new beginning does always contradict the static possibilities and is therefore always improbable, (Arendt 1998, 241) much in the same way as play is open to spontaneity and the freedom of variations according to Gadamer. Arendt argues that the individual takes communicative initiatives without there being any particular decision involved. In opposition to other activities within Vita Activa no man or woman can let go of speech and action.(Arendt 1998, 237-238, 242) Thus speech and action are also essential to humans if we are to believe Arendt. This theory fits well with Asplunds notion of social responsiveness. Initiatives and responses come naturally to (wo)man.

Speech and action, when it is used between people who speak and interact with each other, rather than against and for something, also tell us something about the speaker and (wo)man of action (Arendt 1998, 243), much in the same manner as Gadamer writes that the player to a certain degree plays out him/herself in the play. But here we find a rather big difference. The risk associated with appearing as Someone in the communicative presence of others is something that only a person who is ready stay in that presence will do, according to Arendt (Arendt 1998, 24-244), but in playing you can always say that it was only play. In play you are free to experiment with roles, identities and communicative actions out of the ordinary. Communication is a broader concept, with a broader range of functions, than play 
in the social life. Speech and action need a surrounding world to address and project onto, but this can be for different purposes, and they take on another, not so risky and freer character within play than otherwise. Hence, there exists a relation of mutual influence between play and communication, two concepts that share many similarities but also differ from each other.

The lived action and the pronounced word are expressed in the Aristotelian term 'energia' according to Arendt, which, in contrast to my thinking, stresses an idealised and more narrow version of communication that simply includes the activities that do not have a purpose and do not leave any end result except themselves, and whose meaning is exhausted in their practice. Arendt points to Plato and Demokritos who repeatedly claimed that techne politiche should not be compared to work but with practical arts like medicine, dance and theatre, where the end product is the process in itself. Speech and action was "virtuosic" to her (Arendt 1998, 279-281). This is the origin of Paolo Virno's proposition of the virtuosic character of labour in post-Fordist capitalism.

Habermas' focus on the communicative action in the life world shares this idealism in charging an idealized free communication in the life world with progressive power. One crucial distinction, between Habermas and Arendt is that he situates the life world within the structural transformation of society as a whole, which includes a conflict between the life world and the system world. There is thus a moment of struggle in the vision of Habermas, which is lacking in Arendt's work. This struggle, with its focus on ideas and communication, carries similarities with the Situationist's project of revolutionising everyday life with play, even if the latter was involved in more tangible strategies in a more direct attack on abstract labour.

If action was a necessary (but not sufficient) condition for play according to Huizinga, and communication was the highest form of action, to Arendt, play indeed has fertile soil to expand in when it comes to the trans-historical social life that Jürgen Habermas theorises about with his concept of communicative action (Habermas 1987, 119). In Habermas formalpragmatic analysis, the concept of life world aims at grasping the structures "that in contrast to the historical shapes of particular lifeworlds and life-forms are put forward as invariant". He is engaged in a separation of form and content where he is focusing on the structures of the life world in general. I will here follow his analysis of how the life world is related to the "worlds on which subjects acting with an orientation to mutual understanding base their common definitions of situations" (Habermas 1987, 119-20).

Habermas contends that there exist three different "actor-world relations" in which the subject relates to the world as an object, something social and something subjective (Habermas $1987,120)$. The speech acts' references thus appear to the speaker as something objective, normative, or subjective. Habermas also calls them for formal world concepts and makes a distinction between them and the life world. "[T]he lifeworld is constitutive for mutual understanding as such whereas the formal world-concepts constitute a reference system for that about which mutual understanding is possible" (Habermas 1987, 126). "Communicative actors are always moving within the horizon of their lifeworld; they cannot step outside of it. [...] The structures of the lifeworld lay down the forms of the intersubjectivity of possible understanding (Habermas 1987, 126). A situation, finally, consists of a segment of "lifeworld contexts of relevance" (Habermas 1987, 122).

Hannah Arendt stressed the creative flux of communication and Habermas put more emphasis on the cultural context surrounding each life world and used the formal worldconcepts to show how communication ideally functions in the search for mutual understanding. Communicative actors do not understand their communication as a means to intersubjective agreement about the life world. This instrumental and cultural effect is hidden from them, but they do, Habermas argues, understand that they need a common ground to interpret facts, norms and subjective realities in concrete situations. They need to create common rules and the rule-negotiation appears as rewarding in itself in the context of the life world - a thought that is similar to Gadamer's view of play. 
Ludwig Wittgenstein's theories on language games can perhaps give us a more concrete picture of how communication is used in the situations of real life. In his Philosophical Investigations, paragraph 2, Ludwig Wittgenstein takes the example of a primitive language between a builder $A$ and an assistant $B$. A is building with building stones as blocks, pillars, slabs and beams. They use a language with the words 'blocks', 'pillars', 'slabs' and 'beams'. A calls them and B brings the stones he has learnt to bring at such an such call to A (Wittgenstein 1967, 3).

\begin{abstract}
In the practice of the use of language (2) one party calls out the words, the other acts on them. In instruction in the language the following process will occur: the learner names the objects; that is, he utters the word when the teacher points to the stone-And there will be this still simpler exercise: the pupil repeats the words after the teacher-both of these being processes resembling language.

We can also think of the whole process of using words in (2) as one of those games by means of which children learn their native language. I will call these names "languagegames" and will sometimes speak of a primitive language as a language-game.

And the processes of naming the stones and of repeating words after someone might also be called language-games. Think of much of the use of words in games like ring-aring-a-roses.

I shall also call the whole, consisting of language and the action into which it is woven, the "language-game" (Wittgenstein 1967, 5).
\end{abstract}

Speech and tangible action are here connected to each other in language-games. These language games can have pedagogical and productive results, but the way in which this is done, with repetition and imitation, seems to be playful in a deeper sense to Wittgenstein who in this comes near Gadamer and sees communication as a social "to-and-fro" interaction that is determined by the concrete and situational language games in a sense that resembles Gadamer's view that the players were absorbed by the play. Hence Wittgenstein seems to support the idea of play being central to language that in turn is both central to tangible forms of goal-oriented action as well as determined by the concrete situations (for our purposes speech can then be characterised by play, work or labour).

Wittgenstein makes the point that people do not always have a definite purpose with what they say, and he asks rhetorically if talk without purpose has to be meaningless, implying that it is not (Wittgenstein 1967, 188).

Another play element is touched upon by Wittgenstein when he discusses how we can know what the phrase 'I am frightened' really means. He refutes the possibility of introspection "[W]hat am I referring to when I say it?" Instead the right question is "In what sort of context does it occur?" Asking the first question, the subject repeats the expression of fear at the same time as she attends to herself, as she was observing her soul "out of the corner" of her eye. Wittgenstein asserts that this will not give you an answer to the question on the ground of "observing what accompanied the speaking." The answer given by introspection can only supplement and paraphrase the earlier utterance. The best thing to do in this case, if you want to understand what 'fear' is in a "single shewing", is to "play-act fear".(Wittgenstein $1967,188)$ From this we can learn that Wittgenstein really stressed the relation between play and action and saw play as a way to be in the moment and to re-live the (communicative) action in itself - instead of observing and representing it from the outside. He thus shared the definition of play as something that absorbs you and that you have to lose yourself in to practise.

Gregory Bateson, a social anthropologist that both used cybernetic theories and investigated animal behaviour was explicitly interested in play from a communicational perspective and was interested in the question of how we learn to learn things. The concept of text and context was important for him. Text signified the action at hand in the context. The third concept was meta-communication, meaning unconscious messages that we send to each other at all time to clarify what kind of context we are in-if we are playing or being serious for example. Communication thus labelled the situations. This meta-communication, assigning dif- 
ferent meanings of words and actions in different contexts, was something that the child could train in play according to Bateson. Once again the connection between play, communication and situation seems to be of central importance to humans. Bateson held free play with its intricate meta-communication, higher than (fixed) rule-based play (Hägglund 1989, 54-56).

We cannot leave the category of play without saying something about the surrealists' and situationists' position on play. The latter's position will largely be treated when the relation between play and labour is examined below.

Georges Bataille was part of the surrealist international, but broke with André Breton before the second world war, after it he and some friends and surrealist followers developed an Encyclopaedia Da Costa (1947) that in a joyous but also critical way (against the dialectic of enlightenment) started in the middle of a sentence and just contained words beginning with the letter E. Under the entry "Encyclopedie" you can read that encyclopaedias are going to great trouble to explain words that are no longer in use but that they do not care about the unknown words that are burning to be pronounced. For a child the discovery of language is not the realization of the present but foreknowledge of the future: "Words tell him, not what he is, but what he will be." For each and every new word invented, a link is broken with the effective presence according to the unknown author (Anon 1995, 122, 124). The present now and the creative and experimental power of language to understand the world in new ways was at the core of Bataille's interest in reviving rather than reifying social life with the help of play.

During this time Bataille was writing a major work called The Cursed Share in which you can detect connections between his group's critique of the reified view on knowledge and the reifications of capitalism. In the book Bataille makes a new interpretation of Marcel Mauss essay The Gift, which is centred on how different cultures deal with the question of abundance through rites founded on destruction and euphoric social dissolution. Bataille's thesis was that capitalism gradually had established an economy built on the principle of scarcity and that this had created an imbalance in the social structures manifesting themselves in the accumulation of social wealth by the bourgeoisie. Bataille claimed that accumulation was profanity, homogeneity and stasis, and in contrast to science which depended on homogeneity between its elements, the method of Bataille was a negation that suspended common denominators (Brotchie 1995, 21-23; Bataille 1991, 168-69). Bataille, in contrast to Jorge Luis Borges who delivered his critique against encyclopaedias and classifications by converting the library to a labyrinth, seems more positive about the insecurity of the labyrinth, claiming that trying to understand it would devaluate its presence (Hollier 1989, 60-61; Borges 1998, 35). This celebration of collective rites and the importance of being present in the moment, together with the critique of the stasis and reifications of positivist facts, imply the ideal nonexistence of instrumentality and the abundance of resources, interpretations and communicative inventions, which stresses the same themes as touched on in our discussion of the relation between play and communication.

Roger Caillois, a former Surrealist who together with Bataille broke with the Surrealist International before the war, published a classic account on play and games in 1958 called Man, Play and Games (Les jeux et les homes). He started the book with a critique of Huizinga's definition, but only after first having stressed that Huizingas book Homo Ludens opened up very fruitful avenues for research and reflection, even if most of its premises were debatable. The definition of play that Huizinga presented was both too broad and too narrow. It was meritorious and fruitful to grasp the "affinity which exists between play and the secret and mysterious", but this relation had nothing to do in a definition since doubt, mystery and travesty, when transformed into play tended to lose their very nature of mystery. The old surrealist, taking secret societies and mysteries seriously, in his mission to counteract the dialectic of Enlightenment, thus agreed that play was the opposite of the serious in its exposing and publishing of the mysterious in a way that somehow expended it (Caillois 2001, 4-5). Play had a deconstructive and destructive power according to him, and in this his thought 
came close to Freud's early claim that play was a way to be the master of a situation, implying here that play had the power to take the seriousness out of a threat or mystery, and perhaps also dethrone authorities.

This view of the power of play was taken up by the Situationists in a new way as a strategic means to change everyday life. Play's socialising function has been stressed by many in this overview, especially the psychologically inclined thinkers, but play's subversive function has also been stressed by, besides by the Situationists, Bakhtin and the social anthropologist Helen B. Schwartzman.

Two of Caillois' famous categories of play: Mimicry (simulation) and Ilinx (vertigo), presented in the introductory section, can be easily included in the description of play. The other two are focused on competition and chance. The Situationists of the Situationist International (SI) wanted play to be ridded of all gaming and competition. For them play was perceived as the central category of play and work, perhaps even implying that play had the power to replace socially necessary work as well as labour of capitalism in their struggle to revolutionize everyday reality through creating situations in which all attendants participated in non-reified and playful ways. (Post)modern critics have criticised this both broad and deep perspective, but it has also been defended. In this stress on play the Situationists shared Herbert Marcuse's reading of Freud and Marx. The Situationists will be thoroughly discussed in the sections on the relations between the categories.

Finally, to connect this discussion of play to contemporary cognitive capitalism with its emblematic digital form of work and labour, some words on what Pekka Himanen has called the hacker ethic. Linus Torwalds claims in the foreword to Himanens book that the computer is entertainment for the hacker (Torvalds 2001, xvii) and Pekka Himanen places this statement at the centre of what he calls the hacker ethic. The hacker is enthusiastic about interesting things; they give him energy, according to him. Hacking is joyous and often has its origin in "playful explorations". Himanen thinks that the description of hacker activity as passionate is even more apt, because it conveys the three levels of interesting, inspiring and joyous, which is an improvement on the word entertaining. This kind of "passionate relationship to work" is also seen in academia, among artists, artisans and information professionals according to him (Himanen 2001, 3-4, 6-7).

We leave the category of play with this teaser on constructive play, or is it playful work? Playbour?

\subsubsection{Conclusions}

In this study of the relevant literature on play, I have found that play, as the concept of culture, has both a narrow and broad meaning. Further, I have identified five different dimensions. 1) The purpose of play is the activity itself for the player, but goals can be used within play to form the activity; behind the backs of the players it can have productive outcomes, and Vygotsky stressed that the play of the child later became the work of the adult. 2) Play is a mobile dialectical process which is not reifiable on the subjective level; it is similar to life itself in some ways but free (between the players and in relation to reality) in its use of rules, the processes are open to re-negotiations and improvisations under the activity and therefore play is not totally predictable; play can take place within the solitary player or in his/her relation to the world, or within a playing community, and can often have the character of exaggerated or uneconomical "galumphing". 3) Play occurs when all other needs are satisfied and because the player voluntarily takes the initiative. 4) Play is fun, enjoyable and pleasurable, and can be characterised by a certain ease and relaxation or by a luxury feeling of superfluous abundance, as well as by passion and tension. 5) Play is part of nature and the human constitution, and it is crucial for social life as well as our communication, but in contrast to Gadamer I also stress the importance of the involved subjects' understanding and feeling of play.

There is a fine line between playing and working in some of the digital, or so-called immaterial labour, going on in the general intellect, but it is a crucial one. When it comes to the 
question of activity or result, working always involves production of a use value for yourself and other people (even in the sense of pleasurable or fun for others), and playing involves the pleasurable and fun activities you perform just for the fun of it. It is not play when you perform a pleasurable activity to obtain the relaxation or concentration that the play results in. In the last example the activity is focused on the result that is a use value to satisfy a need. You have to lose yourself in the play, for it to be play.

\subsection{Working}

Lev Vygotsky maintained that the child's play developed into the work of the adult. Play and work were trans-historic. Hannah Arendt as well as Fuchs and Sevignani make a distinction between work and labour, but in different ways. Arendt contrasts labour, as something that is never finished, to work, which always ended up in the world of things. She named the workers homo faber and the labourer animal laborans (Arendt 1998, 126, 140). Fuchs and Sevignani use a Marxist perspective, which is also the perspective used for work and labour in this article.

Work is determined by its concrete aim of producing a value "in use of its product". (Marx $1867,49)$ Hence, work is an instrumental activity, which results in a product, which does not need to be tangible, but could consist of signs, speech, affects and services, that is, useful. It is this aim of producing a use value that makes the work "useful labour"(Marx 1867, 49). Useful labour is a "specific kind of goal-oriented labour", private in character, which "movements and efforts" are conditioned by the use value being produced. Useful labour is defined by Marx as a "productive activity of a definite kind" and is contained in the use value (Marx 1867, 49). Qualitative and particular in its character, work cannot be compared to another particular work (Karlsson 2013, 46), and therefore there can be no competition between different forms of concrete work and their use values; there is not a common ground for them to be measured by as they have different qualitative characters.

To make the point clear: let us imagine a plain barter between two individuals, in which two qualitatively different wants can be met by the exchange of two qualitatively different use values. No competition takes place in the barter, because the use values are as qualitatively different as the wants and needs involved. In the realm of use values and concrete labour, competition can only occur between qualitatively similar use values and activities.

With all this in mind I contend that the activity in itself cannot be a use value for the worker him/herself. This would change the character of the activity. Only the resulting product (or state of mind) can be a use value for the actor, but the activity can be useful in itself for another person who, external to the activity, can use it as a product. This distinction is important for my further study of the relation between play and work/labour.

Moishe Postone interprets Karl Marx's position on work as one where there are two kinds of necessity involved: one that is trans-historical and one that is social and historical (Postone 1993, 381). Some necessity will always exist in a society. Even when the realm of freedom is expanding under communism, some necessity will continue to exist:

One remaining constraint is nature. Although the labor of individuals need not be a necessary means for acquiring means of consumption, some form of social production is a necessary precondition of human social existence. The form and extent of this transhistorical, "natural", social necessity can be historically modified; this necessity itself, however cannot be abolished. (Postone 1993, 382)

Marx himself wrote quite explicitly in volume one of Capital on the topic of man's metabolism with nature. As far as it was work as a creator of use values, useful work, it was a necessary condition that was "independent of all forms of society, for the existence of the human race". It was an "eternal nature-imposed necessity" without which there could be no "material exchanges between man and Nature, and therefore no life" (Marx 1867, 50). Later on in volume three he wrote: 
Just as the savage must wrestle with nature, in order to satisfy his wants, in order to maintain his life and reproduce it, so civilized man has to do it, and he must do it in all form of society and under all possible modes of production. With his development the realm of natural necessity expands, because his wants increase; but at the same time the forces of production increase, by which these wants are satisfied. (Marx 1909)

Work was in the first place a process in which both man and nature participated. Actually man was nature. In his critique of the Gotha program that was adopted by the German Social Democratic Party in 1875, work had a central role. The first paragraph stated that labour was the source of all wealth and culture, and Marx furiously wrote: "Labour is not the source of all wealth. Nature is just as much the source of use values (and it is surely of such that material wealth consists!) as labour, which itself is only the manifestation of a force of nature" (Marx\&and Engels 1991, 301). Work was thus determined and effectuated by nature according to Marx. (Wo)man started the process on his/her own accords and regulated and controlled the material interaction between himself and Nature:

He opposes himself to Nature as one of her own forces, setting in motion arms and legs, head and hands, the natural forces of his body, in order to appropriate Nature's productions in a form adapted to his own wants. By thus acting on the external world and changing it, he at the same time changes his own nature. (Marx 1867, 173)

In this purposeful interaction with nature man transforms himself and "develops his slumbering powers and compels them to act in obedience to his sway" (Marx 1867, 173)—which is yet another parallel to how play functions within the child's development. It is on this selfreflexive dynamic of the work process that the development of the historical phases of labour depends, which in turn allows for the development of new needs, activities and new theoretical knowledge about the world. It is a dynamic that contrast sharply with the instinctive behaviour of animals (Carver 1987, 93-94; Karlsson 2013, 48). Marx was thus not writing about the primitive, instinctive forms that "remind us of the mere animal" in this passage of Capital. He stressed that there was an "immeasurable interval of time" that separated the situation in which a man "brings his labour-power to market for sale as a commodity", from the time when human labour was still in its first instinctive stages (Marx 1867, 173-74), and he therefore presupposes work in a form that stamped it as "exclusively human" (Marx 1867, 173-74).

A spider conducts operations that resemble those of a weaver, and a bee puts to shame many an architect in the construction of her cells. But what distinguishes the worst architect from the best of bees is this, that the architect raises his structure in imagination before he erects it in reality. At the end of every labour-process, we get a result that already existed in the imagination of the labourer at its commencement. He not only effects a change of form in the material on which he works, but he also realises a purpose of his own that gives the law to his modus operandi, and to which he must subordinate his will. (Marx 1867, 174)

The conclusion that work is a trans-historic feature of the human condition carries with it the potentiality that its historical forms of appearances may not necessarily have to be related to hierarchical class societies. The social necessity of work is mainly developed by Marx in relation to work in capitalism, that is labour, but you just have to think of gift economies, like those described by the classics of anthropology, to see that a gift of a use value demands its counter or return gift under different forms of reciprocity (Mauss 1972; Malinowski 1922; Hyde 2012). Social bonds that demand certain behaviour thus exist in all societies.

Marx was clear about the fact that the social character of work was not confined to capitalism. Work as the "special sort of productive activity" that was "determined by its aim, mode of operation, subject, means, and result" was qualitative in kind and not dependent on the production of commodities: 
To all the different varieties of values in use there correspond as many different kinds of useful labour, classified according to the order, genus, species, and variety to which they belong in the social division of labour. This division of labour is a necessary condition for the production of commodities, but it does not follow, conversely, that the production of commodities is a necessary condition for the division of labours. (Marx 1867, 49)

Marx wrote on work in the anthropological way in the Introduction to a Contribution to the Critique of Political Economy, which was later published as the introduction to Grundrisse (Marx 1973). It starts with a famous critique of the Robinsonades of bourgeois political economy:

Individuals producing in a society, and hence the socially determined production of individuals, is of course the point of departure. The solitary and isolated hunter or fisherman, who serves Adam Smith and Ricardo as a starting point, is one of the unimaginative fantasies of eighteenth-century romances a la Robinson Crusoe /---/[?]This is an illusion and nothing but the aesthetic illusion of the small and big Robinsonades. It is, on the contrary, the anticipation of "bourgeois society," [...] The individual in this society of free competition seems to be rid of natural ties. (Marx 1857; Marx 1973, 83)

Work, hence, was social in its character. "Production by a solitary individual outside society" was rare, and if an individual by accident ended up in the wilderness he had already before absorbed the dynamic social forces. It was thus equally absurd to think of these Robinsonades as to perceive of the development of speech and language without assuming "individuals who live together and talk to one another" (Marx 1857; Marx 1973, 84).

But being social, work had the potential of taking on freer and more voluntary forms. "Really free working, e.g. composing, is at the same time precisely the most damned seriousness, the most intense exertion" (Marx 1993, 611). The enjoyment associated with using the bodily and/or mental powers, especially in what Marx called the realm of freedom point to the existing potential of feeling self-fulfilment and self-expression through work. Marx wrote like this of this mixture of necessary work with self-fulfilling and self-expressing work in a way that relates to the close relation between freer forms of work and effortless play:

The less he is attracted by the nature of the work, and the mode in which it is carried on, and the less, therefore, he enjoys it as something which gives play to his bodily and mental powers, the more close his attention is forced to be. (Marx 1867, 174)

When work was enjoyable its character transformed into something similar to art. This potentiality of increasingly more attractive modes of producing which merged work with play into a synthesis of attractive work which seems light and easy also existed as a real potential within the logic of capitalism (Marx and Engels 1991, 306) Marx, finally, wrote in the Introduction to a Contribution to a Critique of Capital about the complex relation between trans-historical and historical forms of work/labour:

Some determinations belong to all epochs, others only to a few. [Some] determinations will be shared by the most modern epoch and the most ancient. No production will be thinkable without them [...] just those things which determine their development, i.e. the elements which are not general and common must be separated out from the determinations valid for production as such, so that in their unity-which arises already from the identity of the subject, humanity, and of the object, nature-their essential difference is not forgotten (Marx 1973, 85).

Marx contends that production is always a particular sort of production, there is thus no production in general, but this must not stop us from assuming there is a common and essential form of work derived from the identity of the human individual and nature (Marx 1973, 85). Herbert Marcuse wrote that work has a Last-Charakter (load-character) that was independent of both the historical mode of producing and the worker's experiences of it. This LastCharakter was founded in the fact that the individual was dependent on the conformity to the laws of the object or Nature (Karlsson 2013, 49). Karel Kosik's understanding of work as de- 
fined by its objectified result (Karlsson 2013,48 ) is more problematic today when we see that work can also express itself in non-tangible and virtuosic forms (Lazzarato 1996; Virno 2004), but it could also be said to confirm my earlier statement that an actor external to the activity could objectify it under the performance, though not the actor himself.

\title{
1.2.1. Conclusions
}

The same five dimensions as in play were found in the view of the Marxist tradition on one of its central concepts: work. 1) Work is goal-oriented and focuses on its result; the goal is to produce use values. 2) Work is a specific and concrete activity, characterized by a specific quality, which changes in its specificity according to what use value it is producing. There is no competition between different concrete work processes due to the fact that they are not commensurable and focus on different social needs. 3) Work is a necessary activity in the human condition; someone has to work if we are to survive as humans. 4) Work is connected to feelings associated with it being necessary and having to be useful, but also to feelings associated with it satisfying social needs through the use of capabilities and knowledge to transform nature in accordance with them. The first category correlates with seriousness, the second with self-expression and self-fulfilment, but also with feelings of social belonging and "togetherness". 5) Work is at the core of human metabolism with nature, connected to survival, and is thus trans-historical.

\subsection{Gaming}

Studies to understand games have frequently been conducted in sociological, anthropological, and philosophical research, to a lesser degree in the aesthetic field, but game theory has also been used within economics and computer sciences (both John von Neumann and Claude Shannon have used so-called game theory to understand strategic choices in economics and in developing the work of the computer). Structuralism has been influenced by game theory. Claude Lévi-Strauss and Vladimir Propp discussed the relation between rules and representation claiming that narratives were based on formal structures, and Ferdinand de Saussure compared chess to language. In psychology Adriaan D. De Groot (1965) studied the psychology of playing chess and Allen Newell and Herbert A. Simon (1972) used game-like problems for studying human problem solving. Marcel Danesi has also shown that games and puzzling solving have yielded many insights in mathematics, for example in the field of graph theory. Hence, the purpose has often been to understand other issues through the study of games and gaming (often called play) (Juul 2005, 8-10).

\begin{abstract}
When rational choice theories attempt a concept of game that excludes play, the Situationists attempt a concept of play outside the game: from each according to their abilities; to each according to their desires" (Wark 2007, paragraph of Cuts (Endnotes) 021). The game, unlike play, is relatively easy to define. Play is what is excluded from any definition of game to give it the appearance of self-consistency (Wark 2007, Cuts [Endnote ] 090).
\end{abstract}

Jesper Juul provides us with a definition of the concept game in which he tries to identify similarities between the things that we call games. He calls his model the classic game model and is building on seven game definitions by previous writers (Juul 2005, 6-7, 23).

The model consists of six features working on three different levels, the levels being the "level of the game itself, as a set of rules; the level of the player's relation to the game; and the level of the relation between the activity of playing the game and the rest of the world" (Juul 2005, 6). The features are then: 1) the rule-based formal system, 2) the variable and quantifiable outcomes, 3 ) the assignment of different values to different outcomes, 4) the exertion of effort from the part of player to influence the outcome, 5) emotional attachment of the player to the outcome, and 6) optional and negotiable consequences of the activity. Juul claims that the six features together are necessary and sufficient conditions for something to be a game (Juul 2005, 6-7). 
Juul focuses on what he calls video games. Video games are defined by the two things they are made up of: real rules and fictional worlds. The rules are real in the sense that players interact with them and that winning or losing is "a real event". The slaying of the dragon, however, is the slaying of a fictional dragon. "To play a video game is therefore to interact with real rules while imagining a fictional world". This fictional world is more concrete than the fictional worlds connected to traditional, non-electronic games that used to be more abstract. Media and video games are a quite new cultural form connected to the appearances of the computer, but as games they have a very long history. (Juul 2005, 1, 3)

When Roger Caillois published his classic account of play, Man, play and games (Les jeux et les hommes), in 1958, he criticised, as we have seen, the definition of play that Huizinga presented. It was both too broad and too narrow according to Caillois (even if he himself did not distinguish between the play and game dimensions). One central problem with Huizinga's definition according to Caillois was that it viewed play as "action denuded of all material interest". This excluded bets and games of chance "which for better or worse, occupy an important part in the economy and daily life of various cultures", according to Caillois, who stresses that "the constant relationship between chance and profit" is striking:

It is certainly much more difficult to establish the cultural functions of games of chance than of competitive games. However, the influence of game of chance is no less considerable, even if deemed unfortunate, and not to consider them leads to a definition of play which affirms or implies the absence of economic interest. Therefore a distinction must be made.

In certain of its manifestations, play is designed to be extremely lucrative or ruinous. This does not preclude the fact that playing for money remains completely unproductive. /---/[?] [The entrepreneur] alone does not play, or if he plays he is protected against loss by the law of averages. In effect, he is the only one who cannot take pleasure in gambling.

Property is exchanged, but no goods are produced. What is more, this exchange affects only the players, and only to the degree that they accept, through a free decision remade at each game, the probability of such transfer. A characteristic of play, in fact, is that it creates no wealth or goods, thus differing from work or art. At the end of the game, all can and must start over again at the same point. Nothing has been harvested or manufactured, no masterpiece has been created, no capital has accrued. Play is an occasion of pure waste: waste of time, energy, ingenuity, skill, and often of money for the purchase of gambling equipment or eventually to pay for the establishment (Caillois 2001, 5-6).

We can here see that play for Caillois is an activity that gives pleasure, but also that he has a strong focus on rule-based games, an attribute that also Huizinga heralded as play, but that I, in the following and partly in line with the critique of Jesper Juul, think it is necessary to understand as gaming. The two forms of play that Caillois here refers to are Agôn (competition) and Alea (chance), and these forms are more inclined toward gaming than Mimicry (simulation) and llinx (Vertigo).

In this section I will focus on the former two and will speak of gaming when I refer to Caillois theories. I also want to claim that Juul goes too far in his criticism of Caillois for his categories to be overlapping. Caillois simple stated that the categorisation of a certain game depended on which category of competition, chance, simulation and vertigo was dominant in it (Caillois 2001, 12).

Caillois's insistence on gaming (agôn and alea) being able to include material interests at the same time as it is not a productive activity, neither in producing use values or use values carrying exchange values that can lead to accumulation of capital, is important for my understanding of gaming and its relation to instrumentality. Gaming is different from both work and labour. Gaming can be in the speculative circuit (but the result is not always M-M'), but takes no part in the capital circuit, M-C...P....'-M', at all. This emphasis on the non-productivity of gaming (as well as playing) is supported by Asplund, who contends that they are redundant and superfluous activities (Asplund 1987, 55) 
Caillois, like the protagonists of psychoanalysis and much in the same manner as Bataille, recognises the relation between gaming and biological energies. He sees gaming as a waste of energies, time and skill for the fun of it, without this excluding money as such. Money could even be a game thing or a toy. This view has some similarities to that of Nietzsche (see below).

The clear separation of gaming from art in the quotation of Caillois above is also an interesting novelty. Taken literally this would lead to concepts like gamework or gamelabour but it is quite clear that the purpose of Caillois investigation is to understand a purer form of gaming, which is pleasurable and fun. The claim in the quotation that it is harder to point to the cultural function of games of chance than of the games of competition elucidates in my eyes the intimate relation between gaming and capitalist logic. When you compete you compete in doing something in accordance to a fixed logic. But at the same time there is gaming in peer production projects as well. Gaming is at work in Wikipedia where the elected administrators are gameworking or workgaming (see below for explication). But maybe we can understand the activities of so-called vandals as being elements of a game of competition with these admins?

Finally, when it comes to the central notion of Caillois, about the goals' peculiar character within games, this view is supported by McKenzie Wark in his work Gamer theory. In what he calls gamespace, which pretends to adhere to Darwins 'the survival of the fittest', the reverse is happening, "the demise of the unfit": "Survival has no positive value. Gamesspace is pure nihilism. The best one can hope for is merely being undefeated" (Wark 2007, 214). Some games, like SimEarth fail because they are too realistic and do not survive. This is then not because they bump up against the reality principle of bare life, but quite the reverse. They fail the fantasy principle (Wark 2007, 214)

Nietzsche's version of the Dionysian play was as a will to power, to overcome yourself, conquering and being master of yourself, your surroundings and all that you meet, and as such this will have more of a distinct goal and a specific form of competitiveness to it even if it does not adhere to any rules but life's enhancement with its irrational frenzy (Nagel 1996, 3 ). This version of play has many resemblances to gaming, even though the breaking of all rules seems rather playful. MacKenzie Wark writes about digital games from the example of the failure of the too realistic SimEarth: "The inclusion of almost everything within the game leaves little by way of topos in which to conquer, expand, colonize, transform. [...] There is no frontier along which a storyline might traffic the unknown into the realm of the known" (Wark 2007, 216). Not that this ever restrained Nietzsche in his fantasies.

The preferred form of gaming of Nietzsche was connected dialectically to the logocentric Apollonian play that Aristotle's saw as a serious and intellectual business when used for good ends by philosophers. The latter profession, thanks to their casual lifestyle (as free citizens and slave owners), engaged as we know from Plato's dialogues, in verbal battles that I also think are more reminiscent of gaming rather than playing.

In reality the Apollonian side of play was less important to Nietzsche. The only thing given as real to him was the "world of desires and passions". Man could only rise or sink in relation to the reality of his drives (Nietzsche 1990, 66). The falseness of a judgement was not the same as an objection to it. Nietzsche affirmed the passions before reason, and the falsest judgement was life-advancing, life-preserving, species-preserving or species-breeding because, in short it is indispensable to us in that it does not need the false logic and falsification of the world by numbers (Nietzsche 1990, 35).

In contrast to this dismissal of scientific reason in the name of life, Nietzsche's affirmation of art was more playful, as mentioned above.

One central theme that Katrina Mitcheson claims is recurrent in the works of Nietzsche is his concept of life as a will to power. This means that the human wants to be the master of him/herself, his/her surroundings. She concludes that the will "is to power in that it strives to feel power in overcoming itself and what it encounters" (Mitcheson 2013). As I see it the dominant feature of this understanding of life is power and competitiveness, and the explora- 
tive dimension is subordinated. Therefore I contend that Nietzsche writes about gaming rather than playing.

The same dual view on play can be seen in three of the maxims in Beyond Good and Evil where Nietzsche mentions play. The first: "Mature manhood: that means to have rediscovered the seriousness one had as a child at play" (Nietzsche 1990, 94). Taking play seriously fulfils you as human. The second: "Around the hero everything becomes a tragedy, around the demi-god a satyr-play; and around God everything becomes - what? Perhaps a 'world'?" (Nietzsche 1990, 102). The world here seems a boring place without the free play of the drives. And finally a quotation from the third maxim: "The industrious races find leisure very hard to endure: it was a masterpiece of English instinct to make Sunday so extremely holy and boring that the English unconsciously long again for their week- and working days", (Nietzsche 1990,112). This witty defence for leisure against labour tells us that labour which is forced upon you, labour before which you are powerless, is contrary to life and gaming in the thought of Nietzsche, who sees gaming as a trans-historical category. Nietzsche's view fits quite well into capitalist society with its stress on competition, expansion and conquering, even if he had nothing but contempt for industrial society.

On a less philosophical and more concrete level of the actual gaming experience, Juul's argument parallels play and that of flow theory within psychology (Csíkszentmihályi 1996). Juul claims that, "the rules of a game provide the player with challenges that the player cannot trivially overcome". The rules are easy to use but present challenges that are not easy. It is this challenge that makes the game enjoyable, and playing a game means improving your skills in order to overcome these challenges. This learning experience takes different forms in different games, but Juul outlines two basic game structures: the structure of emergence (a number of simple rules combining to form interesting variations) and the structure of progression (separate challenges presented serially) (Juul 2005, 5).

Jesper Juul here shows a clear relation between learning and the playing of games. Learning is the unintended consequence of playing games on the subjective level, and this has repercussions on the sociological level in terms of what people learn in society. It also means that games, just like play, can be used as a pedagogical tool and indirectly be made productive. The consequence of an overly blunt manipulation for the sake of an external goal outside of the game affects it in the same way as play. The game becomes more serious from an ordinary life perspective (and thus less fun as the instrumental goal becomes more important), but at the same time games and gaming are already competitive in character like capitalism. Gaming, with its focus on contest, shares the same mentality as capitalism and has the potential of producing a competitive labour force for the capitalist production process. At the same time gaming could also influence capitalism by accentuating the voluntary and enjoyable character, but, on the other hand even Weber saw similarities between the Protestant ethic and gaming - that is between the pursuit of accumulation and a game.

The differences between gaming and playing are still of such importance that I agree with Anthony D. Pellegrini that we must distinguish between play and games. The reason for the common confusion between the two according to him is that they share certain "design features" like organising rules. Pellegrini shares the theories of Piaget that the rules governing games are typically a priori and codified, while rules governing play are flexible and negotiated in communication between the players during the activity. This theoretical understanding is supported by Asplund. The negotiation in pretend play often takes more time than the playing per se according to him. In games the violation of the rules results in some form of sanction rather than any form of renegotiation. He asserts that a large part of the research on games in different playgrounds has tended to support this dichotomization (Pellegrini 2009, 184-185; Asplund 1987, 64).

From this literary overview we can extract three more reasons why we should make the distinction between playing and gaming. First, in playing the activity is all that is important; you cannot objectify it; play is an activity that you lose yourself in. Gaming is different in that 
the goal does have some importance, even if this goal, as Caillois points out, is nonproductive, and erased and annulled before the next game takes place.

Second, playing and gaming are performed between the individual and the context surrounding her/him or between different individuals and their context, while gaming more often (but not always) involves spectators as a central feature of its context. The increased use of media representations of games and the commercialisation of sports, theatre acts and movies in the last hundred years have accentuated the presence and importance of spectators watching the game from the outside. Gaming today, due to this development, stresses the goal or end to a higher degree than before. The involvement of capital together with the spectators and other external actors have driven the character of gaming from, in Gadamer's words, being self-presentation within a community of gamers to being a representation for others (Gadamer 1975, 97). In this movement the similarity with play weakens. If play originates in the biological and psychological constitution of human beings as well as being constructed in social life, gaming is derived from play but socially constructed in a way that marks a rupture with play. According to Gadamer there exists a potential conflict between spectators and play where the threat is that play will lose its "real play character as a contest precisely by becoming a show" (Gadamer 1975, 98). He continues:

Their [the players] mode of participation in the game is no longer determined by the fact that they are completely absorbed in it, but by their playing their role in relation and regard to the whole of the play, in which not they, but the audience is to become absorbed. When a play activity becomes a play in the theatre a total switch takes place. It puts the spectator in the place of the player. He-and not the player-is the person for and in whom the play takes place. (Gadamer 1975, 99)

This difference between 'playing within a community of players' and 'playing for someone else' is stressed here, and religious rites, theatre plays, and sports or other forms of contest, which are played in front of others, are seen as either stressing the goal and result, or the quality of the performance and representation, in an accentuated and qualitatively different way than in play. Play has left the magical circle, and the activity is measured in accordance with social standards that are fixed within a larger societal body.

Play could contain contests (and performances) that have the same "to-and-fro" movement through which "the victor emerges" (Gadamer 1975, 95), but not if they have a focus on the result and on being measured and successfully evaluated by an audience rather than on the to-and-fro movement in itself. Gaming therefore has more in common with sports and arts, but in the distinction of the categories we have to use more criteria than one.

Third, play is explorative and often stresses the co-operation and negotiation between all involved players, while games instead are competitive and stress differences (which are often quantified) between the involved gamers in performances according to fixed rules.

Pellegrini claims that the two categories have different feelings associated with them and shows pictures of an individual who is out cross-country skiing. In one picture the face of the former expresses strain and utmost seriousness; the person is gaming. In another picture the skiers face shows a big smile, the person is out playing and are having fun rather than being concerned about his place in a race. The same individual, the same activity, which are the same in some aspects with totally different attitudes attached to them (Pellegrini 2009, 184185).

This last characteristic of gaming connects it to what Robert Stebbins has called serious leisure: "In an age in which the quest for spectator and sensual diversions dominates the world or leisure." Implying that gaming dominates playing, he contends rather naively that the phrase 'serious leisure' "has a rather curious ring" (what is curious about gaming becoming a commodity and converting leisure activities into unpaid work on your labour or gaming power?) since historically seriousness has been associated with work "whereas leisure has been seen as the happy, carefree refuge from our earnest pursuit of money and the social standing supposedly provided by a paying job". Today this view is losing ground according to 
Stebbins: "Current values and behaviour patterns in work and leisure hint at the presence of a serious orientation toward leisure among a significant proportion $/ . . . /$ of the population in today's postindustrial society." (Stebbins 1992, 1). According to Stebbins, play should, on the other hand, be categorised as casual leisure (Stebbins 2009, 622-623; Stebbins 2013, 340).

This view is confirmed by Pekka Himanen who connects it to the development of capitalism and asserts that the relation to time in the Protestant ethic, time is money, still permeates today's society in what he calls the fridayization of Sunday. There was no play in the work of the Protestant ethic, and today this logic and its time optimization have extended even to "life outside the workplace (if such life still exists)". It has begun to eliminate "the playfulness of free time of Sunday". One of his examples is that today only a beginner relaxes "without having taken a class in relaxation techniques", and he concludes that it is considered an embarrassment to be just a hobbyist "in one's hobbies". Leisure time thus assumes the "patterns of work time" (Himanen 2001, 20, 2-27 32). This comment stresses the competitiveness of both gaming and labouring. Leisure involves more of gaming on the social scene.

The different spirit between playing and gaming is important in two ways. First, players or gamers contribute to the play and game forms being applied in society. Second, the players and gamers construct themselves in their playing and gaming (with different psychological, cultural, social, economic and political effects).

\subsubsection{Conclusions}

Gaming as playing seems to have many implications for other scientific fields. These kinds of consequences, as with play, mainly occur behind the backs of the gamers. The dimensions in gaming are represented by the following treats: 1) Gaming is more goal-oriented than playing, meaning: in gaming goals are set up to structure the activity and make possible the comparison of the activities of the gamers, whereas in playing it is the activity in itself which is the goal. The goals are often quantitative and variable in character, depending on the actions of the gamer. Gaming is not necessarily confined to the gamers and can be performed in front of a public of spectators, which strengthens the importance of the result. But games are also gamed for the fun of the activity. 2) Games have an a priori structure of formal rules governing them. The breaking of rules results in sanctions of some kind. Goals are annulled before a new game is begun. 3) Gaming is voluntarily engaged in, but social pressure (gaming involves competition between gamers in society) is more pronounced than within playing. 4) Gaming involves, like playing, feelings of fun, tension and passion, but also feelings of effort, strain and risk. 5) Gaming is socially constructed in societies that relates to competition for social distinction, as the example of !Kung suggests. Gaming is not trans-historical in character. The increased focus of and on the spectators fundamentally transforms the creative or gaming's affinity with play, much in the same way as Moishe Postone claims that abstract labour transforms the mode of producing of concrete labour (Postone 1993, 6-68).

\subsection{Labouring}

According to Hannah Arendt labour was characterised by never being finished, and the labourer was an animal laborans (Arendt 1998, 126, 140). Karl Marx stated that labour under capitalism had a dual character as concrete and abstract labour. This dual labour produced use values with exchange value (Marx 1969, 3-42) This does not mean that the resulting commodity contains two separate kinds of labour; rather it contains one labour, but that labour can be "regarded from two radically different viewpoints". Johan Fornäs uses the words "contradictory" and "oppositional" to describe the two different perspectives on labour. Every commodity was built with labour characterised by a dialectical unity of these two contradictory aspects; every exchange value had to be a use-value at the same time (Fornäs 2013, 335). Hence, abstract labour is dependent on concrete labour in a way that concrete labour is not in relation to abstract labour. The concrete and qualitatively specific form of labour, with its specific result, is the reason for the exchange of equivalent use values by the social mediation of abstract labour in capitalism (see the section on labour) (Fornäs 2013, 3-35). Marx 
describes this as a coat and linen that have two different use values which can be exchanged and relate to each other as equivalent commodities only because they are the products of qualitatively different concrete work. A coat would not be exchanged for another coat (Marx 1867, 49). On the other hand, concrete labour is dominated, but not erased, by abstract labour under capitalism, that is, work is dominated by labour under capitalism.

The labour we speak of here is thus not the same as the specific and concrete work that is the common denominator of all human labours in all times. Labour is here understood as a historical and particular mode of producing characteristic of the mode of production called capitalism. In capitalism the social production and distribution is organised by the exchange of commodities on markets. This social mediation by markets and exchange is made possible through the common trait of all the commodities-human abstract labour:

\begin{abstract}
Whatever kind of labour is involved, it is spending of labour-power. At the end of the workday the worker is tired, whatever he has spent his force on in the workday. This expenditure of labour-power constitutes the common denominator for all commodities. (Fornäs 2013, 34)
\end{abstract}

This expenditure of a socially standardised and general labour power in all kinds of concrete works is the reason why it is called abstract labour. It is the exchange that expresses the similarity between two different kinds of labour, their shared quality of being values, through the measurement and comparison grounded in the amount of societally necessary abstract labour.

To be a value is no natural property that can be perceived with our common senses. It is a societal characteristic that only becomes 'visible in the exchange process. [...] Value is social, not a natural activity. [...] Yet, they are no pure mental ideas, since the commodity exchange itself shows that values exist. [...] This only happens in the historical conditions of private property, division of labour and exchange. (Fornäs 2013, 35)

Moishe Postone contends that if value is a historically specific form of wealth, then the labour producing it also must be historically determinate. The value form structures the sphere of production as well as that of distribution. And if it is so, it is not enough to simply to abolish class society; you would have to change the mode of producing as well (Postone 1993, 45, 67-68).

In capitalism this particular and historical form of labour is characterised by having an abstract form that can be measured by the amount of societally necessary labour time or the necessary labour force being expended on them. This societal character has, as we shall see, two different meanings. First it points to the historical level of the forces of production in society, and second, it means that it is a production aimed for others-the society in its totality. This abstract and quantifiable value is only expressed in the exchange of commodities and in the prices on the market.

The notion of societally necessary labour time is crucial, and it is often misunderstood due to fact that many scholars confine their analysis of Marx's theory of value to the first volume of capital. If we take in volume two and three, moving up from the deep abstractions of the first volume (where the supply and demand did not affect the value), then supply and demand affects also the values and not only the prices:

For, what is 'socially necessary labour-time, and how is the total labour-time in the whole society allocated onto the production of various kinds of goods? That the labour-time is social means that it is geared towards satisfying other people's needs, which on the surface are expressed through demand. Imagine that far too many TV sets are made, compared to what people have need for. In such a case, a too big part of the total social labour-time has been invested, so that the value of each TV set is much lower than the actual time spent, since it contains superfluous labour-time [...] that the degree to which the labour-time spent on making TV sets is in reality socially necessary is co-determined by 
the social need for TV sets. This need is not visible in the production process, but first on the market. (Fornäs 2013, 37)

The socially mediating market (in capitalism) then affects the production of values according to Marx. It is not simply the amount of socially necessary labour-time according to a certain historical society's average level of the forces of production, the average skill and intensity of production and so on, that determines the value. What is "socially necessary" does not simply change in relation to the development of the forces of production, but also in relation to the development of the needs within a society (as expressed in the demand).

According to Moishe Postone's reading of Marx, as we have seen above, Marx used the notion of 'societally necessary' in two different ways: the trans-historical and the historical form of necessity. The relation between the two is dynamic in the sense that Marx identifies a tendency within capitalism to create the potential for a realm of freedom to grow and prosper at the expense of the realm of necessity, even if it is not possible to get rid of all necessary work. In this section of the article I aim to focus on what Moishe Postone speaks of as the 'mode of producing' (to distinguish it from mode of production) (Postone 1993, 6-68) in an effort to address the effect of capitalism on the immediate labour process in contemporary society.

But before that, some words have to be said about what Ivan Illich has called shadow work. This is a form of unpaid work, not badly paid and not unemployment, that is typical for industrial capitalism. Illich mentions that in most societies "men and women together have maintained and regenerated the subsistence of their households by unpaid activities", but he stresses that this is not what he means by shadow work. The unpaid work of industrial society is an "entirely different form of unpaid work", which is demanded as a "necessary complement to the production of goods and services", which "comprises most housework women do in their homes and apartments, the activities connected with shopping, most of the homework of students cramming for exams, the toil expended commuting to and from job" and so on (Illich 1980, 8). Illich contends that without this "apartheid based on sex or pigmentation, on certification or race, or party membership, a society built on the assumption of scarcity cannot exist."(Illich 1980, 7)

Back to the main track: Postone maintains that the traditional Marxist critique, from the standpoint of labour, that class domination is the fundamental form of social domination, is not enough for a real critique that has to include a social critique of labour per se in capitalism. This latter critique characterises the most fundamental form of domination as "an abstract, impersonal, structural form of domination underlying the historical dynamic of capitalism". In this mode of producing, people are dominated by their labour (Postone 1993, 53, 68). The precondition for the dignity of work is then the abolition of capital and abstract labour, instead of the traditional Marxist view that work accorded dignity to labour, which was fragmented and alienated under capitalism, as soon as class society was abolished. From the traditional position follows: "the perpetuation of such labour and the form of growth intrinsically related to it", whereas Marx saw the "historical overcoming of the 'mere worker' as a precondition for the realisation of the full human being" (Postone 1993, 71).

Production under capitalism of exchange values meant for valorisation and accumulation focuses on processes rather than on the product outcome. The capitalist mode of production results in a two-folded form of practise, depending on which class you belong to, which is mediated through markets. Roughly: for the majority it means forced, alienated and exploited labouring (surplus labour) for which they paradoxically often compete with other labourers to get on the labour market: this being their only way to make a living for themselves; and for the few, that is capital, the practice of non-labouring and appropriation, including managing, of the result from the valorisation and accumulation processes. The exploitation of labourers results from the systematic sale of labour power on the market by the workers and the systematic appropriation of the result of the actually performed labour in the immediate labour process; this exploitation results in the internal contradictions, struggles and recurrent crises of the capitalist system (Postone 1993; Marazzi 2011, 8-81; Marazzi 2008, 11-119). 
In a classic critique of traditional or positivist theory Max Horkheimer claimed that the conceptual and classificatory systems into which living and dead things, psychological, social and physical phenomena, were sorted in this theory, together with the judgements on them, formed an "apparatus of thought as it has proved and refined itself in connection with the real work process" (Horkheimer 1972, 219). This instrumental reason of traditional theory not only contributed to the prevailing habits of thought and carrying on the business of an out-dated model; it also changed capitalism. The liberalist period of capitalism was connected with the dominance of legal ownership of the means of production, but in the period of monopoly capital (with the start in second half of $19^{\text {th }}$ century), which was caused by technological development that resulted in a concentration and centralisation of capital, the legal owners were excluded from management (Horkheimer 1972, 219, 235). Technology rather than accumulation seemed to be the stronger socio-economic force to Horkheimer, and the powerful managers became the ones dominating whole sectors of industry. "The influence of management, which may initially be exercised only over lower judicial and administrative authorities, finally extends to the higher ones and ultimately the State and its power apparatus" (Horkheimer 1972, 235). The instrumental logic of capitalism thus, according to Horkheimer, extended itself to society and social life, where the individual did not have any ideas of his/her own and the content of mass belief was the immediate product of the "ruling economic and political bureaucracies". These in turn were guided by "atomistic and therefore untrue interests" (Horkheimer 1972, 235. 237). Here we can see how abstract labour and people's thinking changes within a dynamic capitalism, even without agreeing about the primacy of science and technology in relation to capital's own logic of accumulation. Horkheimer contends that this process of an expanding instrumental reason increasingly alienates people from their human condition and social relations.

This ideological pressure and pro-active management of our thought increases, but in a different way within what the autonomist Marxist calls the social factory of the general intellect, where the practice of social life is integrated to the labour processes even when it is not paid for, in the new shadow work of prosumption, prosuming or playbour. Christian Fuchs and Tiziana Terranova have argued that all of the time and effort devoted to generating "digital content" on the Internet should be considered a form of immaterial labour, and they emphasize the exploitive character of this unwaged labour. Brian Brown here makes a contribution when he analyses the biopolitical dimension of this shadow work, thus aiming at linking Fuchs' and Terranova's criticism of unpaid labour to the biopolitical critique of waged immaterial labour of Lazzarato, Hardt and Negri (Brown 2012, iii, 13-134, 18-186). His study of "Factory Flickr" is organised around six themes. Of interest to me are the first and second of the site's "ludic roots"- "the impact of these roots on whether or not all of the work done by members is considered as such"-and the public-by-default nature of all photographs and profiles (Brown 2012). Brown offers some arguments, such as the risk of social isolation, in favour of seeing this seemingly voluntary activity as a new kind of, in practice, forced labour.

But can we still speak of instrumental reason if all of our social life has become productive? Games have an instrumental logic, and our leisure time is being perceived more seriously, but what about play? This subject will be elaborated when the relation between playing and labouring is treated below.

\subsubsection{Conclusions}

The dimensions that have been found in the other categories can also be found within the category of labour. 1) The main purpose of labour is the accumulation of capital by an alien power in relation to the producer-that is the capitalist. The process of valorisation, not the use value, is the purpose that controls all involved parties; for the wage labourers it is a question of survival. 2) Labour is the production of exchange values for the market by the bought labour power (from the same market) of wage labourers. Exploitation makes him/her labour more than is needed for his/her own reproduction (surplus labour is systemic). 3) Labour is historically forced upon the labourer and involves the exploitation of him/her, which 
makes possible the non-work of the few. 4) Labour's associated feelings are competitiveness and alienation, together with feelings of being cheated and bossed around (dominated and used as an instrument for someone else's interest). 5) Labour is a historical form that involves trans-historical work, but that is qualitatively different than all other historical versions which have existed, also compared to other class societies dominated by un-economic factors but equally grounded and determined by economic concerns as Althusser would have it (Larrain 1991, 46), due to its abstract character and growth logic. Labour is dependent on concrete and specific work but also dominates it.

\subsection{The Typology}

The conclusions from these discussions of the four categories can be summarised in the form of a typology of the following character:

\section{Playing}

(1) Purpose: activity in itself is the goal

(2) Form of practice: Mobile, not-reifiable, "life-like", presence in the moment, free relation to rules, non-competitive, isolated within the self of the player or within a playing community

(3) Degree of voluntariness: Voluntarily engaged in; performed when you are experiencing well being

(4) Feelings: Fun, enjoyable, pleasurable, ease, tension, passion

(5) Transhistorical/Historical: Transhistorical: biological and psychologicaldrives; but also originating from communication, social and cultural interaction

\section{Gaming}

(1) Purpose: Goal-directed but both activity and result are important, the result/achievement is annulled before a new game starts, not productive in itself or in its outcome

(2) Form of practice: Rule-based, character of contest, competitive, can involve audiences

(3) Degree of voluntariness: Voluntarily, but social pressure or threat of social isolation can potentially be a reason for activity

(4) Feelings: Fun, "serious leisure", self-fulfilment, strain, risk

(5) Transhistorical/Historical: Historical. Socially constructed in societies focused on competition and social distinction

\section{Working}

(1) Purpose: Goal-oriented, production of useful values (use values) others; productive in its outcome

(2) Form of practice: Concrete labour, living labour, noncompetitive

(3) Degree of voluntariness: Necessary labour

(4) Feelings: Seriousness, self-fulfilment in the productive activity and in an objectified sense in the produced use values, "togetherness" and social belonging

(5) Transhistorical/Historical: Transhistorical; human process of metabolism with nature, for the satisfaction of human needs

\section{Labouring}

(1) Purpose: Accumulation of capital by production of exchange values by wage labourers; the process of valorisation (controlled by an alien power in relation to the production) and not the use value is the goal

(2) Form of practice: Twofold, depending on class division and mediated through markets; exploitation competition, accumulation and run-away growth under abstract standards, crises-ridden

(3) Degree of voluntariness: Forced labour due to class society

(4) Feelings: Alienated seriousness, instrumental reason, feelings of being exploited on one part, greed on the other, feelings of superiority or subordination

(5) Transhistorical/Historical: Historical. Socially constructed due to historic reasons

Figure 2: The typology (Arwid Lund 2014)

\section{Field Models for Mapping Positions and Opinions Relating to the Typology}

The activities within peer production as well as other activities on the Internet, which take place within an overall system dominated by a capitalism that is turning cognitive (its most dynamic sectors), can be visualised and mapped in the following model. The model merges the earlier model of possible relations between the categories with the developed typology above, and adds two structuring principles. The first structuring principle is the relation between the qualitative character of playing and working and the quantitative character of gaming and labouring. The second structuring principle is the relation between a focus on the activity, characteristic of playing and gaming, and a focus on the result of the activity, characteristic of working and labouring: 


\section{Activity in focus}

\section{Playing}

(1) Purpose: activity in itself is the goal

(2) Form of practice: Mobile, not-reifiable, "life-like", presence in the moment, free relation to rules, non-competitive, isolated within the self of the player or within a playing community

(3) Degree of voluntariness: Voluntarily engaged in; performed when you are experiencing well being

(4) Feelings: Fun, enjoyable, pleasurable, ease, tension, passion

(5) Transhistorical/Historical: Transhistorical: biological and psychologicaldrives; but also originating from communication, social and cultural interaction

Qualitative character

\section{Working}

(1) Purpose: Goal-oriented, production of useful values (use values) others; productive in its outcome

(2) Form of practice: Concrete labour, living labour, noncompetitive

(3) Degree of voluntariness: Necessary labour

(4) Feelings: Seriousness, self-fulfilment in the productiveactivity and in an objectified sense in the produced use values, "togetherness" and social belonging

(5) Transhistorical/Historical: Transhistorical; human process of metabolism with nature, for the satisfaction of human needs

\section{Gaming}

(1) Purpose: Goal-directed but both activity and result are important, the result/achievement is annulled before a new game starts, notproductive in itself or in its outcome

(2) Form of practice: Rule-based, character of contest, competitive, can involve audiences

(3) Degree of voluntariness: Voluntarily, but social pressure or threat of social isolation can potentially be a reason for activity

(4) Feelings: Fun, "serious leisure", self-fulfilment, strain, risk

(5) Transhistorical/Historical: Historical. Socially constructed in societies focused on competition and social distinction

\section{Labouring}

Quantitative character

(1) Purpose: Accumulation of capital by production of exchange values by wage labourers; the process of valorisation (controlled by an alien power in relation to the production) and not the use value is the goal

(2) Form of practice: Twofold, depending on class division and mediated through markets; exploitation, competition, accumulation and runaway growth under abstract standards, crises-ridden

(3) Degree of voluntariness: Forced labour due to class society

(4) Feelings: Alienated seriousness, instrumental reason, feelings of being exploited on one part, greed on the other, feelings of superiority or subordination

(5) Transhistorical/Historical: Historical. Socially constructed due to historic reasons

\section{Result in focus}

Figure 3: The field model (Arwid Lund 2014)

If we understand the relations between playing, working, gaming and labouring in this way, grounded in the literature on the subject, the next step is to use this model for visualising and mapping the positions (regarding opinions on performed activities) that results from the analysis of empirical material:

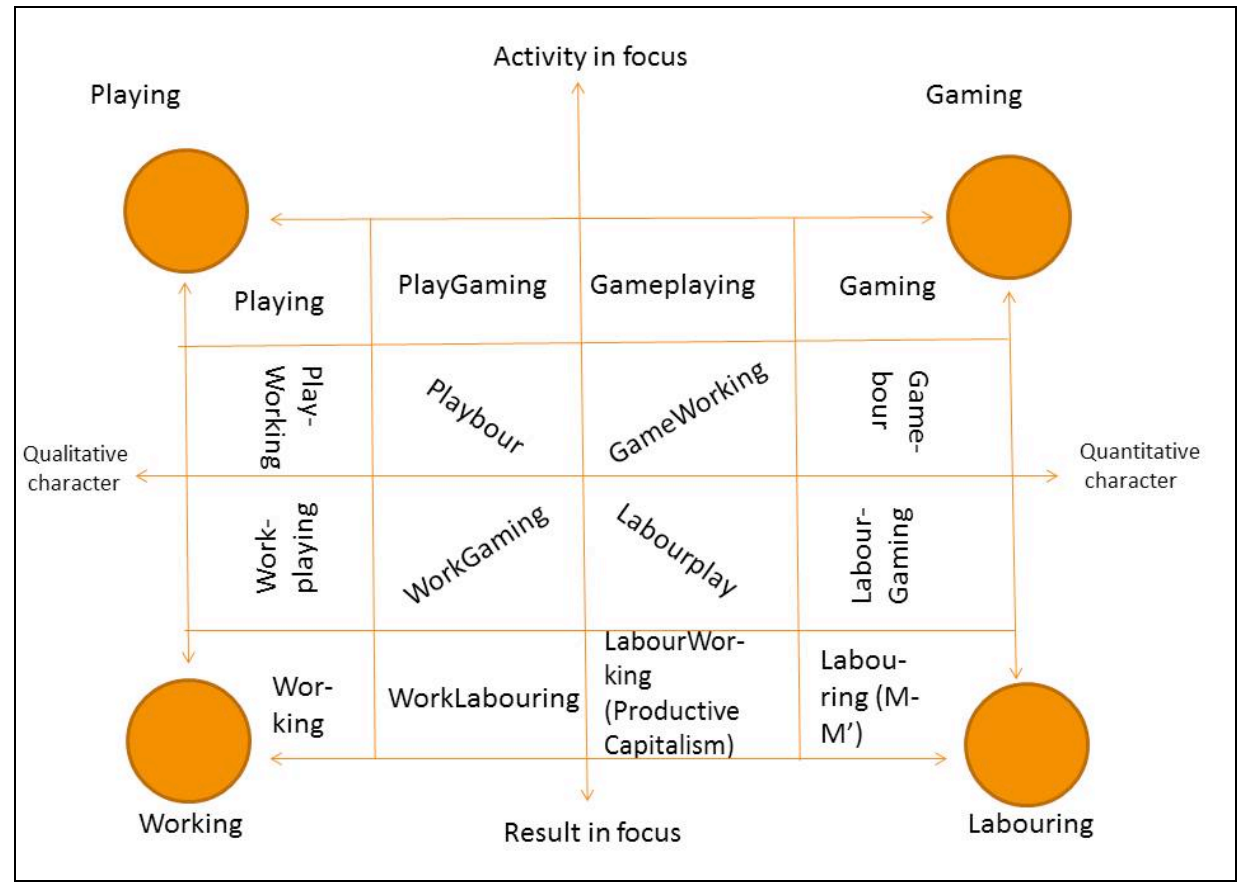

Figure 4: Model for mapping identified positions in empirical material (Arwid Lund 2014) 
In the model above it is only possible to visualise static positions. It is of great interest to understand the relations between these categories in the era of what Marx called the general intellect, but instead of developing a model that can visualise their character I will (for now) limit myself to a study of some of the relevant literature on these relations under capitalism, with the aim of providing some examples of different opinions and statements that can be placed in the field model above, but also of identifying synergies and conflicts that can be departures for future studies and the elaboration of models on the directions, forces and characteristics of the relations.

\section{The Relation between the Categories}

We have six different relations to scrutinize: playing and gaming, playing and working, gaming and working, gaming and labouring, working and labouring, and, finally, playing and labouring. The study has a theoretical focus and does not contextualise the theoretical positions described and analysed as much as would be appropriate. The contextualising that does exist is mainly focused on the contemporary situation.

The ideological concept of playbour focuses on some privileged parts of contemporary labouring life, in so-called creative branches-especially those included in the notion of Web 2.0_-of digital labour (or immaterial labour as some call it). In the new economy of the California ideology (Barbrook and Cameron 1996; Barbrook 2005) flexible exploitation and commodification is combined with a casual life style and creative "gaming" without standardized rules, without there being any friction and conflicts. Everybody is happy in the new economy, capitalists and workers alike.

The notion of playbour is not grounded in a discussion of the concepts of playing and gaming, and it conflates the notions of work and labour. We have here a complex camera obscura image of reality, camera obscura being the word Marx used in the German Ideology to speak of ideology (Marx and Engels [1845] 1998, 42). The term playbour in the discourse of the Californian ideology disguises the reality of its position by using the word play but in reality stresses gaming and competition, and conceals, by way of putting play as the first part of the concept of playbour, that Web 2.0 companies, like all capitalist firms, stress valorisation, labour, rather than even gaming. Hence, it is a gaming that is subordinated to the instrumental reason of capital. Thus a twofold-inverted picture of reality emerges through this criticism of the ideology of the concept of playbour. The activity going on is really about labourgaming, or (maybe sometimes) about, gamebouring rather than playbouring. The two models below are meant to function as examples for how I perceive of the hybrid concepts in this part of the article focusing on the directions and forces that join each other in synergies or clashes. The following two examples of models do not functioning well with the field model that is static in its construction. ${ }^{4}$

\footnotetext{
${ }^{4}$ It is problematic to visualise, for example, an argument about labouring invading gaming almost totally, in the field model. The best way to visualize this argument would be to show how gaming's square turn into a part of labouring's square, but this is not possible at the moment. The analysis is, hence, tentative in character, and explicit in its invitation to critique and further development.
} 


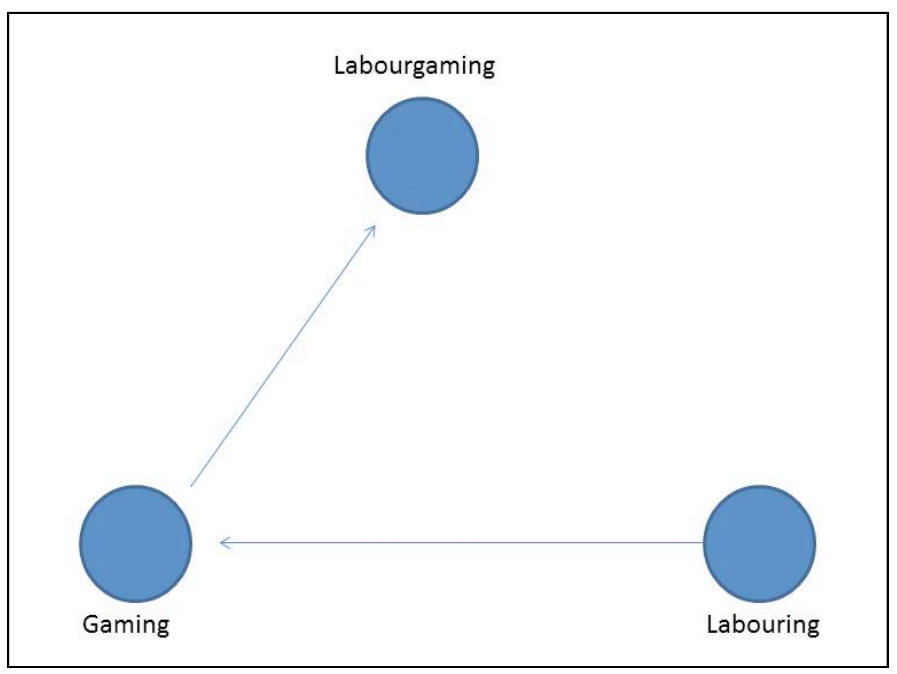

Figure 5: Labourgaming (Arwid Lund 2014)

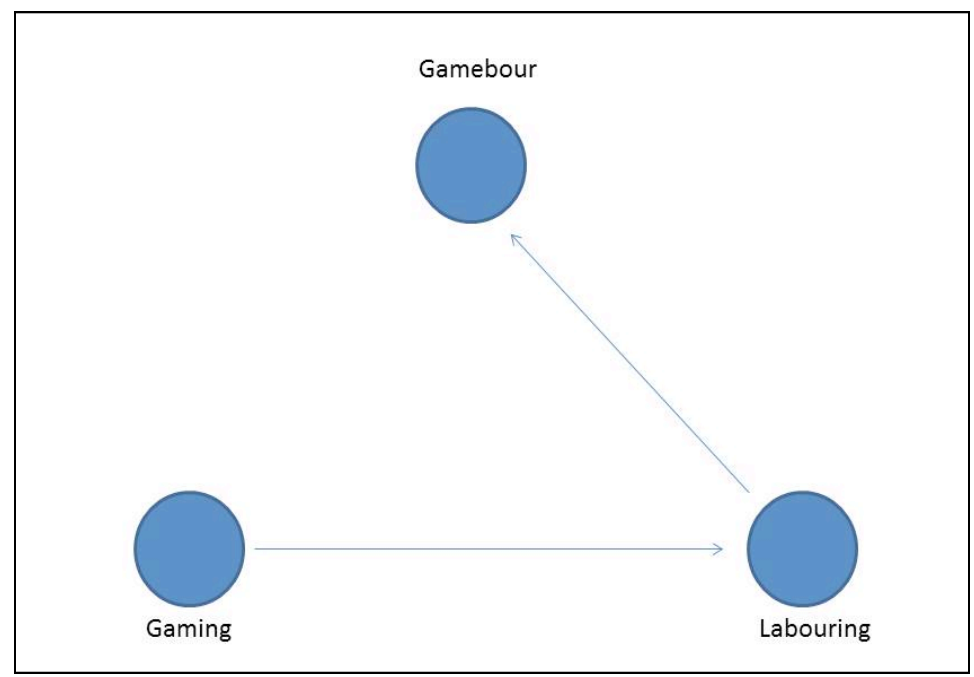

Figure 6: Gamebour (Arwid Lund 2014)

Taking into account commons-based peer production as an embryo of a new mode of production in the centre of capitalism (Rigi 2013, passim), we can use the hybrid concepts of playwork and workplay to describe the core of this mode of production. But now I am getting ahead of myself.

\subsection{Playing and Gaming}

The play of Charles Fourier often had an erotic character and took on the character of gaming. In the Phalanstery, his ideal community, the real contest for prestige and renown was not centred on work or labour but rather on sexual politics, which was a "game of sensual largesse" and the currency of the game was attraction: "but the point of the game is not to hoard and covet, but to dispense and distribute the favours of the favoured" (Wark 2013, 73). Fourier did not see anything un-playful in this competitive gaming and according to himself he would be placed in the middle of playing and gaming on the horizontal axis, but the gaming feature is too accentuated for that. Gameplaying seems more appropriate.

The Situationist International (SI), active about a hundred years later, was instead very much against the game element in play. The play forms in society were according to SI linked to the development of the very forces and modes of production that they tried to chal- 
lenge with play. Play had been dominated by the realm of necessity and labour under capitalism. The political mission of SI was to change the power relations between the two, and the most important question involved a project to make the element of competition disappear from the concept of play and the play actions. According to the organization the question of winning and losing had previously been almost inseparable from ludic activities as a result of "all other manifestations of tensions between individuals for the appropriation of goods" in capitalism. Play was perceived as a "wretched product of a wretched society" and as such was it exploited by all conservative forces, to mask the monotony of the life they themselves imposed (Situationist International 1958a). This statement could be placed in the lower parts of the square for gaming.

According to SI playing was something different from gaming. The former was a propensity of humans and the latter an effect of a class society. The political mission was to infuse everyday life in class society with play instead of play being infused with gaming. The relation between the playing and gaming was an antagonistic one: "[t]he element of competition must disappear in favor of a more authentically collective concept of play: the common creation of selected ludic ambiances" (Situationist International 1958a).

The American anarchist Robert "Bob" Black's anthology of essays from 1985, containing the article "Abolition of Work", is characterised as having a post-Situationist and individual Anarchist perspective by English Wikipedia (Wikipedia contributors 2013b; Wikipedia contributors 2013a). Playing means doing things and being active, to Black: "To be ludic is not to be ludicrous. Play doesn't have to be frivolous, although frivolity isn't triviality; very often we ought to take frivolity seriously. I'd like life to be a game-but a game with high stakes. I want to play for keeps" (Black 1991). He does not distinguish between play and gaming as it seems, and equates both of them with life itself. Play could be competitive, and with high stakes. This position, surprisingly coming from a Situationist, can be placed in the middle between playing and gaming, in its stress on both frivolity and gaming, but at the same time, as we will see more clearly below, the categories of working and labouring have disappeared entirely in Black's ideal society.

The same thing goes for Nietzsche's view of play and wage labour in the third maxim above. He perceived of a conflict between relaxing play and labouring, at the same time as he was in favour of gaming and conquering.

The individualistic approach of Black and Nietzsche contrasts sharply with the playing of the !Kung Bushmen of Southwest Africa. They do not play competitive team games, with the exception of tug-of-war, which re-enacted the founding myth of !Kung, and the idea of winners and losers "is not emphasized as this is a culture that stresses the importance of group and not individual performance". The children's play could otherwise be both free and structured, and conflict, satire and mimicry of animals, other !Kung and other societies formed part of many play activities (Schwartzman 1978, 129-130). This view is firmly placed within the square of play.

Helen B. Schwartzman identifies an important difference between playing and gaming which has the potential to create conflicts between the two forms of activities:

An understanding of game rules provides one with an understanding of the event, and too much spontaneity or individuality (ie, too much play) can spoil the game for all participant. This may mean that, in order fully to understand, we will have to separate it clearly from games. Games rule out the ambiguity, spontaneity, and flexibility characteristic of play, and it may be that it is only our language that is playing tricks on us when we are led to say that we 'play games.' This may actually be a contradiction in terms. (Schwartzman 1978, 327)

\subsection{Playing and Working}

In Grundrisse and the section called the Fragment on Machines Karl Marx stressed that the development of productive power develops both the capabilities of production and the means of consumption. Saved labour time is not the effect of abstinence from consumption, but the 
result of the development of the productive forces. The saving of labour time equals an increase in free time that according to Marx is free time for the full development of the individual which further develops the forces of production (Marx 1973, 71-12). This was a picture of how it could be when, in the era of general intellect, capitalism became so obsolete that the regime of value producing abstract labour potentially could be challenged and defeated. But the increased productivity within capitalism did not produce free time for the labourer. Instead relative surplus value was produced for a capital that struggled to maintain the wage form. Marx thus looked at the relation between playing and working through an historical lens.

In the realm of freedom under communism free time was possible, but it was a free time, which was productive in developing the forces of production. The two phenomena free time and work could no longer be separated as in a bourgeois economy were the labour time is held as the abstract antithesis to free time. Instead free time and work time were dialectically connected then (Marx 1973, 711-12).

These statements are complex. Labour under capitalism, though, just leads to more of the same, placing it in the square of labour, but the tricky question that interests us here is where to place the statement of the shrinking realm of necessity and growing realm of freedom in communism? In terms of what is favoured as positive, the realm of freedom ends up in between play and work as attractive work, while proportions between this and the necessary work, with corresponding positions, depends on the level of historical development.

\subsubsection{Liberating Work Is Serious and Not Mere Fun}

Free time is productive and work has liberating qualities under communism. According to Marx, Adam Smith maintained that labour never changed its value. An hour of labour was always an hour that the worker had to give up the "identical portion of his tranquillity, his freedom, and his happiness" to realize (Marx 1973, 610-11). Marx comments that labour seems like a curse to Smith ${ }^{5}$ in contrast to the tranquillity, freedom, and happiness of free time. For Marx free time could be time for recuperation and reproduction of the labour force under capitalism, but also, as we have seen, productive under communism. In either case it could not be isolated from work. Smith's view of work in turn was flawed in defining it in accordance with its historical form under capitalism:

It seems quite far from Smith's mind that the individual, 'in his normal state of health, strength, activity, skill, facility', also needs a normal portion of work, and of the suspension of tranquillity. Certainly, labour obtains its measure from the outside, through the aim to be attained and the obstacles to be overcome in attaining it. But Smith has no inkling whatever that this overcoming of obstacles is in itself a liberating activity -and that, further, the external aims [...] become posited as aims which the individual himself positshence as self-realization, objectification of the subject, hence real freedom, whose action is, precisely, labour. (Marx 1973, 611)

This view of work as a challenge, obstacles to be overcome, has a structural similarity to the practice of play, even if, in the latter case, it is about inventing imaginary obstacles for the fun of it. The feeling of self-fulfilment when you have overcome an obstacle seems to correlate to play, but has a different form of seriousness added to it if we are to believe Marx. The feeling of freedom is combined with the production of something useful.

Marx agrees that labour in its historical forms as slave, serf or wage labour always appears as repulsive and as externally forced labour, and that not-labour therefore appears as freedom and happiness in these historical realities (Marx 1973, 611). Hence, our way of looking at free time suffers from ideological distortions. Free time is imagined through the camera obscura, upside down (Marx and Engels [1845 ]1998, 42). Maybe it is possible to draw some conclusions of Marx's—not so positive then—view of play from this.

\footnotetext{
${ }^{5}$ The distinction between work and labour, as Fuchs and Sevignani have argued, is of crucial importance to understand this passage. Marx uses the German word Arbeit that can signify both work and labour and does not qualify which he is using at each moment. See the introduction to the typology.
} 
One reason for "not-labour" being idealised under capitalism is that labour has not yet "created the subjective and objective conditions for itself [...] in which labour becomes attractive work, the individual's self-realization (Marx 1973, 611). It is in this context that Marx concludes that Charles Fourier was wrong when he believed that labour could be play (Marx 1973), a statement that also hit the position of SI and implies that play is unproductive. It is in the same spirit that he continues his argumentation after the quotation above: self-realization through attractive work was by no means to be understood as "mere fun, mere amusement" (Marx 1973, 61-12). Play is here assigned a rather minor role by Marx. Play appears as something unimportant in the margins of societal life, with its enjoyable and amusing character. "Really free working", like composing, is instead, at the same time, "precisely the most damned seriousness" and "the most intense exertion" (Marx 1973, 611-12), but the condition for it is that it is social, scientific and at the same time, general in its character. It cannot just be "human exertion" but has to be "exertion as subject" (Marx 1973, 611-12).

Work could, thus, be a really free and liberating activity, giving self-fulfilment in the overcoming of external obstacles. Play, on the other hand was unproductive amusement in itself. Marx did not give importance to the similarities between play and work in any deeper sense, like seeing play as an imaginary variation of work or as a serious and constructive variant of play, but at least favoured play as a subordinated aspect of work when this became attractive.

Marx put the word play in the mouth of the utopian Charles Fourier as a proof of his naivety, although, as we shall see, this was not entirely true. Even so, Marx was not totally negative in his attitude to Fourier. He contended that Fourier's greatest contribution was to express the suspension of the mode of production itself as the ultimate political goal-implying that Marx was not in favour of necessary labour for some moral or political reasons.

We get a closer picture of how play relates to the realm of freedom in a famous passage in volume three of Capital. Work in the sphere of material production is here described as it can never be unconditionally free, it will always exist on the basis of a realm of necessity, but there can be more or less of such necessary work, and it can be executed in a more dignified and joyous way, and thus be more attractive. Freedom within this sphere can only be forwarded by a truly social mode of production of associated producers that in common cooperate to control the interchange with nature in a rational way, which accomplishes its task with the least effort and in the most dignified way for the humans-a statement that places itself in the upper area of the square of working. Beyond this realm of necessity begins the development of human power "which is its own end, the true realm of freedom". The central aim for the freely associated producers should therefore be the shortening of the working day in order to make the realm of freedom, where the human subject could act as a subject and realize and express her/himself, increasingly larger (Marx 1909, 954-55).

Marx, then, even if he in principle was in favour of Fouriers proposition of abolishing the mode of production in itself, did not think that it would be entirely possible. Work in the realm of freedom, on top of the realm of necessity, was attractive, but not pure play. The productive end was still dominating. We do not get closer to Marx's view on play than this. We cannot know if he wanted humans to spend all their time, even if the necessary material production had been suspended by technical development, in his realm of freedom with its "damned seriousness" and "really free work" of social and scientific character, or if there was also room for some play, fun and amusement not focusing on the result of the activity.

The activities in the realm of freedom can be labelled workplay (work is dominating and play is dominated), but not playwork. In his critique of the Gotha programme Marx wrote of the first phase of communism when this society emerges from capitalist society and is "stamped with the birth-marks of the old society" (Marx and Engels 1991, 305-306) In this phase your amount of work according to Marx will render you an equal share in the total amount of social work (that you can exchange for individual means of consumption). The exchange of equivalents in capitalism only exists on the average, here it also exists in the individual case - theory and practice are no longer "at loggerheads" (Marx and Engels 1991, 
306). The problem is that this equal right in theory is an "unequal right for unequal labour" due to the fact that some workers are physically or mentally superior to others (Marx and Engels 1991, 306). This system is abolished in the higher phase of communism:

\begin{abstract}
In a higher phase of communist society, after the enslaving subordination of the individual to the division of labour, and thereby also the antithesis between mental and physical labour, has vanished; after labour has become not only a means of life but life's prime want; after the productive forces have also increased with the all-round development of the individual, and all the springs of common wealth flow more abundantly-only then can the narrow horizon of bourgeois right be crossed in its entirety and society inscribe on its banners: From each according to his abilities, to each according to his needs! (Marx and Engels 1991, 306)
\end{abstract}

Work, thus becomes a "prime want" in the higher phase of communism. Here we have a situation of certain abundance, but what is stressed is that everybody should work in accordance with his/her capability. Of course the realm of necessity is shrinking but nowhere is there anything said about amusement. Instead the prime want was to engage in "really free work".

Let us, in a last effort, visit the Fragment of Machines in Grundrisse again, where Marx follows the logic of capital into the future and the general intellect as the full development of capitalism. The development was based on the total, real subsumption of labour under capital (dead labour) where the worker's activity was reduced to an abstraction of activity and was on all sides determined and regulated by the movements of the machines. The science that was objectified in the machines did not exist in the consciousness of the worker, who was merely supervising the activity as "conscious linkages" of the automated machine system (Marx 1973, 692-93). As gloomy as this appears, the general intellect was also a moment of liberating possibilities. The real subsumption of labour under capital and dead labour, which is manifested in the effectiveness, the intensity and the quantitative extent to which capital is developed as fixed capital, also signifies that science plays a central role in giving production a scientific character that reduces direct labour to "a mere moment" (Marx 1973, 699). This development of fixed capital "indicates to what degree general social knowledge has become a direct force of production, and to what degree, hence the conditions of the process of social life itself have come under the control of the general intellect and been transformed in accordance with it" (Marx 1973, 706).

We now have a situation according to Marx where direct labour is reduced and subordinated (but still an indispensable moment, without it no surplus labour, surplus value and profit-hence no capitalism) to general scientific labour and the general productive force "arising from social combination" (Marx 1973, 706, 709).

This opens up a possibility in history of re-configuring and re-ordering the relations between the realm of necessity and realm of freedom, but also here the argument simply leads to the conclusion that necessary work would be minimized (Marx 1973, 705) and nothing is said of play. Throughout Marx's life his ideal was the well-rounded (wo)man who is not tied to one profession. In communism nobody has an exclusive sphere of activity, and people can therefore take part in any pursuit (s)he wishes. Society regulates general production and makes it possible to "to hunt in the morning, fish in the afternoon, rear cattle in the evening, criticise after dinner [...] without ever becoming hunter, fisherman, shepherd or critic" (Marx and Engels [1845] 1998, 53). The focus is still on "really free work". Could it be that Marx meant that "mere fun, mere amusement" was just an offspring of the mode of producing in class societies, with its dichotomy of free time and labour, and, thus, would necessarily disappear in the classless society where work became attractive work?

This examination of Marx's view of the relation between play and work has revealed that in line with his historical materialist perspective he historicised and contextualised his views on work, free time and attractive work, but that play and the play drive itself never was of any theoretical interest to him. Let us now instead see if we can find some discussions on play and its relation to work in works of Charles Fourier and William Morris. 


\subsubsection{Charles Fourier}

What did Charles Fourier actually say? The question is tricky because Fourier performed a thought experiment with his own unique concepts. In short he argued that labour "forms the delight" of animals such as beavers, bees, wasps and ants, which had the liberty to prefer inertia instead, which led him to conclude that god surely had done the same for the humans. Labour under capitalism was repulsive and odious and what he called "associative labour" had to fulfil "seven conditions" to be attractive. The division of labour would be adapted to the needs and skills of people, not abolished, and the work assignments would rotate before they became "tedious". These short sessions would be "sustained by cabalistic impulses and by friendly union with selected associates", and it could not fail in bringing and finding "cheerfulness everywhere" (Fourier n.d.). Necessary but tedious work was here compensated for by play rather than merged with play.

However, beside the fact that pure play existed for Fourier as an important social phenomenon, play often merged with work in the writings of Fourier rather than substituting for work. Fourier, regardless of the fantastic character of his theories, then seems to have more or less the same opinions on the relation between play and necessary labour as Marx. The differences were located mainly in the attitudes and preferences of the two. Work of the phalanstery, the ideal community of Fourier, was a delight but also tedious and had to rotate and be interrupted by play in the form cabals and orgies. Play and work was distinct categories even for Fourier. Work could be passionate, attractive and social, but not play, on the other hand this work and workplay (when merged with play) sometimes had to be interrupted by pure play. And in some writings the dynamic in the relation between play and work was reversed into some kind of playwork and finally qualitatively changed into other hybrid phenomena.

The nature of the passions was of the utmost importance to Fourier. The passions had been and "will remain invariable among all nations of men". Fourier concluded that these passions and impulses could entice us to evil if "we yield to them individually", but he came up with the following solution:

[A]s soon as the number of associates [...] has reached 1600, the natural impulses, termed attractions, tend to form series of contrasting groups, in which everything incites to industry, become attractive, and to virtue, become lucrative. (Fourier, On the role of the passion.)

The passions were integral to the organization of the Phalanstery, which was characterised by a mixture of playing and gaming; both competition and exchange were central processes in the Phalanstery (see above). McKenzie Wark portrays what he calls the queer theory of Fourier as one of the inspirational sources for leading members of Situationist International. Wark contends that Fourier more than a political economist, wanted to be an "erotic umpire" and characterises his New Amorous World as a "unique kind of philosophy of the orgy, or systems-theory porn". It is the polymorphous play of as much as twelve passions that interests Fourier. "Amour" is not private and not at odds with the world, and he dreamt of a new way to harmonize desire and the social life. In this decentralised word of plenty there was nothing to fight over and no need to build empires. Instead capital, labour and talent cooperated. Fourier was no egalitarian and, as we have and shall see his play was more of a gaming kind, opening up for positions like gameworking and workgaming (Wark 2013, 7-73).

\subsubsection{William Morris on Useful Work and Useless Toil}

William Morris, who initiated the Arts and Crafts Movement in the $19^{\text {th }}$ century in England, made a distinction between useful work and useless toil. Toil signifies an activity connected to certain suffering and pain. In line with Marx he contended that the "race of man must either labour or perish"; humanity had to win its livelihood by work or toil to some degree. Morris claimed that some (not all) work was a curse. Useless toil was an effect of class society and the difference between useful work and useless toil is that one has hope in it and "the other 
has not". The hope is threefold: hope of rest, hope of product and hope of pleasure in the work itself (Morris 1884c). He commented on the hope of rest:

\begin{abstract}
Whatever pleasure there is in some work, there is certainly some pain in all work, the beast-like pain of stirring up our slumbering energies to action, the beast-like dread of change when things are pretty well with us; and the compensation for this animal pain is animal rest. We must feel while we are working that the time will come when we shall not have to work. Also the rest, when it comes, must be long enough to allow us to enjoy it; it must be longer than is merely necessary for us to recover the strength we have expended in working, and it must be animal rest also in this, that it must not be disturbed by anxiety, else we shall not be able to enjoy it. If we have this amount and kind of rest we shall, so far, be no worse off than the beasts (Morris 1884c).
\end{abstract}

Here we can see a relation between free time and work time, which is similar to one of Fourier's positions but different from the way Marx perceived it. This time the word "enjoy" is mentioned in combination with the word "rest". Morris stresses the importance of enjoyment and careless being (no anxiety) in free time as a necessary outside to equally necessary work, which had to be done in all societies and all modes of production. This is quite close to saying that play is the dialectical antithesis to work, but without any synthesis being created in the process. Morris also wanted machinery to be used for cutting down on useless toil (Morris 1884a)-which we can place in the square of labour.

But Morris also spoke of pleasure in work, within the realm of necessity. The argument was ontologically based. All "living things" feel "pleasure in exercising their energies" and even the "beasts rejoice in being lithe and swift and strong". The difference between beast and man was that the latter also exercised the energies of his mind were the memory, imagination and the thoughts of "men of past ages" helped him in his work as part of "the human race" (Morris 1884c). In contrast to Marx he stressed the anthropology or essence of the human race more than historicity and sociality of existing humans, but he still had a clear view of the uneven distribution of labour in capitalist society.

Morris view of the relation of play to the subjectively, scientifically or self-fulfilling work, which Marx spoke about, is expressed in his writings on art and handicrafts and in his involvement in the arts and crafts movement. These accounts also speak of attractive or artistic work as something that should be evenly distributed. Some of the originality of the arguments lay more in its criticism of artistic works degradation under capitalism and it will therefore be treated in the section on play and labour.

In a speech titled Art and Socialism 1884 he contended that capitalism's "haste to gain a very inequitably divided material prosperity" had "entirely supressed popular Art" by excluding the "greater part of the people" that had no share at all in art (Morris 1884b). In another speech titled Art and Labour he developed his view in the relation between the two in a way that tells us something of his view of play's relation to work. Morris defined art as "beauty produced by the labour of man both mental and bodily, the expression of the interest man takes in the life of man upon earth with all its surroundings, in other words the human pleasure of life is what I mean by art" (Morris 1884a). After defining art he focused on the relation of the pleasures of life to labour that produced "all the means of human life" through a historical survey that in the end highlighted the medieval guilds with their roots in the communal life and co-operation of the German tribes. The craft guilds developed in an effort to "free the individuals from the domination and protection of the feudal lord" and mutual protect the associated "guild-brethren". "For a time", Morris concludes, "the constitution of these guilds was thoroughly democratic; every worker apprenticed to a craft was sure [...] to become a master" if he met the standards. Pleasure is here connected to some sort of freedom in the work processes, placing the activity in the middle of play and work, with an extra stress on the non-alienated existence in the world, but, as we saw above, "the animal rest" was also important and could be enjoyed in itself. 


\subsubsection{Psychoanalysis and its Social Critics}

Eros was not only vital and dynamic as a component in psychological life, it was life itself according to Freud. The living cell was dominated by the physiologically constructing force of Eros and not only the individual's life, but also social and cultural life, especially art, had Eros as its "productive source of psychical forces and energies" (Vološinov 2012, 51, 67). Culture grew when Eros was regulated, suspended and sublimated or de-sexualised (by repression of the sexual drives) into creative labour (Fuchs 2013).

Wilhelm Reich and Erich Fromm criticised Freud from a social perspective but came to different conclusions. Erich Fromm contended that the change in Freud's theory of instincts from a mechanistic and physiological approach, where chemically produced tension provoked a need to reduce it to the normal threshold, to the new biologically based theory of Eros as the constructing force of the cell and the unification of all cells and even beyond the cells to the society, was a major one. Freud had discovered non-sexual love and in contrast to earlier, when man was seen in isolation and related to other humans as if in the market, the Eros theory related people primarily to other people with whom the subject needed union. Life, love and growth are one and the same, more deeply rooted and fundamental than sexuality and "pleasure" according to Fromm's interpretation (Fromm 1988, 106-07). The pleasure drive was here something more constructive in the shape of Eros that in this interpretation could be seen as playwork.

Wilhelm Reich, to whom love, work and knowledge were the wellsprings of life, and therefore should govern life, valuated the work of Freud radically differently. He favoured the original theory of the pleasure principle whose limit was set by the reality principle, thus suffering came from society rather than from the biological will to suffer (Thanatos). Reich stressed that Freud's theory of the death wish blocked:

[T] he difficult path into the sociology of human suffering, into which the original psychological formula on the psychic conflict had made considerable headway. /---/ The original formulation of the psychic conflict [...] leads to a critique of the social system (Reich 1990, 23--233).

Reich firmly believed that the pleasure principle was a basic law of the human psyche "according to which pleasure is sought and unpleasure is avoided" (Reich 1990, 233). What this implies when it comes to play and its relation to work is not totally clear, but my guess would be that Reich looked more to the enjoyment of play than its constructive character and relation to work. The former reality principle was not antithetical to the pleasure principle according to him; it only meant that the psyche had to get used to the fact that the external world sometimes demanded that it had to postpone momentary gains of pleasure "and to forgoing some entirely" (Reich 1990, 233), but capitalism certainly created psychological problems. Reich position in contrast to Fromm's was more in the line of Marx's view on attractive work as a kind of workplay.

\subsubsection{The Frankfurt School and the Situationist International}

Theodor Adorno wrote in the essay Free Time (Freizeit), under the counter-culture years, that leisure time was an older concept than 'free time' and 'spare time.' Leisure time stood for the privilege of an unconstrained and comfortable life style, and Adorno thought that its connotations were "qualitatively different and far more auspicious". The concept was not so tied to capitalism, abstract labour and consumption, as the other concepts that were shackled to its opposite, abstract labour (Adorno 1991, 187). The aristocratic pessimism of the statement implied that there once, for the privileged, had existed less friction in the relation between the realm of necessity and realm of freedom, than in the era of free time. The relation between play and work was degrading.

Herbert Marcuse took a more proactive stand. He expressed his political mission in stark contrast to Freud, who maintained that instinctual liberation "would explode civilization itself, 
since the latter is sustained only through renunciation and work (labour) -in other words, through the repressive utilization of instinctual energy" (Marcuse 1955, 175). To meet this position he recalled "certain archetypes of imagination which, in contrast to the cultureheroes of repressive productivity, symbolized creative receptivity". These archetypes "envisioned the fulfilment of man and nature, not through domination and exploitation, but through release of inherent libidinal forces". Marcuse's political mission was then to influence people to set themselves "the task of 'verifying' these symbols [...] demonstrating their truth value as symbols of a reality principle beyond the performance principle" (see section on playing and labouring) (Marcuse 1955, 17-176).

The Situationist International (SI) confronted the state of affairs more proactively and practically, but from very much the same analysis. Instead of being critical to the notion of free time, they wanted free time or play to invade societal life. In contrast to Huizinga, who saw actual play as a temporary and "perfection" limited in space and time, they wrote: "The central distinction that must be transcended is that established between play and ordinary life, play kept as an isolated and provisory exception". The problem of survival, the realm of necessity, was not a problem and could be rationally managed. "[T]his possibility is at the heart of every conflict of our time" (Situationist International 1958a). This means that the realm of freedom was already an existing potential for them and that play and playwork formed a central role in this realm.

In his manifesto, post-Situationist Bob Black claims that we have to stop labouring if we want to stop the sufferings of life, but this does not mean that we have to stop doing things. Play could replace labour in the future society. He describes his position as both "joking and serious" and stresses play's resemblance with work. He equates the will to do things with the drive for play, rather than calling it pleasurable work or attractive work: "Play isn't passive. Doubtless we all need a lot more time for sheer sloth and slack than we ever enjoy now, regardless of income or occupation, but once recovered from employment-induced exhaustion nearly all of us want to act". Play is characterized as vitality and a higher form of existence and not "mere survival". It is also voluntarily engaged in. (Black 1991). Black thus opposes the notion of play as non-instrumental and without consequences:

The point is not that play is without consequences. This is to demean play. The point is that the consequences, if any, are gratuitous. Playing and giving are closely related, they are the behavioural and transactional facets of the same impulse, the play instinct. They share an artistocratic disdain for results. The player gets something out of playing, that's why he plays. But the core reward is the experience of the activity itself. /---/ Conversation, sex, dancing, travel-these practices aren't rule-governed but they are surely play if anything is (Black 1991).

Black interestingly here points to the possibility of the indirect consequences of play (engaged in for the sake of the activity itself) being enough for maintaining society. Necessary work was not needed: all could be managed within the realm of freedom in the form of play. Black here conflates the two categories play and work under the total dominance of the former. The statement that playing and giving is closely related reveals the influence of gift theories and Black concludes that Sahlin's anthropological writings on the original affluent society where the work "is hard to distinguish from what we regard as play" fits well into Schillers definition of play (Black 1991). This understanding also answers Helen Schwartzman critique of the categorical distinction between play and work. Black contends in another version of the text that activities which would be play if performed voluntarily are labour if forced, implying that there is no independent category of work, even though he also stresses in the same context that today's labour is "historically original and horrible" (Black n.d.). Black's position, according to his own statements, should be placed totally within the category of play, especially since he denies the existence of work as an independent category. 


\subsubsection{Contemporary Critics of the SI Concept of Play}

Tom Tenney, describes SI as an intellectual avant-garde collective that rightly used the concept of Homo Ludens to inform a revolutionary praxis, but in doing so also ignored some essential features of the original thesis. Tenney investigates how SI played out the ludic principles in practices as Détournement and Situations and contends that SI ignored the separated realms between play that could represent and anticipate an ideal social order (but still stand apart from it separated in time and space) and real life. The goal of SI was to "create play as real life, as a way of transforming the everyday into a continual play that is seamlessly integrated with quotidian activities, not as something that stands apart" (Tenney 2012, 3). Huizinga's theory perpetuated the division of societal life that SI wanted to eradicate.

The claim of SI that play had been co-opted by consumer culture and the spectacle with the consequence of a "bastardization of play" which had obviated the dichotomy of work and leisure and turned play into an "amusement that carried the same forms that dominate the working life" and simply was used to alleviate tensions created by a mechanized culture, was according to Tenney a misreading of Huizinga, who clearly stressed that competition was "part and parcel of play" (Tenney 2012, 5). In a work called In the shadow of tomorrow, written by Huizinga just before the second world war, he himself spoke of "the perversion of play" as the major malady of his time (Anchor 1978, 78):

The most fundamental characteristic of true play, whether it be a cult, or a festivity, is that at a certain moment it is over. The spectators go home, the players take of their masks, the performance has ended. And here the evil of our time shows itself. For nowadays play in many cases never ends and hence is not true play. A far-reaching contamination of play and serious activity has taken place. The two spheres are getting mixed up (In the shadow of tomorrow [1938] 1964) cf (Anchor 1978, 77).

Huizinga thus saw fascism as a force perverting play much in the same way as SI wanted to use play for changing everyday life, albeit for the opposite political reasons.

Finally Tenney admits that SI implemented the play theory in a successful practice when they used the egalitarianism and freedom experienced in play to challenge established social forms and form a critique that according to him can be "interpreted as active resistance" (Tenney 2012, 5). Some of the mistakes of SI were later corrected according to Tenney by the cultural jammers of the 70 s and 80 s who created a more playful culture rather than demanding a change in the whole of society. Tenney wonders if we could not start to think of the spectacle as a kind of play and SI as the spoiler of its game (Tenney 2012, 14-15). Tenney here precludes the possibility of theorizing about the perversion and bastardization of play, and in this he opens up for the use of ideological concepts like playbour. A management scholar, Douglas Smith, heads in the same direction when he claims that the Situationists gave the game away (Smith 2005, 433). It is hard not to see this critique as a consequence of a change in how the play concept is being used. Lourens Minnema concludes that the $20^{\text {th }}$-century formation of the play concept "reflects the transition from modern to postmodern culture" and a change in interpretation "from play as founding mediation to play as a possible means" that is "closely connected to the failure of mediation efforts which are critical of culture, to overcome radically the disintegration that goes with functional differentiation" (Minnema 1998, 39). This analysis is confirmed by Guy Debord twenty years later when he returns to and comments on The Society of Spectacle (1967). This time play is not positively mentioned as a mediating and progressive force, and the spectacle with its instrumentalism has gained strength (Debord 1990, passim, 4-5). Tenney and Smith are thus directing their critical eyes towards the defeated part rather than against those groups gaining from the expansion of the spectacle.

Helen B. Schwartzman, a social anthropologist, is known for having questioned the dichotomies of play/reality and play/work. In her book Transformations she shows that this understanding of the activities is not a given. In many non-western cultures it is common to mix play with work in a way that does not fit easily within a dichotomous relation between the two. 
In these cultures the more important contrast could instead be between sacred and profane work. Schwartzman connects the difficulties of westerners to perceive of work as playful to the Protestant ethic. This same ethic is also the reason why play sometimes can be perceived of as work, especially when it comes to games (Schwartzman 1978, 4-5, 156). ${ }^{6}$ The activities described by her can be seen in the perspective of this article as either workplay or playwork. Csíkszentmihályi points out here that Max Weber never understood that ascetic withdrawal from all pleasures could in itself be enjoyable, but that he came close to seeing how arbitrary the "work-play distinction" is when he stated in the concluding chapter that the Protestant ethic in its highest form of development, as the pursuit of wealth, took on the character of a game (Csíkszentmihályi [1975] 2000). In line with the argument here this is not so much an example of the relation between work and play as an example of the "gamification" power, which is inherent in capitalism and affects both play and work.

Schwartzman's conclusion is important:

There is nothing to be found in the anthropological literature to suggest that play is not pleasurable or enjoyable except the realization that this is not always the case, and, of course, it is also true that activities that are generally understood to be not-play are also pleasurable and enjoyable. This means that we cannot be satisfied with definitions or theories that argue in a curiously tautological fashion that 'the play element in play is playfulness' (or joy or pleasure or fun) (Schwartzman 1978, 327).

Hence, to define play we have to involve several other criteria than fun, joy and pleasure. ${ }^{7}$

\subsubsection{Hans-Georg Gadamer's view compared to Christian Fuchs' view on Play, Work and Communication}

Gadamer maintained both that play was essential to the animal world, including (wo)man, and had characteristics that differentiated human play from the play of animals. Monica Vilhauer states that human play for Gadamer had the special quality of human freedom, which was not simply a freedom of variability or caprice, but a freedom that involved the intentional "self-restraint that goes along with any effort to accomplish something, do something, play something". Human beings play themselves out by playing something (Vilhauer $2010,34)$. Gadamer's view is very close to substituting play for work. We can call it for playwork.

To this we have to add that Gadamer equates play with understanding. A work of art becomes complete in the inter-play with the spectator, but the same would go for communication based in a free, variable and spontaneous interplay between communicating subjects. Play, the movement of interpretation and communication, is understood as something larger than the individuals and things involved. In short the whole of the hermeneutic circle could be understood as play.

Christian Fuchs, in contrast, contends that communication is work at the same time as, and here Fuchs refers to Marx, sensuousness, speech and communication are taken as signs of a possible non-instrumentality of humans. Hence, Fuchs gives a hint of a possible non-instrumental version of work. Marx also, according to Fuchs, points out "that work is not always and not necessarily a necessity and an instrument to achieve goals, but under communism it becomes a free activity beyond necessity and instrumentality" (Fuchs 2014, 253). I do not totally agree with this. First, in his line of argument on communication being work, Fuchs himself stresses that language is the result of human social activity and that this language is used to co-operate in the production of information (Fuchs 2014, 248). This argument involves a kind of instrumentality, the production of a use value, information. The strength of the argument that sensuousness, speech and communication are signs of noninstrumentality according to Marx is diminished in Fuchs interpretation. Second, I have tried

\footnotetext{
$6 \quad$ Hägglund adds that adults in western cultures also introduce playful moments in their work (Hägglund 1989, 67).

${ }^{7}$ The categorization here depends on the five dimensions mentioned in the beginning of the article.
} 
to show earlier that even when Marx spoke of communism or the realm of freedom, play played a subordinate role under work. Work could indeed be attractive and self-fulfilling, but still focused on use and use value. Hence, work still had an instrumental character in the realm of freedom. Third, this is the time and place to admit the obvious, that communication not only resembles play, but also resembles work. Humans do not always use language and communication in a playful and non-instrumental way. Often they want to accomplish some effect in the outer world with their words. But if communication sometimes is work and sometimes is play, where does that leave us when it comes to the relation between play and work? Should we conflate the concepts under some kind of workplay (or attractive work) or should we just agree that the two share some characteristics and differ in others? That they exist a part from each other as well as being mixed up in different hybrid combinations? I would argue for the second alternative.

An interesting difference between Gadamer and the Situationist International's position on play is that the former sees the spectator as active in the art of work or the event (Gadamer $1975,31-32$ ), and the latter wants to include people in a social situation in a more direct way, implying that being a spectator is a passive mode of being similar to consumption in the "free time". These arguments have ramifications for our understanding of the concept of playbour as well as for the theory of audience labour advanced by Dallas Smythe (audiences were institutionalised by the mass media and their "audience-power" was sold to the advertisers) (Smythe 1984; Smythe 1977) and today used by for example Christian Fuchs (Fuchs 2012), and the theory of the social factory of the autonomist Marxists. This will be dealt with more in detail in the section on playing and labouring.

\subsection{Gaming and Working}

In Rules of Art: Genesis and Structure of the Literary Field (1992) Pierre Bourdieu advances a theoretical understanding of the literary field that can elucidate the relation between working and gaming. In the literary field you can find, argues Bourdieu, an inverted form of economy that is grounded in the dual character of symbolic assets. First there is the commodity aspect, secondly the signification or the symbolic value of the asset. The latter is relatively independent of the exchange value of the former. A developmental process (leading to modernism) resulted in a cultural production for the market and as a reaction against this a production of "pure" works of art intended for symbolic appropriation characterised by the objective and subjective distance of the cultural producers to the market. The strategies of the producers are distributed between two extremes in ways that do not constitute total subordination either under the market or absolute independence. Interestingly there exist two antagonistic forms of production and circulation within these fields (Bourdieu 2000, 215).

The anti-economy of pure art cannot recognise any other demand than the one, which creates itself in the long run. It is focused on the accumulation of symbolic capital as a denied, but generally accepted and legitimate capital, that under certain conditions can be transformed into economic profit (Bourdieu 2000, 216). The culture industry, satisfied with adapting to the existing demand and producing for economic profit as a regular company, has to keep clear of the worst forms of self-interest, if they are to conquer any symbolic capital at all (Bourdieu 2000, 216).

Symbolic capital depends on social and cultural prestige; it can be hoarded but is also easily lost; it is acquired in ways that resembles gameworking or workgaming, with its focus on the quality of the use value and gaming for prestige. This general perspective can be applied to explain peer production in Free and Open Source Software (FOSS) and Wikipedia. If you want to be esteemed and get a position of status within these communities you will have to show that you are committed to the project in deeper sense than in a narrow economic way. This acquisition of social status within a community of practice has a lot to do with gaming. Positions between working and gaming can then be placed according to the same logic as Bourdieu developed in his field theory (Bourdieu 2000, 191, 193). The proportions between working and gaming decide where a phenomenon is positioned. 
Bob Black thinks in the same direction as Bourdieu, but for him working and gaming seems to be the same thing. Playing and gaming mean to be active and do things and can substitute work at the same time as they are voluntary activities for him. He did not see any contradiction between this and his longing for this activity to be competitive in its character. He wanted life, as seen above, to be a game "with high stakes" (Black 1991). But probably the !Kung would not agree with him, being against competition and favouring co-operation as they are.

\subsection{Gaming and Labouring}

Charles Fourier differed from Marx in his view of competition between different groups in the utopian scheme. Where Marx saw co-operation, Fourier saw healthy competition. It would help rotation of work assignments to come about and would arouse such inspiration and passion in the members of the competing groups that the fanaticism would give them the power to do things that seemed humanly impossible (Fourier, Attractive labour.). Fourier, as we have seen above, included capitalists and exchange in his vision of the Phalanstery, hence this analysis of his thoughts on gaming in relation to labouring, although Fourier himself thought of it as non-alienated utopian work. The gaming element is clear in his descriptions; competition between the groups involved a measuring of the achievements, without fostering the usual imbalances of such a system (almost like the vision of the New Economy of the nineties). The point of view can be categorised as gamelabouring and stresses the synergies between the competition of gaming and labour, downplaying the exploitation within capitalism or seeing it as a part of the game. McKenzie Wark speaks of Fourier's philosophy as a heretical reversal of liberalism: "Rather than sacrifice the body to labor in order to sustain a survival in which some modest pleasure might be endured at the margin, the whole social field can engage all of the passions all of the time" (Wark 2013, 75).

This liberal character, albeit heretical, is shown by the fact that the process of exchange was of central importance to the functioning of the Phalanstery. The Exchange would be an institution where the work and pleasure sessions for the following days were planned and all individuals had to attend it with all its "animation and intrigues" (Fourier, The exchange.). Conflicts and intrigues were thus not looked upon as something negative, partly due to the fact that in the Phalanstery everybody desired to manifest his/her intentions and to make them publicly known (Fourier, The Exchange.). These passionate intrigues in the Exchange have a lot of gaming in them but they are portrayed as play, as Fourier did not distinguish between the two (in the earlier analysis his position was categorized as gameplaying, but in the expressed views here it seems appropriate to specify the position as also quite close the labouring square).

The Situationist International ( $\mathrm{SI})$, as we have seen, stressed that the question of winning and losing dominated the ludic activities in contemporary society as a result of all other tensions "between individuals for the appropriation of goods" in capitalism. This way of perceiving gaming as a corrupted, by labour, version of playing (and its ideological function for conservative forces in society) (Situationist International 1958a) that can be placed in the middle of labouring and gaming. The strengthening the competitive part of play seems to be a technique to introduce an alien instrumentality in play.

Helena B. Schwartzman refers to a study which points at some potential weaknesses in the positions of $\mathrm{SI}$ and Caillois on gaming, but in two different ways. In the Kpelle society gaming in the form of ritual speech-acts is ritually used as a regulator in the social distribution of wealth and prestige. Interestingly there exist a number of children's play activities in this community that "serve to develop the verbal and acting skills necessary to engage successfully in 'talking matter"' (Schwartzman 1978, 109). Gaming is not confined simply to capitalism, as could be seen as implied in the position of SI, but rather used in many different historical and cultural contexts, although still this is probably a feature of hierarchical societies as the example of !Kung's collective and their non-competitive perspective on gaming signals. When it comes to Caillois' view on gaming, the gaming of the Kpelle society did not 
simply result in lasting material results, but also affected prestige and future wealth acquisitions of the gamer. In these cases it is better to speak of gameworking than gamebouring.

From now on I will focus on the relation of gaming with capitalist labouring within the general intellect of contemporary society. The autonomist Marxist Paolo Virno stresses, that many of the characteristics of political and communicative action have been absorbed by post-Fordist labour (Virno 2004, 49-51). Hence, poiesis has taken on many characteristics of praxis. At the core of contemporary labour we find the being in the presence of others and "the beginning of new processes, and the constitutive familiarity with contingency, the unforeseen and the possible", and Virno maintains that post-Fordist labour "brings into play the talents and the qualifications" which according to a traditional view had more to do with political action (Virno 2004, 51). Capital activates several new forms of instrumental actions by involving former autonomous actions within alienated and exploited labour.

Virno gives the name of Virtuosity to this hybridisation, meaning "the special capabilities of a performing artist", and proceeds by defining the activity of a performing artist or virtuosic activity which "finds its own fulfilment (that is, its own purpose) in itself without objectifying itself" into an end product or finished product that could survive the performance. Secondly, it is "an activity which requires the presence of others, which exists only in the presence of an audience" (Virno 2004, 52).

This definition opens up for an interpretation in which labour has absorbed characteristics that in many ways also are the characteristics of gaming (more than play-see below) if we follow in the footsteps of Gadamer. If anything connects Virnos' argument to playing, it is his general characterisation of the cognitive character of today's labour that through the mediation of communicative action (see above Arendt, Habermas and Wittgenstein) connects to play. The playful communication on digital platforms is appropriated by the fraction of capital owning the vectors of information; the vectoralist class, as McKenzie Wark named them (Wark 2004). This kind of playbour will be discussed in the section on play and labouring.

One of the most important functions of immaterial labour in post-Fordist capitalism, besides activating productive co-operation, is to develop the social relation to the consumer by communication (Lazzarato 1996, 136-137, 140). This is an additional twist to a performance in the presence of others that corrupts playful communication and converts it into a game for profit, thus gamelabouring or labourgaming. At the same time the consumer is already inscribed in the manufacturing of the product offered. "[H]is or her consumption should be productive in accordance to the necessary conditions and the new products." (Lazzarato 1996, $136-137,140)$ Lazzarato advances the hypothesis that what is productive "is the whole of the social relation" (here represented by the author-work-audience relationship) (Lazzarato 1996,145$)$.

How should we evaluate this new form of work? Lazzarato's claim supports my position on gamelabouring and labourgaming within the general intellect and gives it a material foundation. But at the same time he asserts that immaterial labour starts where the social labour power is independent and able to organize both its own work and its relations with business entities. "Industry does not form or create this new labor power, but simply takes it on board and adapts it." He concludes that this "cooperation can in no case be predetermined by economics, because it deals with the very life of society." Economics can just "appropriate the forms and products of this cooperation, normalizing and standardizing them" (Lazzarato 1996, 137). Here we have progressive potential that will be dealt with, together with my criticism of it, in connection to playing and labouring.

Where we are in this process can only be judged by empirical studies.

On a more concrete level, suggesting that there is also a broad and narrow definition of gaming (as of culture and playing), the autonomist Marxists Nick Dyer-Witheford and Greg de Peuter describe the birth of digital gaming some 50 years ago by Pentagon programmers "who killed away tedious hours tending giant military computers by transforming the electronic screens of nuclear war preparation into whimsical playgrounds". Only years after Atari, the first commercial games company, "converted this bold experiment in computer liberation into 
an entertainment commodity" (Dyer-Witheford and De Peuter 2009, xv). Witheford, de Peuter and Stephen Kline contend that the fetishism of commodities (production processes are hidden and the relations between the products seem to be properties of the commodities in themselves) is "peculiarly intense" when it comes to commercial game products:

Play after all, is the opposite of work. Games are "fun" experiences. Every bit of game marketing and promotion actively discourage us from associating them with such mundane and boring realities as jobs, management, and labour relations (Kline et al. 2003, 197).

In gaming magazines and on the game boxes we find information of how "cool" it is to labour "in the gaming industry":

In such depictions making games is itself shown as play-work as fun. The blurring of boundaries between labour and leisure so that not only consuming games but also producing them is represented as a continuum of endless fun is part of the interactive game industry's hip self-image (Kline et al. 2003, 197).

But there is also another connection between gaming and labouring. Not all of us buy our games but download them with the help of the Warez scene or swap our games with our friends. The authors contend that we are pirates that reckon the chances of getting caught are small.

We may even get a charge out of cracking the various technological systems while Microsoft and Sony try to keep us out: hell, it's just another level of the game. If work-as-fun is the interactive game industry's wet dream, then piracy-as-play is its worst nightmare (Kline et al. 2003, 198).

Here we have both synergies and conflicts represented in the relation between gaming and labouring. It is the first time that some gaming is portrayed as being antagonistic to capital and its labour, placing it between playing and gaming.

\subsubsection{Bruno Latour and Steve Woolgar}

Labourgaming and gamelabouring could perhaps also be said to have been touched upon in a study by Bruno Latour and Steve Woolgar. In Laboratory life from 1986 they developed a theory on the motives of the labouring scientists. In one of the essays, Cycle of Credits, they stress that the scientist has to be understood as part of the laboratory rather than as an individual, even if there are differences between the scientists. When one scientist claimed that a scientific finding was made through them personally, other scientists claimed that the finding was the result of a collective process. Some scientists were more closely tied to the laboratory in their career compared with other more successful ones (Latour and Woolgar 1986, 18189). Four different kinds of credit were discovered in their study, which generally showed that quasi-economic reasoning was common in, for example, the counting of published papers. These credits could be used in several ways: 1) they could be exchanged as commodities, 2) they could be shared, 3) they could be stolen, and 4), they could be accumulated or wasted (Latour and Woolgar 1986, 18-192). Latour and Woolgar stressed that it was difficult to interpret the testimony of the informants, but that it seemed that they were economic in a very broad sense. The informants did not seem to make any distinction between internal and external motives for their actions (Latour and Woolgar 1986, 19-192)

References to credit can frequently be found, but it only assumes prominence in discussions of the past, or of group structure, or of issues of priority. Consequently, credit as reward cannot adequately account for the behaviour of a scientist practising science (Latour and Woolgar 1986, 193). 
Scientific practice was not only about the pursuit of recognition and trustworthiness, it was also about personal interest, curiosity, dedication and playfulness, but the authors also point to the possibility of converting one form of creditworthiness into another within a similar logic as the logic of capital accumulation (the M-C-M' formula): credit-investment-credit' (C-I-C'). This is what they call the cycle of credit. A scientist is more than anything (more than pecuniary rewards) interested in getting more credit to use for their advancement within their field, but this also involves a risk of wasting the credits already accumulated (Latour and Woolgar 1986, 19-198, 201). To me this sounds like the accumulation of symbolic capital of Bourdieu, but without the inverted character of the economy. No conflicts are at hand here, only synergies. The credits could be sold as commodities or stolen as property as well as be used as symbolic capital, at the same time as it was the intrinsic motives that spurred the research activities. Playbour as a phenomenon seems to be confirmed by the study of Latour and Woolgar even if it seems to be labourgaming, when looked at from the structural perspective of post-Fordism entering the attention economy (Davenport and Beck 2001).

\subsection{Working and Labouring}

Here we have at least three themes within Marxist tradition. The first stresses that the concept of abstract labour involves several abstractions from the concrete forms of labour, that is, work: an abstraction from the physical properties of the use values, an abstraction from the single products to establish social relations through the exchange of commodities, an abstraction from simple to more complex activities, and finally, an abstraction "from specific qualities under which specific labour processes took place (such as bad working conditions, low payment, etc.) so that common properties of commodities are foregrounded by the value concept" (Fuchs and Sevignani 2013, 248). This leads up to a one-dimensional perspective focused on realized, fixed and crystalized social labour (Marx 1865, cited through Fuchs and Sevignani 2013, 248).

The second theme, represented by William Morris, asserts that the class society is at the root of creating useless toil that does not produce socially necessary use values. The middle classes do not produce utilities, but they consume utilities "out of all proportion to their due share". The commercial and manufacturing classes "spent their lives and energies in fighting amongst themselves for their respective shares of the wealth which they force the genuine workers to provide for them". The rest of the middle classes are "almost wholly the hangerson" and "parasites of property". The middle class as a whole had one common aim, and that was:

[N]ot the production of utilities, but the gaining of a position either for themselves or their children in which they will not have to work at all. It is their ambition and the end of their whole lives to gain [...] the proud position of being obvious burdens on the community. For their work itself, in spite of the sham dignity with which they surround it, they care nothing (Morris 1884c).

Morris here portrays a large part of labour as antagonistic to work at the same time as he shows the connection between the two. This traditional critique-which position many activities in capitalism within the square of labouring alone-from the standpoint of labour (or rather work) is complemented by Postone's claim that the abstract and self-propelling logic of capital and its labour affects the mode of producing on even deeper levels. Postone's position leads us to the third theme, here represented by Harry Braverman. He wrote a seminal work on the degradation of work under monopoly capitalism in the seventies focusing on, among many things, the extreme division of labour under Fordism (Braverman 1974). With this degradation of the concrete work process, the attractiveness of producing use values disappeared with the impoverishment of skills and knowledge of the labourer-leading to feelings of increased alienation rather than self-fulfilment. Today such work, which can be placed within the category of labour, could be exemplified by the new forms of division of labour through Amazon's Mechanical Turk. 


\subsection{Playing and Labouring}

Labour is dependent on social standards in two ways. The use value produced that carries the exchange value needs to meet social standards, and the exchange of different use values has to be standardised and conducted in the form of equivalents, by the mediation of societal necessary labour time, when it comes to value, and market prices. This abstract logic changes and determines production together with it being conducted within a system that maximises growth and accumulation on a basis of uneven social distribution of the produced value that in turn forces some to labour and leaves other free not to labour. Play is very much the opposite thing. It is spontaneous and improvisational and open for negotiations and renegotiations in a careless, voluntary, but also serious way. It can function as socialisation and a learning process, but also as a critique of social norms.

If we are to believe William Morris it was not simply the work process per se that was degraded under capitalism. The artistic aspect, which was the connecting element between the enjoyment of play and self-fulfilment of work, also disappeared due to the abstract logic of machine-based capitalism.

The degrading processes started as early as with the freeing of the serfs that crowded the medieval craft guilds and led the complete workmen to employ wage labourers. Later on with the introduction of big machinery and "the rise of producing for profit" the workman got "robbed of one pleasure which as long as he is a workman is perhaps his most important one: pleasure in his daily work: he is now only part of a machine, and has indeed little more than his weariness at the end of his day's work." (Morris 1884a) In such a situation it was better, according to Morris, if either all pretence to art was abandoned in the wares produced or that pleasure and interest were added to the necessities of work (Morris 1888).

This picture fits very well with capitalism up until Fordism with its extreme separation of the cognitive content of the production process and the execution of it, but how does it apply to the quite self-sufficient immaterial labour of Maurizio Lazzarato?

\subsubsection{The Frankfurt School and the Situationist International}

Herbert Marcuse connected Marx's theory of capitalism with Freud's pleasure/Eros principle. Alienated labour, domination and accumulation under capitalism constituted a surplusrepression of Eros that exceeded the cultural needs. The demand for surplus labour within capitalism created a surplus repression of the Eros, transforming the reality principle into the performance principle. Marcuse was not against all suppression of Eros and claimed that societally necessary labour for subsistence in society was equal to the necessary suppression of Eros. The reality principle was founded in the basic fact that scarcity ruled in a world too poor for "the satisfaction of human needs without constant restraint, renunciation, delay" (Marcuse 1955, 35). The problem was exploitation under capitalism.

Creatively he proposed turning play and Eros against capitalism, instead of attacking capitalism on part of labour from the site of production-thus attacking capitalism from its periphery or outside rather than from its centre (Marcuse 1955, 175-176)

Marx claimed that material production in the realm of necessity was the foundation for the realm of freedom. A shorter working day would improve the conditions for the development of the realm of freedom and its playful, social, scientific, artistic, dare I say creative, work, characterised by being "damned serious". These two concepts, the realm of necessity and the realm of freedom, were connected to the issue of free time by Marx, who concluded that it was productive in itself under communism when it could not be separated from work. Theodor Adorno made another analysis of the free time of his day. In the essay Free Time (Freizeit) we learn that 'free time' in capitalism was shackled to its opposite: labour.

Indeed the oppositional relation in which it stands imbues free time with certain essential characteristics. What is more, and far more importantly, free time depends on the totality of social conditions, which continues to hold people under its spell. Neither in their work nor in their consciousness do people dispose of genuine freedom over themselves /---/ 
the existence foisted upon people by society is identical neither with people as they are in themselves nor with all that they could be (Adorno 1991, 187).

The character of free time was historically and socially constructed in ways that formed the innermost articulations of human characteristics and this in an age with unparalleled social integration to ascertain anything in humans that is not functionally determined. Free time was neither free nor spare, and it was occupied by labour which one "could designate as heteronomous" (Adorno 1991, 188). This free time was not only productive and connected to the realm of necessity, as Marx had stressed it would be in communism, but invaded by capitalism. The focus of Adorno on heterogeneity makes this a forerunner to the autonomist Marxist notion of the Social Factory. In Marxism concrete work is heterogeneous and carries a onedimensional exchange value. In free time social life itself in its heterogeneity had become concrete work subordinated under abstract labour.

Even when the spell of social conditions was relaxed and the individuals felt themselves acting as free subjects, their will was shaped by the very forces they were trying to escape during their hours of non-labour. He asks himself what the future of free time would be when productivity keeps on rising under persisting conditions of unfreedom.

Free time has already expanded enormously in our day and age. And this expansion should increase still further [...] If one were to try and answer the question without ideological preconceptions, one could not avoid the suspicion that 'free time' is tending toward its own opposite, and is becoming a parody of itself. Thus unfreedom is gradually annexing 'free time', and the majority of unfree people are as unaware of this process as they are of the unfreedom itself (Adorno 1991, 188).

The term 'hobby', in continuation with this, was understood as a paradox by Adorno. The human condition, traditionally seen as the opposite of reification and an "oasis of unmediated life within a completely mediated total system" (Adorno 1991, 187-188), had itself been reified. This was according to Steven Connor's interpretation contrary to real freedom and play:

\begin{abstract}
Adorno's judgement on hobbies and free time will in fact turn out to be another version of the grim verdict supplied in his long, contemptuous condemnation of 'The Culture Industry' of two decades earlier, that 'Laughter is the fraud practised on happiness'. For Adorno, the very distinction between the seriousness of work and the irresponsibility of free time is to be understood as an extension of the remorseless drilling of the bourgeois subject into the required rhythms of modern life (Connor 1998)
\end{abstract}

Happiness and play were manipulated into hobbies and consumption by capitalism. Due to these constraints and manipulations the people were not free in relation to themselves and their potentialities.

The Situationist International (SI) was more practical in its opposition to capitalist society than Adorno, but nonetheless also theoretically interesting. Under the banner of homo ludens they turned Marcuse's theories into practice with the aim of revolutionizing everyday reality with play and gaining their strength from a playful free time. SI attacked the commodifying and reifying processes under the name of the spectacle (this being "a social relationship between people that is mediated by images") (Debord 1967, 12). Slogans such as "Fantasy to the power" and "Demand the impossible" were the anarchic banners of the 1968 rebellion in France. Guy Debord, the author of The Society of Spectacle (1967) both praised collective anarchism for "the merit of representing the refusal of existing conditions from the standpoint of the whole of life" and criticized it for its systematic contempt for method and for ignoring the question of how political ideas should become practice (Debord 1967, 6-64). The rejection of capitalism in the whole of life meant that politics, art and everyday life were seen as a whole. Debord concluded that revolutionary organizations cannot "combat alienation by means of alienated forms of struggle" (Debord 1967, 86, 89). 
Homo Ludens was put up against the consumption society and free time became an important battleground for the new social movements of the time. The contemporary society of spectacle was according to Debord without festivals, even if it presented itself as "essentially made up of many frequently recurring festivities" and as an "enormous positivity where everything that appears is good". Mass-pseudo-festivals made a parody of the gift and dialogue and incited people to excessive spending producing disillusionment with its false promises (Debord 1967, 15, 113) The revolutionary project, in a time when the ruling order by means of the spectacle endlessly discoursed upon itself in an "uninterrupted monologue of self-praise" (Debord 1967, 19) was also: [T] he project of a withering away of the social measurement of time in favor of an individual and collective irreversible time which is playful in character and which encompasses, simultaneously present within it, a variety of autonomous yet effectively federated times - the complete realization, in short, within the medium of time, of that communism which "abolishes everything that exists independently of individuals."(Debord 1967, 116-117).

This is a clear statement on how play was thought to counteract the abstract and selfpropelling logic of value-producing labour. Debord continues the same line of thought in his critique of human geography. Individuals and communities had to create places and events commensurate not just with the appropriation of their labour but with their total history and resulting in a "mobile space of play" that "by virtue of freely chosen variations in the rule of the game" would restore the authentic journey to humanity (Debord 1967, 126). Play for Debord, together with work, had a trans-historical character that was central to social life. The lines between the two were blurry, but rather in the way that play was productive, than work (never labour) playful. The merger of play with work is perceived much as Marx perceived it, but Debord departs from play rather than necessary work. Thus playwork seems an appropriate placing in the field model. Debord stressed play in social life, outside of material production and the realm of necessity, and it is hard to tell in what proportions play pointed to the realm of freedom and sheer playful sociality.

SI was buried in its original form some years after 1968. In 1972 Debord and Raoul Vaneigem broke with each other. Asger Jorn's younger brother, the poet and painter Jörgen Nash later founded the Second Situationist International (SSI), also called the Bauhaus Situationists, and developed a special form of happening, or anti-happening, as an artistic and playful method to radically change society. They wanted to break away from the bourgeois way of using happenings and instead focus on people coming together and creating in cooperation. The new form of activity was called Co-Ritus. Nash held that labour in capitalism stole human lust and imagination to create and stimulated us to use our free time for consumption of mass-produced commodities. This second coming of Situationism contended that emotions came before actions. To Nash the emotions were the ludic element, but the Bauhaus Situationists did not so much develop a new definition of the situation, as a new practice (Thelin 2010, 7, 12; Wikipedia contributors 2013).

The constructed situation was in 1958 understood theoretically by SI as: "A moment of life concretely and deliberately constructed by the collective organization of a unitary ambiance and a game of events" (Situationist International 1958b). Debord wrote that a 'situation' required that one person functioned as a kind of director forcing passive spectators to action (an idea that later was developed by Brazilian dramatist Augusto Boas in his Theatre of the Oppressed) (Debord and SI cf. Tenney 2012,11). In the artistic field SI defined the situation as the "integration of present or past artistic productions into a superior construction of a milieu" and the play-character of the activities in these situations could only be understood properly as movements or processes. There could be "no situationist painting or music", only the use of painting and music as practices (Situationist International 1958b).

Hans-Georg Gadamer holds the same general perspective on play as SI. Vilhauer claims that according to Gadamer you cannot truly participate half-heartedly in play, creating a distance to it by saying it is "just a game". When you do this, you objectify the game by looking at it from the outside, and this takes you out of "true involvement in play" which demands "that the players be completely engaged with other players in the game" (Vilhauer 2010, 36). 
The Fordist capitalism of the sixties and seventies, as well as the mass media of that day, was built on the dichotomy of the artist and the spectator. The question is how relevant the critical mission of the Frankfurt School, SI and Gadamer are today when the mass media have turned into interactive so-called social media?

\subsubsection{Perspectives on the Postmodern Spectacle}

Position one: Adorno was in a sense right in his essay on free time, according to Steven Connor. Connor mentions the nineties as a period when pleasure became "repressively desublimated" into grotesque, compulsive and compulsory pleasures like the "alleged ecstasies of the cyber-body through to the stem delights of fin-de-siècle sadomasochism". He claims that these activities are the subject of "much postmodernist "celebration", but asks himself whether a vital element is not missing in a political and ethical philosophy that has been able to make so little accommodation to the powers of laughter (Connor 1998).

Connor tackles the question of laughter and its co-option by capital and instrumental logics by discussing an essay written by Terry Eagleton in 1983 when the latter, by the analysis of a single line in Yeats's 'Easter 1916', tried to achieve a theoretical knowledge of the mechanisms of pleasure so that it could be used for political objectives. The project became a parody:

The essay is comically poised between convincing its reader of the possibility of subsuming pleasure within cultural politics and acknowledging that such a work of analysis could never be complete or sufficient, would always remain comically, laboriously retarded with respect to its object (Connor 1998).

Hence, laughter and play could not be made instrumental, neither for post-Modernists nor for Marxists. It was fun in itself and stayed in its own square, but at the same time social life lost touch with it.

Position two: Play for Bob Black was the antithesis of labour. Play was always voluntary and what "might otherwise be play is work if it's forced. This is axiomatic". Play was not passive, but at the same time we also needed more time "for sheer sloth and slack than we ever enjoy now". Leisure according to Black was "nonwork for the sake of work", and it was spent "recovering" from labour in a "frenzied but hopeless attempt to forget about work". But something in Situationism's attitude had changed. Labour was even better than leisure, because it was at least paid (Black 1991). The reason that was the foundation for the degradation of leisure time, the social necessity of earning a wage in a market economy, had now some positive effects.

Black's recognition of money and wages as something good is a telling sign of an altered mentality in society, even if we need more time for "sloth and slack", getting money for labour is better than leisure activities in waiting for work. Black confirms the criticism of Connor and Adorno, of leisure time being invaded by capital. The play of today's leisure time is subordinated to labour and under such circumstances it is better for the individual to at least get paid. Labouring dominates this vision totally and playing dissolves as a category.

Position three: Wark concludes that the spectacle of the SI has been replaced by a Spectacle of disintegration today. In Gamer Theory he concludes regarding Guy Debord's treatise on the society of spectacle that the term 'separation' was of key importance to an understanding of the spectacle:

Some argue that the "interactive" quality of contemporary media can, or at least might, rescue it from separation and its audience from passivity. One could with more justice see it the other way around: whatever has replaced the spectacle impoverishes it still further, by requiring of its hapless servants not only that they watch it at their leisure but that they spend their leisure actually producing it. Play becomes work (Wark 2007, Cuts (Endnotes) 111). 
The spectacle of disintegration is explained historically by Wark. If Debord had identified two spectacles in 1967, one the concentrated one of Stalinism and Fascism and the other the diffused one of "endless pictures of models and other pretty things", he identified the integrated spectacle in his Comments on the society of spectacle from 1988. The integrated spectacle had subsumed the earlier two into a new spectacular universe "which molds desire in the form of commodity" and became less and less transparent with its most emblematic concentration in the 'occulted state' that was "occult even to its rulers". Since Debord died in 1994 Wark claims that the spectacle has evolved into an ever more "fecund and feculent form" that "integrates both diffusion and concentration":

\begin{abstract}
The spectacle speaks the language of command. The command of the concentrated spectacle was: OBEY! The command of the diffuse spectacle was: BUY! In the integrated spectacle the commands to OBEY! and BUY! Became interchangeable. Now the command of the disintegrating spectacle is: RECYCLE! Like oceanic amoeba choking on granulated shopping bags, the spectacle can now only go forward by evolving the ability to eat its own shit (Wark 2013, 2-3).
\end{abstract}

Wark's criticism of playbour as unpaid labour, that has an already alienated world as its raw material, comes close to Black's position in portraying social life and play as totally invaded by capital.

Position four: Wark mentions the writings of Pat Kane, who in The Play Ethic describes the consulting business and concludes that once you have got a taste for un-alienated labour "then even the slightest alienation comes to seem like a temporary stay in the prison house" (Pat Kane, The Play Ethic cf. Wark 2007, Cuts (Endnotes) 112). This position gives some hope of play being able to influence labour, rather the other way around, and as such it places itself within labour, but closer to the square of play.

Position five: Pekka Himanen portrays the fourth position in a slightly more independent form, with what he calls the hacker ethic. But he still does not understand it within an anticapitalist framework (with such a framework the position would be positioned in relation to work instead). According to him, we do not have to use new technology to further workcentredness (labour-centredness). This development could be turned around and transformed into the sundayization of Friday. "Hackers optimize time to be able to have more space for playfulness", that is programming that does not have "immediate goals"-work is not always the most important thing (Himanen 2001, 32). This playful motivation is mainly based in human nature and the development of technology and can be placed as a complement to labour (placing it as a dependent position-on labour-in the square of play?).

Position six: Wark focuses on the fifth perspective in a more radical way in his Hacker Manifesto, where the social relations of hacker production, the hacker's interest in the free expansion of the vectors of information as well as freely accessible knowledge and culture (for them to explore and tinker with) are taken into account. He stresses the hackers antagonist interest vis-à-vis the commodity and its production of scarcity (Wark 2004, 381-382) placing it within the category of play.

\title{
3.6.3. Autonomist Marxists on Playing and Labouring in the General Intellect
}

The question for Paolo Virno is if the public character of the intellect, which is a technical requirement of the contemporary production process, can be the basis of a "radically new form of democracy, a public sphere antithetical to the one anchored in the state and its 'monopoly on political decision'"? He highlights two interdependent aspects in his answer: 1) "the general intellect can affirm itself as an autonomous public sphere only if its bond to the production of commodities and wage-labour is rescinded", 2) the subversion of capitalism "can only manifest itself today through the institution of a public sphere outside the state and of a political community that hinges on the general intellect" (Virno 2007, 8). Why is this so?

Virno claims that we have to criticize Marx's position in the Fragment. Marx conceives of the general intellect in a way that "fully coincides with fixed capital", even if it also is an exter- 
nal and collective, public good. Marx also "neglects the way in which the general intellect manifest itself as living labour" (Virno 2007, 5; Virno 2004, 37-38). Post-Fordist production, exemplified by the radically innovated Fiat factory in Melfi, show that the system of machinery does not exhaust the relation between knowledge and production:

\begin{abstract}
In post-fordism, conceptual constellations and logic schemata that cannot be reduced to fixed capital play a decisive role, since they are inseparable from the interaction of a plurality of living subjects. The 'general intellect' comprises formal and informal knowledge, imagination, ethical inclinations, mentalities and 'language games'. In contemporary labour-processes there are thoughts and discourses that function as productive 'machines' in their own right, not needing to take on a mechanical body or even an electronic soul (Virno 2007, 5).
\end{abstract}

This rupture between the general intellect and fixed capital, and the "partial redistribution of the former within living labour" is the cause of small and great disorders. Virno calls this the mass intellectuality to the extent that it is "the depository of cognitive competencies that cannot be objectified in machinery". This is also the prominent form today of the manifest general intellect. He stresses that he speaks of competencies, not the work that is produced by thought, when he talks of the general intellect. "In this regard, mass intellectuality has nothing to do with a new 'labour aristocracy'; it is actually its exact opposite." The general intellect is furthermore conceived as a different real abstraction (with an operational materiality) than the typical ones of modernity: "which embody the principle of equivalence" (Virno 2007, 6).

Whilst money-precisely as the 'universal equivalent'-embodies in its independent existence the commensurability of products, labours and subjects, the general intellect establishes the analytical premises for any kind of praxis. The models of social knowledge do not equate varied labouring activities; rather, they present themselves as 'immediately productive force'. They are not units of measure; they constitute the immeasurable presupposition of heterogeneous operative possibilities (Virno 2007,6).

This is why the homogenising state is not the political body of the general intellect. Social relations are built on communicative actions that are immediately productive and ordered by general cognitive processes and not by the exchange of equivalents. This is not only good, according to Virno. If the public character of the general intellect "does not yield to the realm of a public sphere, of a political space in which the many can tend to common affairs, then it produces terribly effects" (Virno 2004, 40).

Virno here speaks of playful communication within the general intellect and the need for a truly public sphere in this epoch. But post-Fordist capitalism is doing what it can to impose an instrumental logic by commodifying communication. Sharing of linguistic and cognitive habits is at the core of post-Fordist production, but even if this sharing is opposed to the logic of the division of labour, capital still uses segmentation of duties even if they no longer correspond to technical criteria, leaving us with arbitrary hierarchies that are reversible and changeable (flexible). At the same time a personal dependency develops when it is a "person's basic communicative and cognitive habits" that is being subsumed under the logic of capital (Virno 2004, 41).

Maurizio Lazzarato asserted that the old dichotomy of manual and mental labour, or material and immaterial such, had taken on new properties under post-Fordism. Labour could now be defined as the "capacity to activate and manage productive cooperation"; workers were expected to become 'active subjects' in the coordination of the various functions of production" and the "collective learning process" became the heart of productivity, because it was "no longer a matter of finding different ways of composing or organizing already existing job functions, but of looking for new ones" (Lazzarato 1996, 134). Lazzarato's description fits the so-called creative industries well, but his theory also applies to the service and care-industry.

Lazzarato describes how the organization of the cycle of production of immaterial labour is designed. The organisation is not "obviously apparent to the eye" because it is not "defined 
by the four walls of the factory". Immaterial labour is active in the society at large, in what he calls the basin of immaterial labour. Small productive units are organised for specific ad hoc projects and often exists only for the duration of those particular jobs. "Precariousness, hyperexploitation, mobility, and hierarchy are the most obvious characteristics of metropolitan immaterial labor" Lazzarato concludes and points to the self-employed labourer as an "intellectual proletarian" (Lazzarato 1996, 136).

Virno asserts that the contemporary cynicism is connected to the character of the general intellect. The equivalents in Fordist capitalism, despite their constitution of hierarchies and inequalities, ensured a visibility "for the social nexus as well as a simulacrum of universality" that ideologically was the prospect of "unconstrained mutual recognition", "the ideal of egalitarian communication" and "theories of justice". Instead the general intellect "occludes the possibility of a synthesis, fails to provide the unit of measure for equivalence and frustrates all unitary representations". Cynicism is reflecting this and the cynic sets aside aspirations for dialogical communication and relinquishes the search for inter-subjective foundation as a guide for his praxis. This being the "subaltern adaption" to the central role played by the general intellect. In the same manner the growth of the state administration is the example of an "authoritarian concretion of the general intellect" (Virno 2007, 7).

From this we can draw the conclusion that Virno claims that the theory of value has problems, if it is not outright out-dated, in contemporary society. This also means that our society is ready for communism understood as a plurality of individuals interacting in free associations rather than in the state. For the purpose of this investigation we have to dwell a bit on Virno's understanding of living labour's subsumption as activity under capital. He asserts that the classical, threefold division of the human experience in poiesis (labour), praxis (political and communicative action) and intellect (life of the mind) is in crisis. For the multitude who populate the era of the general intellect these spheres are juxtaposed or hybridise. It is this tripartitioning, "the boundaries between pure intellectual activity, political action, and labour", that has dissolved today, but not in the way Arendt theorized it as political action imitating labour in producing the state, party and history. Instead, Virno stresses, as we have seen above, that many of the characteristics of political action has been absorbed by post-Fordist labour (Virno 2004, 4-51). Hence, poiesis has taken on many characteristics of praxis (Virno 2004, 51).

The question is then if the commodification of communication also leads to the commodification of play?

Lazzarato turn the argument around and claims that capital can only "appropriate the forms and products of this cooperation, normalizing and standardizing them", but is not needed in organising and producing them (which is a question of social life) (Lazzarato 1996, 137). This would point to a progressive potential, but I wonder to what degree Lazzarato's argument holds true, and the same goes for the arguments of Hardt and Negri, and Carlo Vercellone below. Is not normalising and standardising becoming increasingly important, as well as an intrusion into the autonomy of the subject's living (and manipulation of it) in cognitive capitalism? On the other hand Yann Moulier Boutang has a point when he stresses that cognitive capitalism is interested in the "valorisation of intelligence and innovation" and not in the "valorisation of information", which according to him was already broadly taking place under mass industrial capitalism. "In order to be productive, cognitive capitalism is condemned to live with the new and unprecedented degrees of freedom" (Moulier Boutang 2011, 41). Such a position seems to imply that capital would have to yield at least a bit to pleasure and play.

Brian Brown points to newer research by Christian Fuchs and Tiziana Terranova who stress that "all of the time and effort devoted to generating digital content on the Internet should be considered a form of immaterial work" even if it is unpaid, and thus "broaden the concept of immaterial labour to include both its waged and unwaged variants" of productive work in post-Fordist capitalism. In so doing they emphasize the "exploitive dimensions" rather than the biopolitical one of Lazzarato. Brown develops an understanding of the biopolitical 
dimensions of unwaged immaterial labour through a case study of Flickr. His research questions focus on how the members of the community look upon their 'labours of love' and what kinds of subjectivities the biopolitics of unwaged immaterial labour produces (Brown 2012, iii, 93).

The majority of his research subjects do not see their activities on Flickr as labour, not even after they had been informed of the commercial character of the project and the business model. Labour was associated with hard toil, and Flickr-activities felt recreational, like a hobby, diversion, escape from there being no "real work" and as an addiction. Several of them experienced enjoyment and felt that they got more than they gave to Flickr; someone stressed the voluntary character. The majority of the few critical remarks stressed that they knew they technically were being exploited, but did not really care about it, not even the ones that had paid for their accounts. Only one of them felt a bit exploited and therefore did not tag the images with a lot of details. He also usually advises people not to geo-tag them (Brown 2012, 135-138). In his analysis Brown stresses that Flickr's early history as Game Neverending that was a "decidedly non-competitive game that prioritized sociality and play over accumulating points or advancing to the next level", and makes the claim that this influenced the ties between the "players" to assume a non-instrumental logic that did not "regard others as tools to advance one's position or competitors to be vanquished, but were based on friendship or companionship". Also contributing to the playful character of the Flickr activities was the public character of the site (Brown 2012, 134).

At the same time the research subjects were well aware of the variety of copyright licenses that they used for marking their content. They were generally happy to share the fruits of their labour, but they wanted to be compensated if someone else could make profit from them, but if no money is to be gained as in relations to non-corporate or not-for-profit status of the collaborators, then they were happy to give away the content for free. There exists an ethos of "non-proprietary sharing", and Brown concludes that Flickr "complicates the traditional notion of the commons in that those working within it regard it as a common resource, at the same time as it is a privately owned domain where profits must be made". He coins the concept of quasi-commons (Brown 2012, 146). The argument could also be turned around: the business model may be weakened by building on voluntary active members with an ethos of free sharing.

Tiziana Terranova conceptualized and tried to understand free labour as early as 2000 , and she defined it as simultaneously voluntarily given and unwaged, enjoyed and exploited (Brown 2012, 93; Terranova 2013). So, once again, how should we explain and problematize that an individual is exploited in his/her labour, which is voluntarily given and enjoyed? How should we understand the subjective side and cultural meaning of it?

Brown answers the criticism about the need for further explanation of the notion of exploitation if the labour going on is not appropriated under threat of force, with the claim that the "threat of social isolation and communicative seclusion may be compulsion enough" to get people 'working'. This is a biopolitical influence of normalized action and behaviour that compels individuals into joining these networks because it is where their peers are (Brown 2012, 97). This statement is supported by Robert Stebbins, who emphasizes that not all "intentionally-productive" and unpaid labour is voluntarily engaged in. He identifies a "domain of nonwork obligation" that contains activities that are "by definition disagreeable". But he also think it is "possible to marry the economic and leisure understandings of volunteering"-which sounds quite like playbour-and stress that volunteering, like serious leisure, combine several instrumental logics regarding career, benefits, ethos and identity issues, which include ten "personal and social rewards" (Stebbins 2013, 34-341). It seems like people in contemporary society have instrumental reasons for everything, according to Stebbins. Even the activity of doing disagreeable and unpaid work because of a perceived obligation is done in a voluntary way because of its rewards. In such a reality it is hard to be unhappy.

Still, the argument that your commenting on Facebook should be seen as forced labour is not entirely convincing. Still we have to further explain the funny and giving activity that the 
users, members, fans, or whatever they are called, feel they are engaged in, besides being exploited. But having said this, it could well be that we are in the beginning of a process of commodification of our social interaction and communication that ultimately will change our view of them from one of play to forced labour. If communication and social interaction increasingly get used for commercial ends, there is a possibility that even the tensions within the quasi-commons will increase, raising questions about privacy but also questions of guaranteed basic income or the abolishment of the wage system all together.

Let us instead approach the relation of playing and labouring from the standpoint of the progressive potentials in contemporary society, remembering Lazzarato's claim that capital is losing its grip over the immediate production process. Can play and work exert their autonomy and free themselves from labour?

Michael Hardt and Antonio Negri develop a political strategy in their Commonwealth. In the preface we read that both socialism and capitalism were "regimes of property" that excluded the common(s). According to them the perspective of the common cuts "diagonally across these false alternatives-neither private nor public, neither capitalist nor socialistand opens a new space for politics" (Hardt and Negri 2009, ix). The contemporary forms of capitalist production is dominated by sectors that involve information, code, knowledge, images, and affects and their producers "required a high degree of freedom as well as open access to the common", especially in the forms of "communication networks, information banks, and cultural circuits " (Hardt and Negri 2009, x). The transition to a "social and economic order grounded in the common" was already in progress, and contemporary capitalism's addressing its own needs created the bases for emancipation (Hardt and Negri 2009, $\mathrm{x})$.

Virno also sees the possibility of a radically new democracy not anchored in the state, a vision that Carlo Vercellone instead calls communism. The latter claims that Marx's idea of the general intellect designates a "radical change of the subsumption of labour to capital and indicates a third stage of the division of labour" surpassing the division of industrial capitalism and making possible the "direct transition to communism" (Vercellone 2007, 15).

The change of the technical composition of capital and of the social labour process in contemporary society is a qualitative change that overturns the subordination of living labour under "dead knowledge incorporated in fixed capital". Vercellone characterizes it as "the tendential fall of the capital's control of the division of labour" (Vercellone 2007, 1 ). When the productive value of intellectual and scientific labour becomes the dominant productive force, knowledge re-socialises everything, and this presents a problem for capital (ultimately ending capitalism). According to him, the cognitive labourer, still dependent on wages (and thus not voluntarily engaged) has his/her autonomy in the labour process, like the craftsmen under formal subsumption, but this also leads to a more brutal capitalism (the use of extra economic methods) or a focus on financial ways of getting hold on surplus value/labour (Vercellone 2007, 2-22, 31-32).

It is possible to criticise Vercellone for downplaying the class aspect in this argument, and also to pose the question: what were the real consequences of the growth of the middle and managerial classes in the $20^{\text {th }}$ century? Could it not be that the privileged strata of today also get "bought" or "corrupted" by capital?

To me the alternative of peer producing (PP) seems more promising. It is an emerging mode of production that is based in the form of commons, built on voluntary, potentially global, yet quite horizontally organised, co-operation online and the free access to the (digital) material under copy-left licenses. ${ }^{8}$ According to Jacob Rigi the "logic of equivalents" is absent in peer production and he does not see any gift economy going on (by focusing on formal rules and using a rather limited view of that phenomenon) within it (Rigi 2013, 397-398, 400,

\footnotetext{
${ }^{8}$ Copy Left is a play with words. In contrast to traditional uses of copyright law, the copy-left licenses use the copy-right to shortcircuit copy-right, and open up the distribution and use of the licensed content. You are free to distribute, use, tinker with and make derivative works of the licensed material as long as the derivative works are distributed under the same "free" or "open" license.
} 
403). More important for our purposes is that PP "negates alienation by transcending the division of labour and replacing labour with joyful and creative productive activity". The new mode of production is not identical to Hardt and Negri's the common which is "ubiquitously present everywhere". PP is instead emerging as "islands within the capitalist social formation" and its generalisation "will require a social revolution" (Rigi 2013, 4). Such a revolution would primarily realize a generalised workplay or playwork.

\section{References}

Adorno, Theodor W. 1991. The Culture Industry: Selected Essays On Mass Culture, edited by J. M. Bernstein, London: Routledge

Anchor, Robert. 1978. History and Play: Johan Huizinga and his Critics. History and Theory 17 (1): 63-93.

Arendt, Hannah. 1998. Människans Villkor: Vita Activa. Göteborg: Daidalos.

Asplund, Johan. 1987. Det Sociala Livets Elementära Former. Göteborg: Korpen.

Bachtin, Mikhail. 1988. Det Dialogiska Ordet. Gråbo: Anthropos.

Bachtin, Mikhail. 2007. Rabelais Och Skrattets Historia : François Rabelais' Verk Och Den Folkliga Kulturen Under Medeltiden Och Renässansen. Gråbo: Anthropos.

Barbrook, Richard. 2005. High-Tech Gift Economy. First Monday (Special Issue Update Nr. 3). http://firstmonday.org/article/viewArticle/1517/1432

Barbrook, Richard and Andy Cameron. 1996. The Californian Ideology. Science As Culture 6 Part 1 (26): 44-72.

Bataille, Georges. 1991. Den Fördömda Delen: Samt Begreppet Utgift, Stockholm; Stehag: B. Östlings Bokförl. Symposion.

Bataille, Georges, Waldberg, Isabelle, and lain White. 1995. Ecyclopaedia Da Costa. In Encyclopaedia Acephalica. London: Atlas Press.

Black, Bob. 1991. The Abolition of Work. Accessed November 18, 2013. http://inspiracy.com/Black/Abolition/Abolitionofwork.html

Black, Bob. The Abolition Of Work. Accessed January 6, 2014. http://Deoxy.Org/Endwork.htm

Borges, J.L. 1998. Biblioteket I Babel: En Antologi Sammanställd Ur Novellsamlingarna Ficciones Och El Aleph. Stockholm: Bonnier.

Bourdieu, Pierre. 2000. Konstens Regler: Det Litterära Fältets Uppkomst Och Struktur. Stockholm/Stehag: Brutus Östlings Bokförlag Symposion.

Braverman, Harry. 1974. Labor And Monopoly Capital: The Degradation Of Work In The Twentieth Century. New York: Monthly Review Press.

Brotchie, Alastair. 1995. Introduction. In: Encyclopaedia Acephalica. London: Atlas Press.

Brown, Brian. 2012. Will Work For Free: Examining The Biopolitics Of Unwaged Immaterial Labour. University Of Western Ontario-Electronic Thesis And Dissertation Repository. http://ir.lib.uwo.ca/Etd/620

Caillois, Roger. 2001. Man, Play and Games. Urbana, Illinois: University Of Illinois Press.

Carver, Terrell. 1987. A Marx Dictionary. Oxford: Polity Press.

Connor, Steven. 1998. Art, Criticism and Laughter: Terry Eagleton On Aesthetics. In Aesthetics, Gender Nation Organised, by The Raymond Williams Trust. Oxford.

Csíkszentmihályi, Mihaly. 2000. Beyond Boredom and Anxiety. San Francisco, Chichester: JosseyBass Publishers; Wiley.

Csíkszentmihályi, Mihaly. 1996. Creativity: Flow And The Psychology Of Discovery And Invention. New York: Harper Collins.

Davenport, Thomas, and John Beck. 2001. The Attention Economy: Understanding The New Currency Of Business, Boston, Mass.: Harvard Business School Press.

Debord, Guy. 1990. Comments On The Society Of The Spectacle. London: Verso.

Debord, Guy. 1967. The Society Of Spectacle. New York: Zone Books.

Dyer-Witheford, Nick, and Greig de Peuter. 2009. Games Of Empire: Global Capitalism And Video Games. Minneapolis: University Of Minnesota Press.

Fornäs, Johan. 2013. Capitalism: A Companion To Marx's Economy Critique. London: Routledge.

Fourier, Charles. Attractive Labour. Charles Fourier, Selections From His Writings. Accessed November 9, 2013. https://www.marxists.org/reference/archive/fourier/works/ch26.htm

Fourier, Charles. On The Role Of The Passions. Charles Fourier: Selections From His Writings. Accessed November 9, 2013a. http://www.marxists.org/reference/archive/fourier/works/ch01.htm 
Fourier, Charles. The Exchange. Selection From Charles Fourier. Accessed November 9, 2013c. http://www.marxists.org/reference/archive/fourier/works/ch24.htm

Freud, Sigmund. 1974. Beyond The Pleasure Principle. London: The Hogarth Press and The Institute Of Psycho-Analysis.

Fromm, Eric. 1988. Greatness and Limitations of Freud's Thought. New York: Meridian.

Fuchs, Christian. 2012. Dallas Smythe Today-The Audience Commodity, the Digital Labour Debate, Marxist Labour Debate, Marxist Political Economy and Critical Theory. Prolegomena to a Digital Labour Theory of Value. tripleC_-Cognition, Communication, Co-operation: Open Access Journal for a Global Sustainable Information Society 10 (2): 692-740.

Fuchs, Christian. 2014. Digital Labour and Karl Marx. New York: Routledge

Fuchs, Christian. 2013. Social Media and Capitalism. In Producing The Internet: Critical Perspectives Of Social Media, edited by T. Ollsen. Göteborg: Nordicom.

Fuchs, Christian, and Sebastian Sevignani. 2013. What Is Digital Labour? What Is Digital Work? What's Their Difference? And why do these Questions Matter for Understanding Social Media? tripleC-Cognition, Communication, Co-operation: Open Access Journal for a Global Sustainable Information Society 11 (2): 237-293.

Gadamer, Hans-Georg. 1975. Truth and Method. London: Sheed and Ward.

Habermas, Jürgen. 1987. The Theory of Communicative Action: The Critique of Functionalist Reason. Cambridge: Polity Press.

Hägglund, Kristopher. 1989. Lekteorier. Solna: Esselte Studium.

Hardt, Michael, and Antonio Negri. 2009. Commonwealth. Cambridge, Mass: Belknap Press Of Harvard University Press.

Heidegger, Martin. 1991. Nietzsche. New York: HarperCollins.

Hein, Hilde. 1968. Play As an Aesthetic Concept. The Journal Of Aesthetics And Art Criticism 27 (1): 67-71.

Himanen, Pekka. 2001. The Hacker Ethic, and the Spirit of the Information Age. New York: Random House.

Hollier, Denis. 1989. Against Architecture: The Writings Of Georges Bataille. Cambridge, Mass: MIT Press.

Horkheimer, Max. 1972. Critical Theory: Selected Essays. New York: Continuum.

Huizinga, Johan. 1955. Homo Ludens: A Study of the Play-Element in Culture. Boston: Beacon Press.

Hyde, Lewis. 2012. The Gift. Canongate.

Illich, Ivan. 1980. Shadow-Work. Philosophica 26 (2): 7-46.

Juul, Jesper. 2005. Half-Real: Video Games Between Real Rules and Fictional Worlds. Cambridge, MA: MIT Press.

Karlsson, Jan Ch. 2013. Begreppet arbete: definitioner, ideologier och sociala former. Lund: Arkiv.

Kline, Stephen, Dyer-Witheford, Nick, and Greig de Peuter. 2003. Digital Play: The Interaction Of Technology, Culture and Marketing. Montreal: Mcgill-Queen's University Press.

Larrain, J. 1991. Base and Superstructure. In A Dictionary Of Marxist Thought, $2^{\text {nd }}$ edn, edited by T.

Bottomore. Malden: Blackwell Publishing

Latour, Bruno, and Steve Woolgar. 1986. Laboratory Life: The Construction of Scientific Facts. Princeton, New Jersey: Princeton University Press.

Lazzarato, Maurizio. 1996. Immaterial Labor. In Radical Thought in Italy: A Potential Politics. Minneapolis: University of Minnesota Press.

Locke, John. 1988. Two Treatises of Government, edited by P. Laslett. Cambridge: Cambridge Univ. Press.

Malinowski, Bronislaw. 1922. Argonauts of the Western Pacific: An Account of Native Enterprise and Adventure in the Archipelagoes of Melanesian New Guinea. London: Routledge and Kegan Paul.

Marazzi, Christian. 2011. Capital and Affects: The Politics of the Language Economy. Los Angeles, CA: Semiotext(E).

Marazzi, Christian. 2008. Capital and Language: From The New Economy to the War Economy. Los Angeles, CA: Semiotext(E).

Marcuse, Herbert. 1955. Eros and Civilization. Boston: Beacon Press.

Marx, Karl. 1867. Capital: A Critique of Political Economy. London: Lawrence and Wishart.

Marx, Karl. 1909. Capital: A Critique of Political Economy. 1909th edn. Chicago: Charles H. Kerr and Company.

Marx, Karl. 1973. Grundrisse : Foundations of the Critique of Political Economy: (Rough Draft). London: Penguin. 
Marx, Karl. 1857. Introduction to a Contribution to the Critique of Political Economy. Economic Manuscripts: Appendix I: Production, Consumption, Distribution, Exchange. Accessed November 28, 2013. https://www.marxists.org/archive/marx/works/1859/critique-pol-economy/appx1.htm

Marx, Karl. 1969. Kapitalet: kritik av den politiska ekonomin. Bok 1. Kapitalets produktionsprocess. Lund: A-Z.

Marx, Karl. 1865. Value, Price and Profit. Economic Manuscripts: Value, Price And Profit, Karl Marx 1865. Accessed November 11, 2013. http://www.marxists.org/archive/marx/works/1865/valueprice-profit/

Marx, Karl, and Friedrich Engels. 1972. Karl Marx/Friedrich Engels: Brev I Urval. Stockholm: Gidlunds Förlag.

Marx, Karl, and Friedrich Engels. 1991. Marx Engels: Selected Works. London: Lawrence and Wishart.

Marx, Karl, and Friedrich Engels. 1998. The German Ideology: Including Theses on Feuerbach and Introduction to the Critique of Political Economy. Amherst, NY: Prometheus Books.

Mauss, Marcel. 1972. Gåvan. Uppsala: Argos.

Miller, Stephen. 1973. Ends, Means, and Galumphing: Some Leitmotifs of Play. American Anthropologist 75 (1): 87-98.

Minnema, Lourens. 1998. Play and (Post)Modern Culture: An Essay on Changes in the Scientific Interest in the Phenomenon of Play. Cultural Dynamics 10 (21).

Mitcheson, K. 2013. Nietzsche's Concept of Life. Journal of the University of York Philosophy Society. http://dialecticonline.wordpress.com/issue-04/nietzsche's-concept-of-life/

Morris, William. 1888. Art and its Producers. William Morris-Art And Its Producers. Accessed January 7, 2014. https://www.marxists.org/archive/morris/works/1888/producer.htm

Morris, William. 1884a. Art and Labour. William Morris-Art And Labour. Accessed January 7, 2014. https://www.marxists.org/archive/morris/works/1884/art-lab.htm

Morris, William. 1884b. Art and Socialism. William Morris-Art And Socialism. Accessed January, 7 2014. https://www.marxists.org/archive/morris/works/1884/as/as.htm

Morris, William. 1884c. Useful Work Versus Useless Labour. William Morris-Useful Work Versus Useless Toil. Accessed November 9, 2013. https://www.marxists.org/archive/morris/works/1884/useful.htm

Moulier-Boutang, Yan. 2011. Cognitive Capitalism. Cambridge: Polity.

Nagel, M.E. 1996. Philosophical Perspectives on Play from Homer to Hegel. Amherst: University Of Massachusetts Amherst, Department Of Philosophy.

Nietzsche, Friedrich. 1990. Beyond Good and Evil. London: Penguin Books.

Pellegrini, Anthony D. 2009. The Role of Play in Human Development. New York: Oxford University Press.

Piaget, Jean. 1962. Play, Dreams and Imitation in Childhood, New York: Routledge and Kegan Paul.

Postone, Moishe. 1993. Time, Labor, and Social Domination: A Reinterpretation of Marx's Critical Theory. Cambridge: Cambridge University Press.

Reich, Wilhelm. 1990. Character Analysis. New York: The Noonday Press.

Reich, Wilhelm. 2012. Sex-Pol : Essays 1929-1934, edited by L. Baxandall. London: Verso.

Rigi, Jakob. 2013. Peer Production and Marxian Communism: Contours of a New Emerging Mode of Production. Capital And Class 37 (3): 397-416.

Schwartzman, Helen B. 1978. Transformations : The Anthropology of Children's Play. New York: Plenum Press.

Situationist International. 1958a. Contribution to a Situationist Definition of Play. Situationist International Online. Accessed November 12, 2013. http://www.cddc.vt.edu/sionline/si/play.html

Situationist International, 1958b. Definitions. Situationist International Online. Accessed November 12, 2013. http://www.cddc.vt.edu/sionline/si/definitions.html

Smith, Douglas. 2005. Giving The Game Away: Play and Exchange in Situationism and Structuralism. Modern and Contemporary France 13 (4): 421-434.

Smythe, D. W. 1977. Communications: Blindspot of Western Marxism. Canadian Journal Of Poliitical And Social Theory 1 (3): 1-27.

Smythe, D. W. 1984. New Directions for Critical Communications Research. Media, Culture and Society 6 (3): 205-217.

Stebbins, Robert. 1992. Amateurs, Professionals and Serious Leisure. Montreal, Quebec, Canada: McGill-Queen's University Press. 
Stebbins, Robert. 2013. Unpaid Work of Love: Defining the Work-Leisure Axis of Volunteering. Leisure Studies 32 (3): 339-345.

Stebbins, Robert. 2009. Leisure and its Relationship to Library and Information Science: Bridging the Gap. Library Trends 57 (4): 618-631.

Tenney, Tom. 2012. (I Will) Never Work: A Critique of the Sitautionists' Appropriation of Johan Huizinga's Theory of Play. Academia.edu. Accessed November 14, 2013. http://www.academia.edu/1564331/It_Will_Never_Work_A critique of the Situationists appropri ation of Johan Huizingas theory of play

Terranova, Tiziana. 2013. Free Labor. In Digital Labor: The Internet as Playground and Factory, edited by Trebor Scholz, 33-57. New York: Routledge.

Thelin, C. 2010. Fantasin till makten! Om 60-talets situationistiska happenings och 00-talets aktions-

konst. Bachelor Thesis. Uppsala University. Department Of Art History.

Torvalds, Linus. 2001. What Makes Hackers Tick? a.k.a. Linus's Law. In the Hacker Ethic and the Spirit of the Information Age. New York: Random House Trade Paperbacks.

Vercellone, Carlo. 2007. From Formal Subsumption to General Intellect: Elements for a Marxist Reading of the Thesis of Cognitive Capitalism. Historical Materialism 15 (1): 13-36.

Vilhauer, M. 2010. Gadamer's Ethics of Play. Lanham: Rowman and Littlefield Publishing Group.

Virno, Paolo. 2004. A Grammar Of The Multitude. Cambridge, MA: MIT Press.

Virno, Paolo. 2007. General Intellect. Historical Materialism 15 (1): 3-8.

Vološlnov, Valentin. 2012. Freudianism: A Marxist Critique. London: Verso.

Vygotskij, Lev Semonovich. 1987. The Collected Works of L.S. Vygotsky: Volume 5, Child Psychology. New York: Springer.

Wark, Mckenzie. 2004. A Hacker Manifesto. Cambridge, MA: Harvard University Press.

Wark, Mckenzie. 2007. Gamer Theory. Cambridge, MA: Harvard University Press.

Wark, Mckenzie. 2013. The Spectacle of Disintegration. New York: Verso Books.

Wikipedia Contributors. Activity Theory. Wikipedia. Accessed December 18, 2013. http://en.wikipedia.org/wiki/Activity theory

Wikipedia Contributors. 2013a. Bob Black. Wikipedia. Accessed November 18, 2013. http://en.wikipedia.org/wiki/Bob_Black

Wikipedia Contributors. Recapitulation Theory. Wikipedia. Accessed December 18, 2013. http://en.wikipedia.org/wiki/Recapitulation theory

Wikipedia Contributors. 2013. Second Situationist International. Wikipedia. Accessed November 14, 2013. http://en.wikipedia.org/wiki/Second Situationist International

Wikipedia Contributors. 2013b. The Abolition of Work. Wikipedia. Accessed November 18, 2013. http://en.wikipedia.org/wiki/The_Abolition_of_Work

Wittgenstein, Ludwig. 1967. Philosophical Investigations. Oxford: Basil Blackwell.

\section{About the Author}

\section{Arwid Lund}

PhD-student in Library- and Information Science at the Department of ALM (Archival, Library \& Information, Museum \& Cultural Heritage Studies), University of Uppsala, Sweden. He is the author of three books in Swedish, and has worked as a librarian with digital publishing and digital repositories. He was an activist in social movements during the 1990's, and the first years of the new millennium. You can contact Arwid Lund at arwid.lund@abm.uu.se. 